\title{
The Influence of Dams on Downstream Larval and Juvenile Fish and Benthic Macroinvertebrate Community Structure and Associated Physicochemical Variables
}

\author{
R. Daniel Hanks
}

Follow this and additional works at: https://researchrepository.wvu.edu/etd

\section{Recommended Citation}

Hanks, R. Daniel, "The Influence of Dams on Downstream Larval and Juvenile Fish and Benthic Macroinvertebrate Community Structure and Associated Physicochemical Variables" (2016). Graduate Theses, Dissertations, and Problem Reports. 5755.

https://researchrepository.wvu.edu/etd/5755

This Dissertation is protected by copyright and/or related rights. It has been brought to you by the The Research Repository @ WVU with permission from the rights-holder(s). You are free to use this Dissertation in any way that is permitted by the copyright and related rights legislation that applies to your use. For other uses you must obtain permission from the rights-holder(s) directly, unless additional rights are indicated by a Creative Commons license in the record and/ or on the work itself. This Dissertation has been accepted for inclusion in WVU Graduate Theses, Dissertations, and Problem Reports collection by an authorized administrator of The Research Repository @ WVU.

For more information, please contact researchrepository@mail.wvu.edu. 
The Influence of Dams on Downstream Larval and Juvenile Fish and Benthic Macroinvertebrate Community Structure and Associated Physicochemical Variables

R. Daniel Hanks

\author{
Dissertation submitted \\ to the Davis College \\ at West Virginia University
}

in partial fulfillment of the requirements for the degree of

Doctor of Philosophy in

Forest Resources

with an emphasis in

Wildlife and Fisheries Science

Kyle J. Hartman, Ph.D., Chair

Patricia M. Mazik, Ph.D.

Raymond P. Morgan II, Ph.D.

J. Todd Petty, Ph.D.

Stuart A. Welsh, Ph.D.

Morgantown, West Virginia

2016

Keywords: larval fish, aquatic macroinvertebrates, serial discontinuity concept, river continuum concept, disturbance

Copyright 2016 Daniel Hanks 


\begin{abstract}
The Influence of Dams on Downstream Larval and Juvenile Fish and Benthic Macroinvertebrate Community Structure and Associated Physicochemical Variables

R. Daniel Hanks
\end{abstract}

The influence of dams on downstream biotic and abiotic components of aquatic ecosystems has been largely studied within the context of the River Continuum (RCC) and Serial Discontinuity Concepts (SDC). Few of these studies have sufficiently studied how these variables change along the longitudinal gradient below the impoundments in a systematic manner, comparing equal distances below both epilimnetic and hypolimnetic dams to a reference condition. This is especially true of early life stages of fish (i.e., larval and juvenile stages) and macroinvertebrate functional groups. Here, I systematically evaluated the effects of dams at 16 sites downstream of dams for their impact on physicochemical (instream habitat [e.g., substrate, flow, etc.] and water quality [i.e., DO, pH, conductivity, and temperature], and landcover [i.e., \% forested land, \% developed land, and \% grassland]) and various metrics for larval and juvenile fish and benthic macroinvertebrates.

Effective capture of larval and juvenile fish was paramount for the evaluation of dam influences on larval and juvenile. Sampling larval fish at various life stages can be difficult in shallow, structurally and spatially diverse streams. I evaluated three commonly employed methods (light traps, drift nets, and spot-and-sweep) for sampling larval fish in these systems. I found the spot-and-sweep method captured a higher abundance of larvae than either drift nets or light traps during both daytime and nighttime hours. Additionally the spot-and-sweep method captured as many different taxa as drift nets and more than light traps. The coefficient of variation was lower for spot-and-sweep than for either drift nets or light traps for both taxa richness and larval abundance. Richness for daytime and nighttime spot-and-sweep sampling was equal. Mean richness was also equal between the two periods, and mean CPUE was not significantly different between periods. The coefficient of variation was lowest for daytime spotand-sweep sampling, suggesting it was less variable than nighttime sampling. The spot-andsweep method showed promise for determining taxa presence and relative abundance. Discrepancies in the ability of personnel while performing spot-and-sweep sampling was investigated and found to be insignificant. Of the three methods evaluated for sampling structurally complex and spatially heterogeneous streams the spot-and-sweep method was found to be the most effective.

I investigated the effects of dams on downstream larval and juvenile fish. Generalized additive models indicated that there was a general increase in abundance, genus richness, and Shannon diversity associated with increasing distance from dams. Principal component analysis (PCA) indicated three influential PC's that were structured by landcover, habitat and water quality, and disturbance. Nonmetric multidimensional scaling (NMDS) indicated larval and juvenile fish communities were structured differently between epilimnetic and hypolimnetic releases and that habitat variables structuring those communities were more variable in epilimnetic releases than hypolimnetic releases. 
I systematically evaluated both the abiotic and biotic (i.e., benthic macroinvertebrates at the family level) along the stream continuum below impoundments with both epilimnetic and hypolimnetic releases and compared those findings to a reference stream. Generalized additive models (GAMs) identified six habitat variables (i.e., substrate coarseness, substrate diversity, $\mathrm{pH}$, temperature, stream width, and stream depth) as significantly related to distance from dam. GAMs also indicated that abundance was not significantly related to distance from dam but both family level richness and Shannon diversity exhibited significant increases with increasing distance from dams.

I evaluated patterns of changes in physicochemical and macroinvertebrate functional group components of aquatic systems along the longitudinal gradient below dams and compared changes in these variables to an undammed reference stream. Generalized additive models indicated that genus richness, functional richness, tolerance, dispersal, percent five dominant genera, EPT, and GLIMPSS were lower in dammed streams than in the reference stream. Genus and functional richness, percent 5 dominant genera, EPT, and GLIMPSS all increased as distance from dams increased while they remained relatively consistent within the reference stream. Tolerance and dispersal changed with distance from dams in dammed streams but showed little change in the reference stream. Percent composition of functional groups was different between dammed and reference streams; in dammed streams the percent composition changed with increasing distance from dams, but remained relatively stable in the reference stream. Genus and functional richness also exhibited two distinct gradients within the 5,100-m that I sampled below dams where a short, rapidly changing gradient existed immediately below dams to approximately 2,000-m, followed by a more gradual steadily increasing gradient that appeared to continue beyond the most distant sampling location below dams (i.e., 5,100-m). Important explanatory variables that varied in statistical significance between response variables but were commonly significant with distance from dams was substrate coarseness and percent forested land. Eighty five percent of the measured abiotic variables below dams had higher $r$ values where curvilinear relationships were modeled as compared to linear relationships; whereas only $46 \%$ of the biotic variables had higher $r$ values with curvilinear models. Nonmetric multidimensional scaling (NMDS) confirmed the GAM results indicating benthic macroinvertebrates below dams show structural changes along the stream continuum.

In all cases (larval and juvenile fish, family level aquatic macroinvertebrates, and genus level aquatic macroinvertebrate metrics) my findings generally agreed with the SDC but future studies should aim to sample in a spatially systematic manner, as this will improve the understanding of how dams influence abiotic and biotic components of aquatic systems. Additionally, my studies consistently indicated two gradients existed for most biotic measures. I believe further studies are required to understand the two recovery gradients that exist below dams and the extent of dam influences along the stream continuum. 


\section{Dedication}

To Sara for your full and unfaltering support throughout my doctoral work and standing by me as I chased and continue to chase elusive antelopes. To my parents for always being supportive and encouraging me to pursue my dreams. In memory of Papa Tom who let me fall in love with fish so long ago as I reeled in those tiny "bream". In memory of Granny Hanks and Papa Hanks who I know would be proud beyond words. In memory of Rob Cathey and Michael Stovall whom I never got to tell how much you influenced my life's trajectory.

For Laurel. I hope that my pursuing my own dreams and aspirations will act to guide you to do the same. May you always pursue the person you wish to be. 


\section{Acknowledgements}

I would like to acknowledge and sincerely thank my doctoral committee: Drs. Kyle Hartman (advisor), Pat Mazik, Ray Morgan, Todd Petty, and Stuart Welsh whom supplied helpful guidance all along the research process. Thanks to Dominion Power for financial support for this project. Thank you to West Virginia University and the West Virginia University Division of Forestry and Natural Resources for supplying lab space to complete this research. I appreciate the opportunity to teach various classes while at West Virginia University and the mentorship I received while doing so. Special thanks to Dr. Michael Strager for his support in my teaching pursuits. Special thanks to Dr. Kyle Hartman for accepting me as a graduate student and being supportive and understanding throughout the six years I was his advisee and mentee. Thanks to fellow graduate students Dr. Eric Merriam, Dr. Gabe Strain, and Ross Andrew for your willingness to discuss my research and for your friendship. Thank you to technicians without whom I could not have completed my degree without Tim Owen, Nicole Dawson, Carrie Jameison, Alex Aspinwall, and Kyle Manning. Thank you to all the other technicians and students who helped me in the lab and field. 


\section{Table of Contents}

Chapter 1. Comparison of Three Larval Fish Sampling Methods in Shallow, Complex, Wadeable Streams

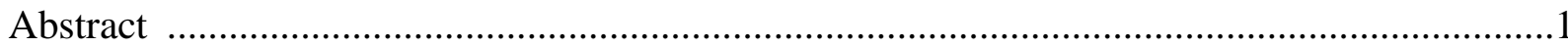

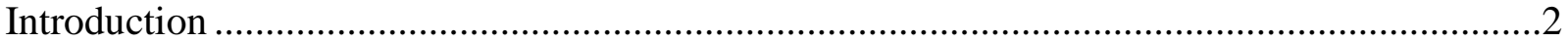

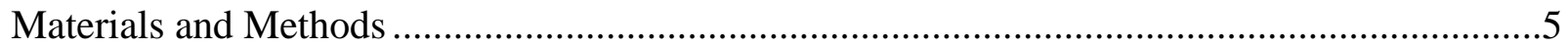

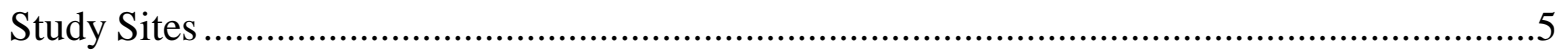

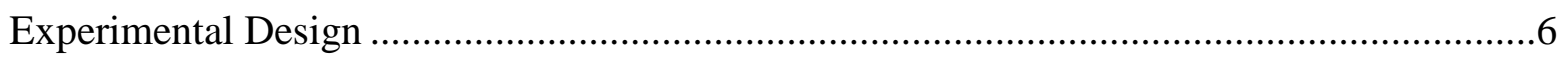

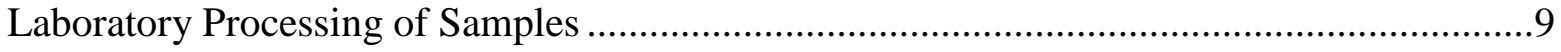

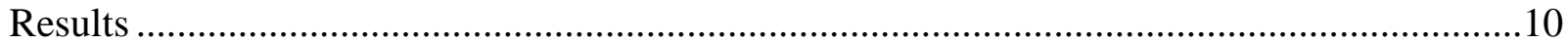

Comparison of Nighttime Samples .............................................................................11

Comparison of Daytime and Nighttime Spot and Sweep Samples ..................................12

Comparison of Personnel Bias in the Spot and Sweep Method .......................................12

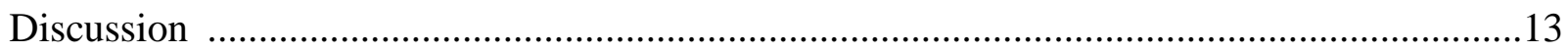

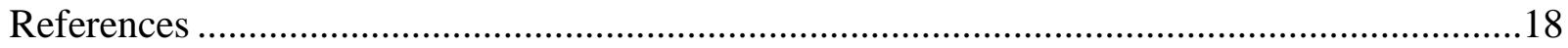

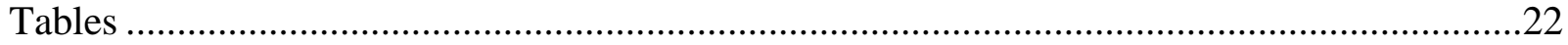

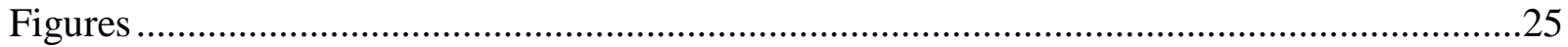

Chapter 2. Identifying Impacts from Dams that may Affect Abundance, Richness, Diversity, and Community Structure for Larval and Juvenile Fish ......................................................................28

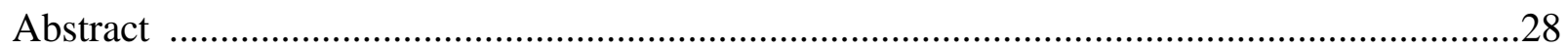

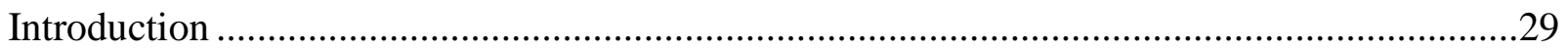

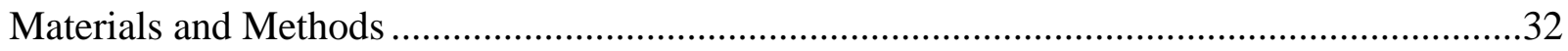

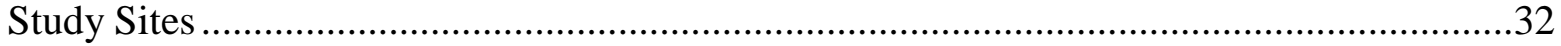

Sampling: Larval Fish and Physicochemical Variables .................................................32

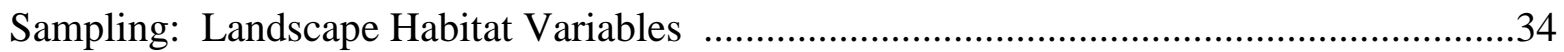

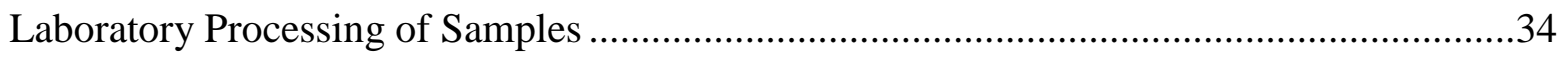

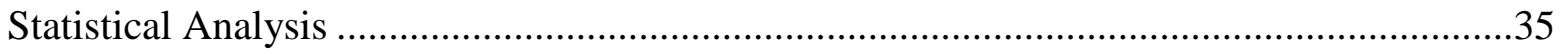

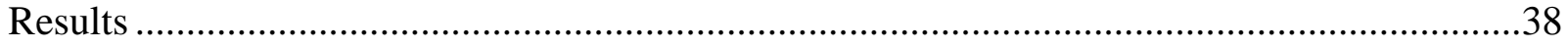

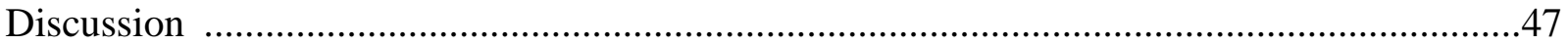

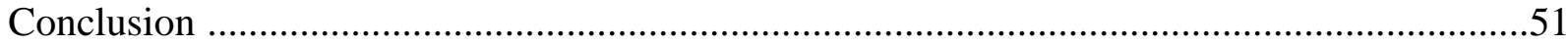

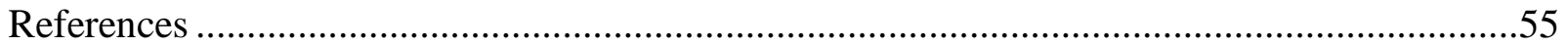

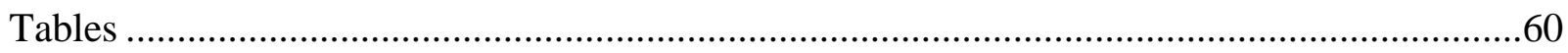




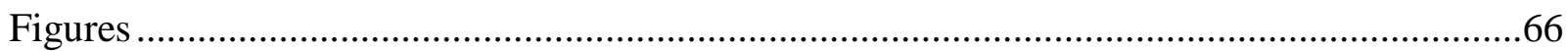

Chapter 3. Identifying Impacts from Dams on Downstream Microhabitat Variables that may Affect Richness, Abundance, and Diversity of Aquatic Macroinvertebrates ..............................................72

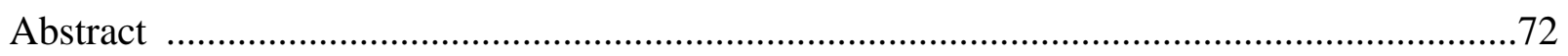

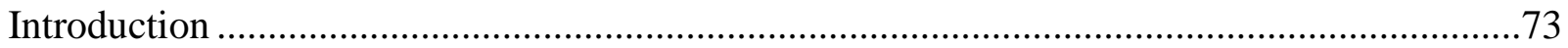

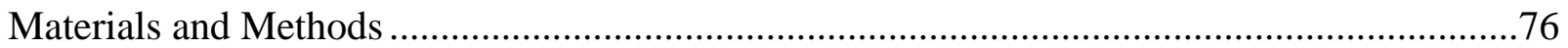

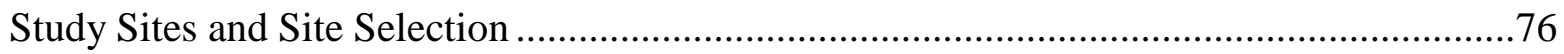

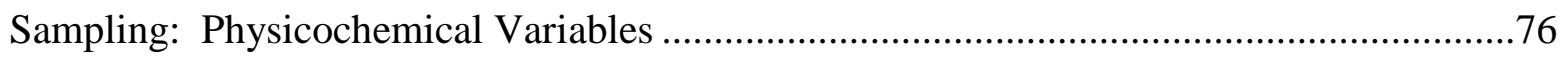

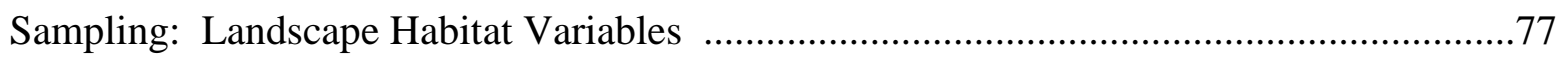

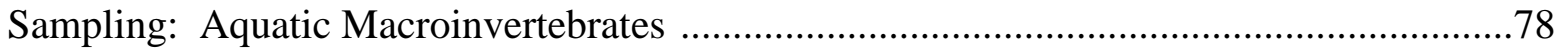

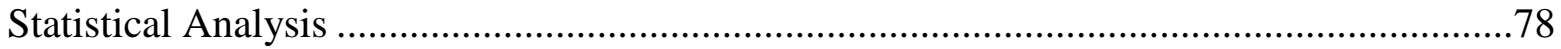

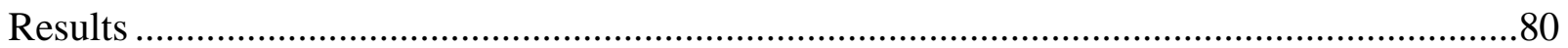

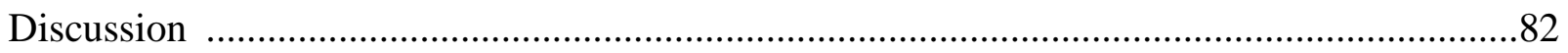

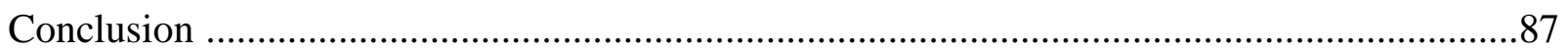

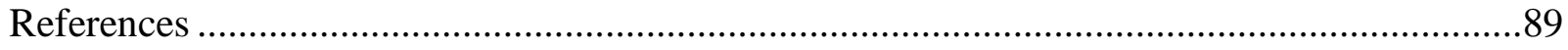

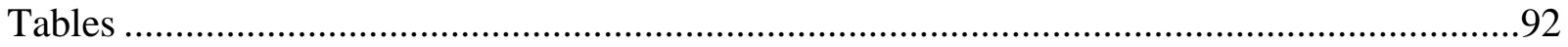

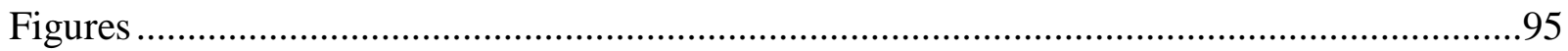

Chapter 4. Identifying Impacts from Dams on Downstream Functional Groups and Community

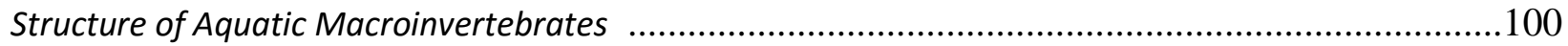

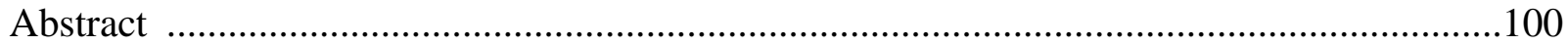

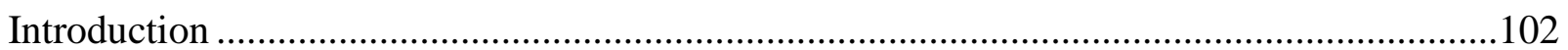

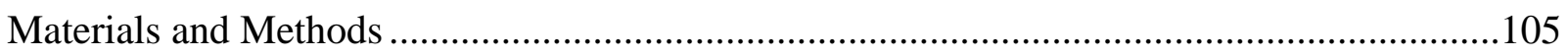

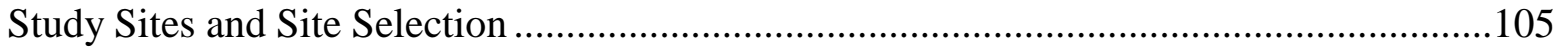

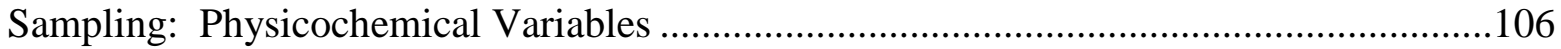

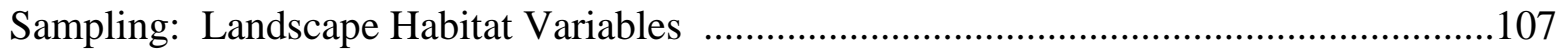

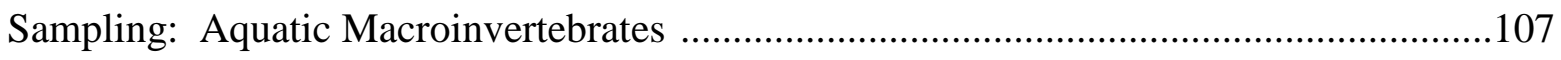

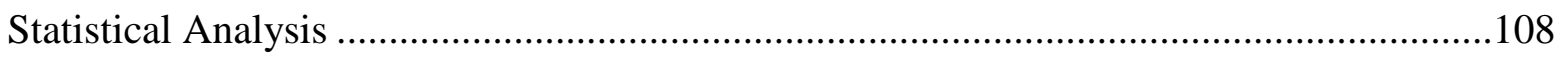

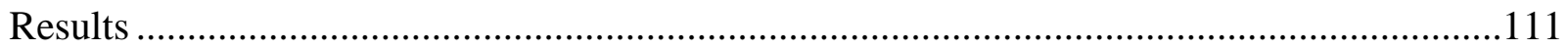

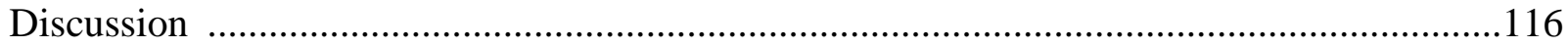

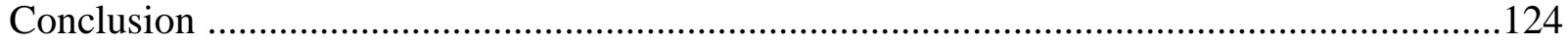




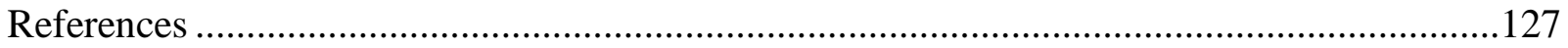

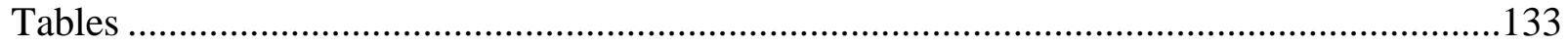

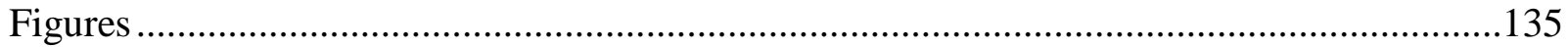

Vita 
Chapter 1. Comparison of Three Larval Fish Sampling Methods in Shallow, Complex, Wadeable Streams

\begin{abstract}
Sampling larval fish can be difficult in shallow, structurally and spatially diverse stream systems. We evaluated three methods (light traps, drift nets, and spot-and-sweep) for sampling larval fish in these systems. We also evaluated differences in personnel abilities in capturing larval fish. Larval fish were sampled during daytime and nighttime hours June 18-19, 2011, dates when most resident larvae are present. Unlike spot-and-sweep, drift nets and light traps captured no larvae during daytime hours. During nighttime sampling spot-and-sweep collected more individuals (207) than light traps (23) and drift nets (58) and captured more taxa than light traps and an equal number to drift nets (6 versus 4 and 6 taxa, respectively). Coefficient of variation was lower for spot-and-sweep than drift nets and light traps. Daytime and nighttime spot-and-sweep sampling collected six taxa each, mean richness was equal (2.3) between the two periods, and mean CPUE was not significantly different between periods; however, the coefficient of variation was lowest for daytime spot-and-sweep sampling (75.4 versus 139.1 for nighttime sampling). The spot-and-sweep method performed well for determining taxa presence and relative abundance. Discrepancies in the ability of personnel while performing spot-andsweep sampling were found to be insignificant. Of the three methods evaluated for sampling structurally complex and spatially heterogeneous streams the spot-and-sweep method was found to be the most effective.
\end{abstract}




\section{Introduction}

Effective sampling methods for early life stage (ELS) fish should aid in the accuracy of assessment of the study objectives. Desirable results from larval sampling methods include accurate taxa richness and abundance, high catch efficiency, and low variability thereby providing truly representative samples of the larval fish community. Qualities of good sampling methods include low costs, ease of use, and ease of replication. Passive sampling methods may be used to show relative abundance of fish taxa (Hubert et al. 2013) but have been found to be size and species selective with low and variable catch efficiency (Rozas and Minello 1997). Active sampling methods have the advantage of being spatio-temporally mobile, resulting in the possibility of a greater number of samples being taken over a larger geographic space in a smaller amount of time (Hayes et al. 2013).

Streams that are wadeable, yet exhibit spatial structural complexity present difficulties when sampling larval fish due to various complications, such as exposed and submerged rocks and logs, non-uniform bottoms, constrained channels, etc. (structurally complex hereafter). Traditional active gears such as plankton nets and seines can become tangled in shoreline and in stream structures, while electrofishing and underwater observation may ineffectively sample the smallest larvae (Kelso et al. 2013). There is a substantial amount of literature dealing with larval fish sampling in rivers; however we found no other evaluation of larval fish sampling methods in wadeable, structurally complex streams.

A variety of larval fish sampling methods exists for large rivers, lakes, and oceanic waters, such as various traps, plankton nets, and trawls (Kelso et al. 2013). These methods, however, may be poorly suited for sampling structurally complex streams where stream depth, 
exposed rocks and woody debris, and narrow channel width make it impractical to impossible for some sampling gear types and/or research vessels. Methods for sampling larval fish have been developed to overcome the constraints of structural complexities (e.g., pushnets [Claramunt et al. 2005], plankton pumps [Taggart and Leggett 1984]; larval purse seines [Kingsford and Choat 1985]; light traps [Doherty 1987]; and drift nets [Clifford 1972]). However, Burdick et al. (2008) found that gear types were subject to performance inconsistencies due in part to habitat characteristics (e.g., depth), larvae size and abundance.

Larvae of many fishes are positively phototactic, which has led to the development and effective use of light traps (Kelso et al. 2013). Light traps employ artificial light sources to attract these taxa and have been effective at determining taxa abundance (Turner et al. 1994). The quatrefoil light trap (Floyd et al. 1984) uses a centrally located light-distributing rod that is surrounded by four Plexiglas cylinders with slits allowing for larvae to enter but making it difficult for them to escape. Floyd et al. (1984) found that 26 of 28 total species were captured with a quatrefoil light trap in a small Kentucky stream. The quatrefoil light trap was modified by Secor et al. (1992) to include floatation, a chemical light source (e.g., Cyalume® light stick), and a collection apparatus. Larval fish show variable patterns in movement, phototactic behavior, and microhabitat preference making light traps well suited for determination of species presence or absence (Kelso et al. 2013). Knight and Bain (1996) found light traps were able to capture six of seven families, were more effective than dip netting, and captured the majority of larval fish in forested floodplain wetlands in Alabama. When checked frequently (e.g., hourly), light traps have been shown to be less likely to damage specimens (Faber 1982), allowing for easier taxa identification. 
Larval fish in streams may enter the current and become part of the drift for various ecological and abiotic reasons such as habitat selection (Bertolo et al. 2012), avoiding competition, inbreeding, and environmental stochasticity (Johnson and Gaines 1990). This knowledge has led to the development and use of drift nets captured larval fish. In the Susquehanna River in Pennsylvania, Gale and Mohr (1978) found drift nets captured 17 species of larval fish. Drift nets were used by Boehler and Baker (2013) in Honey Creek, Seneca County, Ohio to investigate diel drift patterns in larval fish, where they found significantly more larvae in nighttime samples than samples taken during the day. Ferreira et al. (2012) suggests larvae may be behaviorally selective in their diel activities as a means to balance the ability to continue feeding, while reducing the risk of predation. Robinson et al. (1998) used drift nets to investigate movement patterns and longitudinal distributions of larval fish in the Little Colorado, Arizona. When deployed in optimal conditions, larval drift nets may be very effective at capturing drifting taxa (e.g., Walleye Sander vitreus). However, larval behavior and predation may reduce the effectiveness of drift nets, as some taxa may not enter the drift and taxa may be differentially preyed upon (Franzin and Harbicht 1992).

Adaptive cluster sampling allows for concentration of effort in areas of high larval density and is founded on the principle that an area with a high number of individuals is likely to have neighboring areas that also contain high numbers of individuals (Greenwood and Robinson 2009). Variability in the distribution of larval fishes in riverine systems may result in limited information gleaned from random sampling methods. For the spot-and-sweep method we used a modified adaptive cluster sampling technique where we waded in the stream until spotting larval fish and subsequently concentrated efforts in areas where larvae were spotted. 
Active sweep net methods show potential in overcoming the limitations of structurally complex streams due to their ability to sample these complex locales. However, due to their relatively large size (e.g., $500 \mathrm{~mm}$ X $250 \mathrm{~mm}$ ), sweep nets are often difficult to maneuver within these structurally complex waters in a fashion that allows one to capture larval fish. This relatively large size manifests itself in two ways: 1) the large surface area creates drag that makes it difficult to sweep the net through the water and 2) the large net circumference makes it impractical to maneuver in and between the spatial complexities in areas of the stream where larvae often reside. However, small $(15 \mathrm{~cm}$ x $15 \mathrm{~cm})$ aquarium nets with mesh size $\leq 500 \mu \mathrm{m}$ may supply a feasible alternative to larger sweep nets. Using a modified adaptive cluster sampling approach, we developed a spot-and-sweep method where we sampled with small aquarium nets. Active sampling methods may be susceptible to variability in sampler abilities and biases while searching and capturing larvae. Such biases should be considered and evaluated when performing active sampling methods.

The objective of this study was to evaluate the effectiveness of passive drift nets, light traps and an active spot-and-sweep method in shallow $(<1 \mathrm{~m})$, structurally complex (i.e., with both submerged and exposed rocks, logs, and debris), wadeable (mean depth $<1 \mathrm{~m}$ ) streams during daytime and nighttime hours.

\section{Methods}

\section{Study Site}

This study was performed in New Creek, Mineral County and Patterson Creek, Grant County, West Virginia (Figure 1). New Creek and Patterson Creek are in close proximity to the cities of 
Keyser and Scherr, WV respectively. Both streams are small, spatially heterogeneous, and wadeable with a mean depth $<1 \mathrm{~m}$. Three sites were selected within each stream based on visual estimation of suitable habitat, which included locations where light traps, drift nets, and spotand-sweep could all be performed. Site riparian areas were forested with the exception of New Creek site 3, which was within the Keyser city limits. Sites were approximately 30-m in length and the substrate at all sites were dominated by pebbles, cobble, and boulder with sandy stream margins. Water was clear and stream bottoms were clearly visible during all sampling. Mean water quality variables are displayed in Table 1.

\section{Experimental Design}

In order to identify the best method for monitoring structurally complex stream habitats for larval fish, three gears (larval drift nets, light traps, and a spot-and-sweep method; Figure 1) were employed. The light traps and drift nets collected larval fish passively from the water column. The spot-and-sweep method actively collected larvae along stream margins and eddies behind boulders. These gears provided both relative abundance and species composition (Kelso et al. 2013). Light traps and drift nets were chosen based on literature review revealing these methods as suitable for structurally complex habitats (Gale and Howard 1978; Secor et al. 1992; Turner et al. 1994; Rozas and Minello 1997; Robinson et al. 1998; Boehler and Baker 2013; Kelso et al. 2013). The spot-and-sweep method was developed from personal visual observations of larval fish presence along stream margins and in eddy areas behind boulders, from where we believed we could adequately sample larvae. For each sampling effort a total of three light traps, three drift nets, and three spot-and-sweep samples were collected at each of three sites per stream 
during daytime and nighttime hours $(n=3$ for each gear type and time period at each sample site. Total number of sites per stream was 3 , therefore $n_{\text {total }}=9$ of each gear type per stream.). Sampling sites consisted of approximately $30-\mathrm{m}$ stream reaches, where spot-and-sweep sampling could occur concurrent with the other two methods without disrupting the efficacy of these methods. The 30-m distance allotted ample space for light traps and drift nets to sample passively while the spot-and-sweep method was actively employed downstream thereby reducing the potential for one sampling method to influence another (e.g., Increased turbidity due to wading while performing spot-and-sweep sampling possibly reducing light trap effectiveness.)

Light traps were 30-cm X 30-cm X 15-cm floating Plexiglas traps. Each trap had four 15-cm entrance slots and was lit with a six inch long Cyalume ${ }^{\circledR}$ green chemical light stick, placed in a central light tube (Floyd et al. 1984). Gerhke (1994) found that green light sticks were brighter in the first hour of sampling than other colored chemical light sticks and green light was sufficient to attract larval and juvenile fish. Light traps were placed randomly within fishable areas of each sample location (i.e., low flow and water deep enough to float traps). Light traps were deployed and anchored for two hours starting no earlier than one half hour post dusk for the nighttime sampling periods (between 2200 and 0500). Daytime sampling occurred between 1000 and 1800 hours and traps were deployed for two hours. Times of deployment and retrieval were recorded to the nearest minute. When retrieved traps were slowly raised, allowing for chamber contents to be filtered into and through the $500-\mu \mathrm{m}$ mesh collection chamber and into a collection bottle. All samples were washed into sample jars, labeled, and preserved in $10 \%$ buffered formalin while in the field (Kelso et al. 2013).

Drift nets were constructed of a stainless steel rectangular frame $(22-\mathrm{cm} \mathrm{X} 45-\mathrm{cm})$ attached to a 500- $\mu \mathrm{m}$ mesh collection chamber capped with a collection bottle. Eyelets were 
fashioned on the top and bottom of each side of the drift nets so that they could be anchored with rebar in the stream. Bottoms of the drift nets were in contact with the stream bottom, the top of the nets were $\pm 2.5 \mathrm{~cm}$ of the stream surface, and nets were placed within the main flow of the stream. Nets sampled for two hours starting no earlier than one half hour post dusk for the nighttime sampling periods (between 2200 and 0500). Daytime sampling occurred between 1000 and 1800 hours and traps were deployed for two hours. Times of deployment and retrieval were recorded to the nearest minute. When retrieved, drift nets were slowly raised, allowing for net contents to be filtered into and through the 500- $\mu \mathrm{m}$ mesh collection chamber and into a collection bottle. All samples were washed into sample jars, labeled, and preserved in $10 \%$ buffered formalin while in the field.

An active spot-and-sweep method coupled with an adaptive cluster sampling approach was also evaluated for capturing larval fishes. Aquarium nets were employed $(12-\mathrm{cm}$ X $15-\mathrm{cm}$, 500- $\mu \mathrm{m}$ mesh) as sweep nets. During daytime sampling (1000-1800 hours), individuals walked along the stream bank and/or in the stream actively searching for larvae. Once spotted, fish were swept into the net and placed into a labeled sample jar. Observers continued this process for three continuous minutes. Nighttime sampling (2200-0500 hours) followed the same protocol but visual spotting was aided with a light-emitting diode (LED) headlamp. Adaptive cluster sampling is based on the premise that areas with high numbers of individuals will have adjacent areas that also have high density, therefore an observer samples more intensely in areas where specimens have already been found (Greenwood and Robinson 2009). After each three minute sampling period was completed, sample jar contents were preserved in $10 \%$ formalin.

All sampling for the comparison of light traps, drift nets, and the spot-and-sweep method occurred June 18-19 2011. Daytime sampling occurred between 1000 and 1800 hours and 
nighttime sampling occurred between 2200 and 0500 hours. Sampling locations were chosen based on their being representative of each stream and presenting suitable larval habitat (e.g., low velocity areas, depths sufficient to float light traps, and spatial heterogeneity [Niles 2004]). At each site we collected water quality measurements of temperature $\left({ }^{\circ} \mathrm{C}\right), \mathrm{pH}$, conductivity $(\mu \mathrm{S} / \mathrm{cm})$, and dissolved oxygen $(\mathrm{mg} / \mathrm{L})$ with an YSI meter (Computer module: $650 \mathrm{MDS}$, Sonde: 6820). Temperature and conductivity did not differ between daytime and nighttime sampling periods (T test: $P>0.05, \mathrm{df}=5$ ). Dissolved oxygen and $\mathrm{pH}$ both differed between daytime and nighttime sampling periods (T test: $P<0.05, \mathrm{df}=5$ ). However, we do not feel that these differences in water quality affected the larval fish captures and therefore we did not consider them further in our analysis.

Personnel bias in the spot-and-sweep method.

Potential differences in sampler abilities (e.g., abundance and richness) while performing the spot-and-sweep method were evaluated using ANOVA (Alpha $=0.05$ ). This analysis was performed on a separate data set which included only spot-and-sweep sampling. Sampling occurred between 15 May and 30 June 2012. This data set consisted of 16 sample sites on seven streams during two discrete sampling periods separated by a minimum of two weeks (one stream in each of Maryland, Ohio, and West Virginia, and four streams in Pennsylvania). Three individuals performed all sampling, resulting in a comparison of 224 sampling efforts per sampler. Sampling by each individual occurred for five minutes, concurrently within a 30-m stream reach. 


\section{Laboratory processing of samples}

All samples were washed through a 500- $\mu$ m-mesh sieve before being transferred to a dissecting tray where larvae were transferred to $15-\mathrm{mL}$ vials for later processing. Larvae were identified using a Leica MZ6 microscope fitted with a Cole-Parmer light ring and a polarizing filter. Using Auer (1982) as a reference, larvae were identified to genus. Total lengths were measured to the nearest mm with an ocular micrometer mounted in a stereo dissecting microscope. Fishes were identified as either larvae or juveniles according to Auer (1982). There were 193 juveniles captured, which comprised $29.6 \%$ of our total catch. However, all juvenile fish were removed from the analysis, as $>93 \%$ of the captured juveniles were of a single taxon (Rhinichthys). The remaining juveniles consisted of five taxa and were comprised of a single individual of Campostoma, Notropis, and Pimephales, two Catostomus and nine Etheostoma.

Statistical analysis. - Drift nets, light traps, and the spot-and-sweep method cannot be compared directly due to the unknown volume of water that both light traps and the spot-and-sweep method sample. Alternatively, we evaluated the three methods based on the mean number of larvae captured per sample (catch per unit effort [CPUE]) for all methods, along with taxa richness and coefficient of variation. The data for CPUE and richness were calculated and analyzed for each gear separately using ANOVA in the R language and environment for statistical computing (R Development Core Team, Vienna, Austria). Catch per unit effort and richness were calculated based on each sampling replicate, where a single trap, net, or sweep represents a sampling replicate (i.e., the number of fish captured per hour for light traps and drift nets and the number of fish captured per minute for the spot-and-sweep method). Alpha was set to 0.05 for all tests. 
As an estimate of variation for CPUE among the methods and time periods (day and night) for collecting larval fish, we calculated coefficient of variation ( $\mathrm{CV}=100 \bullet \mathrm{SD} / \mathrm{mean})$. Coefficient of variation is a measure of the variability relative to the mean and is used to compare the relative dispersion between different types of data (Ott and Longnecker 2001). The coefficient of variation is applicable for the evaluation of different larval fish capture methods because the data being compared may be of the same or different units and have the same or different means.

\section{Results}

There were a total of 108 samples (all gears combined) containing 480 larvae from eight taxonomic groups (Table 2). Drift nets and light traps captured no larval fish during daytime hours (Table 2); therefore analyses between drift nets, light traps, and the spot-and-sweep method used only nighttime sampling events. When comparing nighttime samples the spot-andsweep method performed better than the two passive gear types in their ability to capture larval fish in the three measured variables: number of individuals captured, taxonomic richness, and sampling variability of CPUE (Table 2).

\section{Comparison of nighttime samples}

When comparing nighttime captures, more larvae were captured with the spot-and-sweep method (207 individuals) than light traps (58 individuals) and drift nets (23 individuals) (Table 2). The spot-and-sweep method also collected as many or more taxonomic groups (6 groups) 
than drift nets (6) or light traps (4) (Table 2). Four taxonomic groups were common to all three capture methods (Notropis spp., Pimephales spp., Rhinichthys spp., and Etheostoma spp.) (Table 2). One taxonomic group (Hypentelium spp.) was captured only with the spot-and-sweep method and one taxonomic group (Cottus spp.) was only captured with drift nets. Light traps collected no unique taxonomic groups.

Average CPUE for nighttime sampling differed between the three methods (Figure 2a) (ANOVA: $F=6.32, P<0.05, \mathrm{df}=2$ ) and was significantly higher for the spot-and-sweep method (11.5) than for both light traps (3.2) and drift nets (1.3) (Tukey's HSD P>0.05). Statistical differences in mean taxonomic richness existed between the three methods (Figure 2b) (ANOVA: $F=13.8, P<0.05, \mathrm{df}=2$ ) and was significantly higher in the spot-and-sweep method (2.33) than both the light traps (0.72) and drift nets (0.61) (Tukey's HSD $P>0.05$ ).

Nighttime CPUE was less variable in the spot-and-sweep method $(\mathrm{CV}=139.1 \%)$ than drift nets $(\mathrm{CV}=175.6 \%)$ and light traps $(\mathrm{CV}=221.6 \%)$. Larval fish sizes differed among sampling methods (ANOVA: $F=19.8, P<0.05, \mathrm{df}=2$ ). Light traps and drift nets captured similar sized larvae, while the spot-and-sweep method captured significantly longer larvae than both light traps and drift nets (Tukey’s HSD $P<0.05$ ) (Table 3).

\section{Comparison of daytime and nighttime spot-and-sweep samples}

There were 192 larvae captured by the spot-and-sweep method during daytime hours as compared to 207 during nighttime hours (Table 2). Average CPUE was 11.5 and 10.7 for nighttime and daytime spot-and-sweep sampling respectively, however the two sampling periods were not statistically different from one another $(P>0.05)$ (Figure 3a). Both daytime and 
nighttime sampling captured six taxa, mean richness was 2.3 for both daytime and nighttime sampling periods, and richness was not statistically different from one another $(P>0.05)$ (Figure 3b). However, each sampling period captured one unique taxon (daytime: Catostomus spp.; nighttime: Hypentelium spp.).

Variability of CPUE was lower in daytime spot-and-sweep sampling (CV=75.4\%) than in nighttime spot-and-sweep sampling $(\mathrm{CV}=139.1 \%)$. Average total length of larvae for daytime spot-and-sweep samples were $13.2 \mathrm{~mm}$, while that for nighttime sampling was $13.8 \mathrm{~mm}$. However, these size differences between daytime and nighttime spot-and-sweep samples were not significant $(P>0.05)$ (Table 3$)$.

Comparison of personnel bias in the spot-and-sweep method

Differences among personnel in sampling with the spot and sweep method were not statistically significant. Average richness for each of the three individuals sampling was 1.09 $(\mathrm{SD}=1.2), 1.12(\mathrm{SD}=1.3)$, and $1.06(\mathrm{SD}=1.3)$, while average CPUE was $5.5(\mathrm{SD}=10.1), 5.66$ $(\mathrm{SD}=10.9)$, and $6.46(\mathrm{SD}=12.6)$ respectively. Neither richness nor total abundance was significantly different among individual samplers (ANOVA: $F=0.65 P>0.05, \mathrm{df}=2$ and $F=0.73$, $P>0.05, \mathrm{df}=2$ respectively).

\section{Discussion}

The spot-and-sweep method was the best method of the three compared for rapid qualitative sampling of larval fish in structurally complex streams. When comparing nighttime 
sampling, the spot-and-sweep method captured more taxa than light traps and, while capturing the same number of taxa as drift nets, the ability of the spot-and-sweep method to consistently capture taxa was evident, as the method's mean richness was higher than that of drift nets. Coefficient of variation for nighttime sampling was lowest for the spot-and-sweep method as compared to the other gears evaluated. Spot-and-sweep captured more individuals (CPUE) than either drift nets or light traps. There also appears to be no difference between daytime and nighttime sampling periods in the ability of the spot-and-sweep method to capture individuals and taxa. The size range of larval fish captured was similar among the three methods, the spotand-sweep method captured larger larvae ( $\bar{x}=13.8$ and 13.2 night and day samples respectively) than light traps $(\bar{x}=11.0)$ and drift nets $(\bar{x}=8.78)$. The smallest larvae may be difficult for observers to see and therefore capture while performing spot-and-sweep sampling; however, the smallest larvae that all three methods captured was $7 \mathrm{~mm}$.

The spot-and-sweep method is well suited for sampling structurally complex streams where sampling by a research vessel is not practical. The spot-and-sweep method is likely not suitable for determining larval fish densities but it can be effective at determining presence and relative abundance. The adaptive nature of the spot-and-sweep method allows for active searching and sampling areas where larvae can be seen and captured. As far as we know no other studies have evaluated ELS sampling with the spot-and-sweep method in such spatially heterogeneous streams. The short duration of sampling required and ability to move quickly from one site to another with minimal gear allow for sampling of multiple sites within one day or night using the spot and sweep method, suggesting the method is particularly suitable where rapid assessment may be needed or required. 
Earlier research found no advantage of a sweep or dip net method as compared to light traps for sampling larval fishes. Knight and Bain (1996) found that in forested floodplain habitat light traps captured more families than dip netting. Falke et al. (2010) found no significant difference between a sweep net approach and light traps in a Great Plains river. However, we found the spot and sweep method to outperform both drift nets and light traps in larval fish CPUE, richness, and CV in the streams that we sampled. It is likely that differences in habitat or larval communities are responsible for differences in gear performance between these studies. Knight and Bain (1996) sampled a floodplain wetlands which likely had negligible currents to move drifting larvae downstream, while Falke et al. (2010) (a Great Plains stream) and our study took place in lotic environments. Additionally, the spot-and-sweep method sampled daytime and nighttime larval fish equally (differences were not statistically significant) suggesting this method has utility when researchers are interested in larvae diel comparisons and/or when researchers may not be able to safely sample during nighttime hours.

Each light trap and drift net sampled for two hours (collective time $=6$ hours per sample location), while we sampled with the spot-and-sweep method for three minutes per sample (collective time $=$ nine minutes per sample location). Active sampling methods are known to be efficient in both time and space (Hayes et al 2013) and the relatively small amount of time required for spot-and-sweep sampling, while outperforming the other two methods compared here, may be especially beneficial when time and money are a constraint. Additionally, while there were no significant differences between individual samplers, personal observation suggests that individual samplers increased their capture ability through time; however, we were unable to evaluate this statistically due to the nature of our sampling regime. Collectively, this suggests the spot-and-sweep method is a suitable larval fish sampling method for structurally complex 
streams and rivers, especially where rapid characterization of the larval fish community is important.

Sampling for the evaluation of the three methods compared here occurred during a single day/night cycle (18-19 June 2011). While it is understood that this may be outside of the time frame where many taxa are still in the larval stage (Auer 1982), we believe that we captured enough of the reproductive variability (i.e., seasonally available larvae) within these systems to accurately compare the efficacy of the described methods. In a separate $2010-2013$ study where we sampled every two weeks from the beginning of April to the end of August and used light traps and drift nets exclusively at one site in both Patterson Creek and New Creek (each site was congruent with one of the sites in the study described in this manuscript), in addition to the taxa listed in Table 2 we captured Campostoma, Ambloplites, and Nocomis. Sampling during the 2011 field season (April through August) yielded Campostoma as the only genus not captured during our three methods comparison here. While additional research of the spot-and-sweep method is needed in order to evaluate its efficacy within other systems, it is unlikely that additional sampling in our study would have led to representative taxa that would have displayed strategies and behaviors that we did not see in the taxa collected in our study. However, upon consideration of these methods as part of a sampling protocol for future research, we suggest careful evaluation of phenology of the system being studied.

Larval fish dispersal and within habitat retention are subject to stream hydraulic conditions and habitat structure; and the ability to capture larvae can be complicated by temporal patterns in drifting behavior and effects of larval size (Schludermann et al. 2012). The underlying principles of the three methods evaluated differ from one another. Light traps depend on a larval fish's ability to perceive the light source and willingness to enter the illuminated 
enclosure. Water clarity, current speed, spatial heterogeneity (objects that may block light penetration such as large woody debris, rocks, etc.), positive phototaxis, and swimming ability are all factors that may affect the effectiveness of light traps (Doherty 1987; Milicich et al. 1992; Thorrold 1992). These factors may restrict the ability of light traps to capture some larvae even when conditions are optimal. The ability of drift nets to capture larvae are affected by factors such as area of the opening, current velocity, behavioral drift response of larvae, and mesh size, all of which can affect the taxonomic composition, size structure, and quantity of samples (Clutter and Anraku 1968; Colton et al. 1980; Brander and Thompson 1989; Morse 1989; Suthers and Frank 1989). Increased turbidity may reduce the effectiveness of light traps but this may not be the case for drift nets which are not known to be affected by turbidity; however, increased flows associated with relatively turbid waters may render drift nets impractical. Spotand-sweep sampling is affected by water clarity, current velocity, spatial heterogeneity, and evasive swimming abilities of larvae (personal observation). Shoreline areas may be important for larvae (Claramunt et al. 2005), as they provide refuge from predation and high velocities and are likely areas where food availability is high (Basu and Pick 1996; Nunn et al. 2012). The ability of the spot-and-sweep method to sample shallow stream margins (depths $<0.25 \mathrm{~m}$ ), habitat areas where larvae may escape (Nunn et al. 2012) both predation and high velocities (Garner 1997) may contribute to the method outperforming light traps and drift nets in shallow, structurally diverse systems. These factors are potentially highly variable between systems and should be carefully considered when designing a sampling protocol for larval fish, regardless of sampling methods employed, but specifically if planning to use the spot-and-sweep method. 


\section{References}

Auer, N. A. 1982. Identification of larval fishes of the Great Lakes basin, with emphasis on the Lake Michigan drainage. University of Michigan, Special Publication 82-3, Ann Arbor.

Basu, B.K. and F.R. Pick. 1996. Factors regulating phytoplankton and zooplankton biomass in temperate rivers. Limnology and Oceanography 41:1572-1577.

Bertolo, A., F. G. Blanchet, P. Magnan, P. Brodeur, M. Mingelbier, and P. Lengendre. 2012. Inferring process from spatial patterns: the role of directional and non-directional forces in shaping fish larvae distribution in a freshwater lake system. PLoS ONE 7:e50239.

Boehler, C. T., and K. Baker. 2013. Diel larval fish drift in a small Ohio stream (Honey Creek, Seneca Co., OH). Ohio Journal of Science 111(2-5):33-36.

Brander, K., and A. B. Thompson. 1989. Diel differences in avoidance of three vertical profile sampling gears by herring larvae. Journal of Plankton Research 11:775-784.

Burdick, S.M., H. A. Hendrixon, and S. P. VanderKooi. 2008. Age-0 Lost River Sucker and Shortnose Sucker nearshore habitat use in Upper Klamath Lake, Oregon: A patch occupancy approach. Transactions of the American Fisheries Society 137(2):417-430.

Claramunt, R. M., D. E. Shoup, and D. H. Wahl. 2005. Comparison of push nets and town nets for sampling larval fish with implications for assessing littoral habitat utilization. North American Journal of Fisheries Management 25:86-92.

Clifford, H. F. 1972. Downstream movements of white sucker, Catostomus commersoni, fry in a brown-water stream of Alberta. Journal of the Fisheries Research Board of Canada 29:1091-1093.

Clutter, R. I., and M. Anraku. 1968. Avoidance of samplers. Monographs on Oceanographic Methodology 2:57:76.

Colton, P. L., J. R. Green, R. R. Byron, and J. L. Rosella. 1980. Bongo net retention rates as affected by towing speed and mesh size. Canadian Journal of Fisheries and Aquatic Sciences 37:606-623.

Doherty, P. J. 1987. Light traps: selective but useful devices for quantifying the distributions and abundances of larval fishes. Bulletin of Marine Science 41:423-431.

Faber, D. J. 1982. Fish larvae caught by a light trap at littoral sites in Lac Heney, Quebec, 1979 and 1980. Pages 42-46 in C. F. Bryan, J. V. Conner, and F. M. Truesdale, editors. Proceedings of the $5^{\text {th }}$ annual larval fish conference. Louisiana Cooperative Fisheries Research Unit, Louisiana State University, Baton Rouge. 
Falke, J. A., Fausch, K. D., Bestgen, K. R., and Baily L. L. 2010. Spawning phenology and habitat use in a Great Plains, USA, stream fish assemblage: an occupancy estimation approach. Canadian Journal of Fisheries and Aquatic Sciences 67:1942-1956.

Ferreira, A. S. de A., E. K. Stenevik, K. W. Vollset, R. Korneliussen, and A. Folkvord. 2012. Vertical migration of Norwegian spring-spawning herring larvae in relation to predator and prey distribution. Marine Biology Research 8(7):605-614.

Floyd, K. B., W. H. Courtenay, and R. D. Hoyt. 1984. A new larval fish trap: the quatrefoil trap. Progressive Fish Culturist 46:216-219.

Franzin, W. G., and S. M. Harbicht. 1992. Tests of drift samplers for estimating abundance of recently hatched walleye larvae in small rivers. North American Journal of Fisheries Management 12(2):396-405.

Gale, W. F., and H. W. Mohr, Jr. 1978. Larval fish drift in a large river with a comparison of sampling methods. Transactions of the American Fisheries Society 107:46-55.

Garner, P. 1997. Habitat use by 0+ cyprinid fish in the River Great Ouse, East Anglia. Freshwater Forum, 8, 2-27.

Gerhke, P. C. 1994. Influence of light intensity and wavelength on phototactic behavior of larval silver perch Bidyanus bidyanus and golden perch Macquaria ambigua and the effectiveness of light traps. Journal of Fish Biology 44:741-754.

Greenwood, J. J. D., and R. A. Robinson. 2009. Principles of Sampling. Pages 11-86 in W. J. Sutherland, editor. Ecological Census Techniques, $2^{\text {nd }}$ edition. Cambridge University Press, New York.

Hayes, D. B., C. P. Ferreri, and W. W. Taylor. 2013. Active fish capture techniques. Pages 267-300 in A. V. Zale, D. L. Parrish, and T. M. Sutton, editors. Fisheries techniques, $3^{\text {rd }}$ edition. The American Fisheries Society, Bethesda, Maryland.

Hubert, W. A., K. L. Pope, and J. M. Dettmers. 2013. Passive capture techniques. Pages 223253 in A. V. Zale, D. L. Parrish, and T. M. Sutton, editors. Fisheries techniques, $3^{\text {rd }}$ edition. The American Fisheries Society, Bethesda, Maryland.

Johnson, M. L., and M. S. Gaines. 1990. Evolution of dispersal: theoretical models and empirical tests using birds and mammals. Annual Review of Ecological Systems 21:449$49=80$.

Kelso W. E., M. D. Kaller, and Rutherford A. 2013. Collection, processing, and identification of fish eggs and larvae and zooplankton. Pages 363-413 in A. V. Zale, D. L. Parrish, and 
T. M. Sutton, editors. Fisheries techniques, $3^{\text {rd }}$ edition. The American Fisheries Society, Bethesda, Maryland.

Kingsford, M. M., and J. H. Choat. 1985. The fauna associated with drift algae captured with a plankton-mesh purse seine net. Limnology and Oceanography 30:618-630.

Knight, J. G., and M. B. Bain. 1996. Sampling fish assemblages in forested floodplain wetlands. Ecology of Freshwater Fish 5:76-85.

Milicich, M. J., M. G. Meek, and P. J. Doherty. 1992. Larval supply: a good predictor of recruitment of three species of reef fish (Pomacentridae). Marine Ecology Progress Series 86:153-166.

Morse, W. W. 1989. Catchability, growth, and mortality of larval fishes. U.S. National Marine Fishery Bulletin 87:417-446.

Niles, J. M. 2004. Examination of experimentally engineered larval fish habitat in the Marmet Pool, Kanawha River, West Virginia. Master's thesis. West Virginia University, Morgantown.

Nunn A. D., L. H. Tewson, and I. G. Cowx. 2012. The foraging ecology of larval and juvenile fishes. Reviews in Fish Biology and Fisheries 22:377-408.

Ott R. L., and M. Longnecker. 2001. An Introduction to Statistical Methods and Data Analysis, $5^{\text {th }}$ edition. Duxbury, Pacific Grove, California.

R Development Core Team. 2015. R: A Language and Environment for Statistical Computing. R Foundation for Statistical Computing, Vienna, Austria. URL http://www.R-project.org/.

Robinson, A. T., R. W. Clarkson, and R. E. Forrest. 1998. Dispersal of larval fishes in a regulated river tributary. Transactions of the American Fisheries Society 127(5):772786.

Rozas, L. P., and T. J. Minello. 1997. Estimating densities of small fishes and decapod crustaceans in shallow estuarine habitats: a review of sampling design with focus on gear selection. Estuaries 20:199-213.

Schludermann E., M. Tritthart, P. Humphries, and H. Keckeis. 2012. Dispersal and retention of larval fish in a potential nursery habitat of large temperate river: an experimental study. Canadian Journal of Fisheries and Aquatic Sciences 69:1302-1315.

Secor, D. H., J. M. Dean, and J. Hansbarger. 1992. Modification of the quatrefoil light trap for use in hatchery ponds. Progressive Fish-Culturist 54:202-205. 
Suthers, I. M., and K. T. Frank. 1989. Interannual distributions of larval and pelagic juvenile cod (Gadus morhua) in southwestern Nova Scotia determined with two different gear types. Canadian Journal of Fisheries and Aquatic Sciences 46:591-602.

Taggart, C. T., and W. C. Leggett. 1984. Efficiency of large volume plankton pumps and evaluation of a design suitable for deployment from small boats. Canadian Journal of Fisheries and Aquatic Sciences 41:1428-1435.

Thorrold, S. R. 1992. Evaluating the performance of light traps for sampling small fish and squid in open waters of central Great Barrier Reef lagoon. Marine Ecology Progress Series 89:277-285.

Turner, T. F., J. C. Trexler, G. L. Miller, and K. E. Toyer. 1994. Temporal and spatial dynamics of larval and juvenile fish abundance in a temperate floodplain river. Copeia 1994(1):174-183. 
Table 1. Mean water quality data at sampling locations for Patterson Creek, Grant County and New Creek, Mineral County, West Virginia on June 18-19, 2014 during daytime and nighttime sampling periods $(n=12)$. Standard deviations are given in parentheses.

\begin{tabular}{|c|c|c|c|c|c|}
\hline Location & Sample Period & Temperature $\left({ }^{\circ} \mathrm{C}\right)$ & Conductivity ( $\mu \mathrm{S} / \mathrm{cm})$ & Dissolved Oxygen (mg/L) & $\mathrm{pH}$ \\
\hline \multirow[t]{2}{*}{ Patterson Creek } & Day & $20.31(0.26)$ & 342.00 (16.09) & $13.63(0.27)$ & $8.37(0.14)$ \\
\hline & Night & $20.57(0.83)$ & $371.00(17.04)$ & $11.16(0.79)$ & $7.98(0.08)$ \\
\hline \multirow[t]{2}{*}{ New Creek } & Day & $25.23(0.08)$ & 286.67 (19.01) & $13.01(0.27)$ & $8.41(0.10)$ \\
\hline & Night & $25.36(0.31)$ & $296.33(14.11)$ & $9.83(0.36)$ & $7.97(0.06)$ \\
\hline
\end{tabular}


Table 2. Number of larval fish ( $n$ ) and percent of total taxa for each taxon collected in 18 each of spot-and-sweep, light traps, and drift nets. Each of the three methods was performed during both daytime and nighttime sampling periods in Patterson Creek, Grant County and New Creek, Mineral County, West Virginia on June 18-19, 2014. Drift nets and light traps captured zero larvae during daytime sampling, therefore only nighttime data are shown for drift nets and light traps, while daytime and nighttime results are displayed for the spot-and-sweep method.

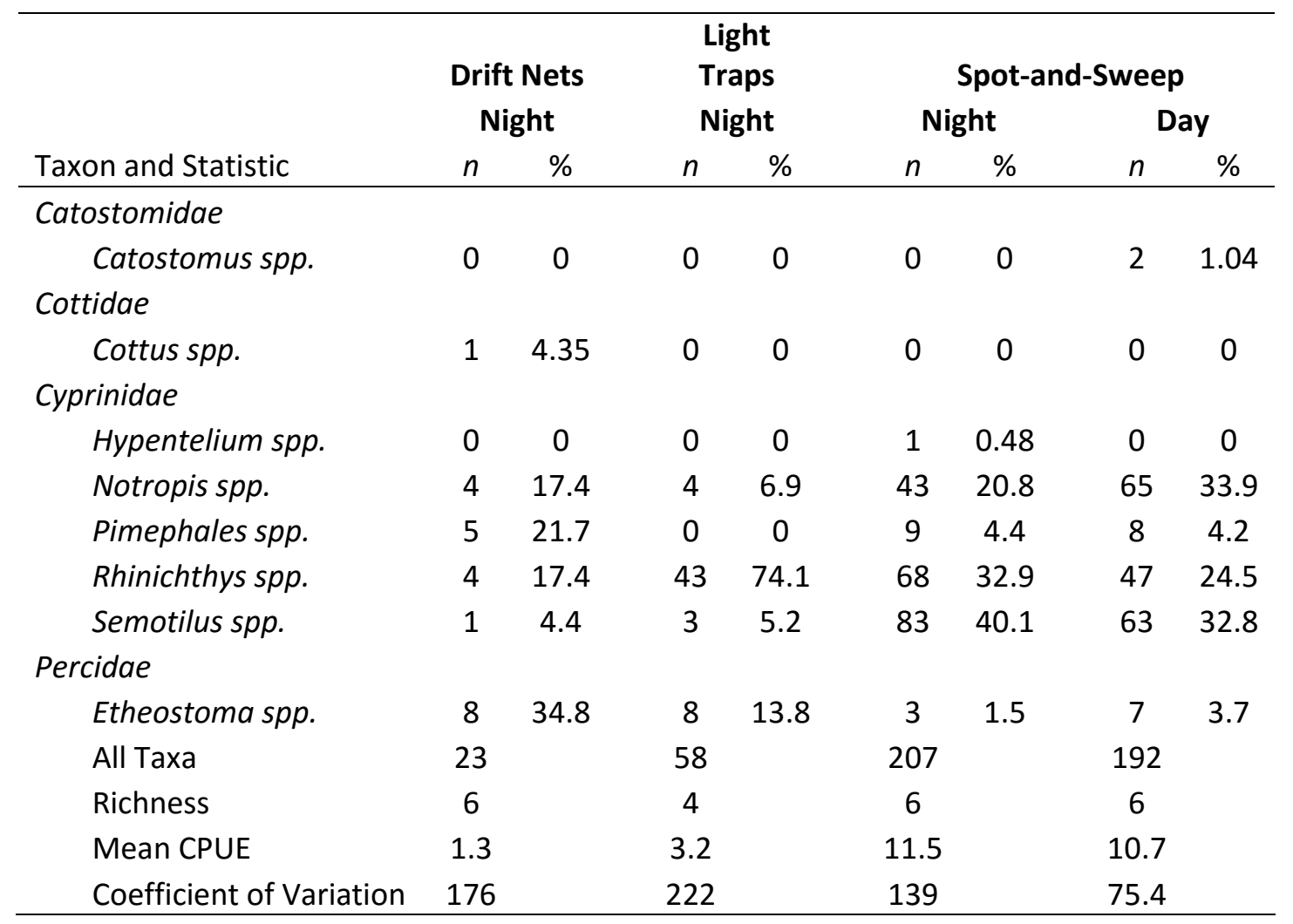


Table 3. Average minimum (Min) and maximum (Max) length (mm), average length (Avg) (mm), and standard deviation (SD) for each taxon collected in 18 each of spot-and-sweep, light traps, and drift nets for night sampling periods and day and night for spotand-sweep samples in Patterson Creek, Grant County and New Creek, Mineral County, WV on June 18-19, 2014. Drift nets and light traps captured zero larvae during daytime sampling, therefore only nighttime data are shown for drift nets and light traps, while daytime and nighttime results are displayed for the spot-and-sweep method.

\begin{tabular}{|c|c|c|c|c|c|c|c|c|c|c|c|c|c|c|c|c|}
\hline \multirow[b]{2}{*}{ Taxon and Statistic } & \multicolumn{4}{|c|}{$\begin{array}{c}\text { Drift Nets } \\
\text { Night }\end{array}$} & \multicolumn{4}{|c|}{$\begin{array}{l}\text { Light Traps } \\
\text { Night }\end{array}$} & \multicolumn{4}{|c|}{$\begin{array}{c}\text { Spot-and-Sweep } \\
\text { Night }\end{array}$} & \multicolumn{4}{|c|}{$\begin{array}{c}\text { Spot-and-Sweep } \\
\text { Day }\end{array}$} \\
\hline & Min & Max & Avg & SD & Min & Max & Avg & SD & Min & Max & Avg & SD & Min & Max & Avg & SD \\
\hline \multicolumn{17}{|l|}{ Catostomidae } \\
\hline $\begin{array}{l}\text { Catostomus spp. } \\
\text { Cottidae }\end{array}$ & -- & -- & -- & -- & -- & -- & -- & -- & -- & -- & -- & -- & 10 & 23 & 16.5 & 9.2 \\
\hline Cottus spp. & 9 & 9 & 9 & $\mathrm{~N} / \mathrm{A}$ & -- & -- & -- & -- & -- & -- & -- & -- & -- & -- & -- & -- \\
\hline \multicolumn{17}{|l|}{ Cyprinidae } \\
\hline Hypentelium spp. & -- & -- & -- & -- & -- & -- & -- & -- & 22 & 22 & 22 & N/A & -- & -- & -- & -- \\
\hline Notropis spp. & 8 & 8 & 8 & 0 & 8 & 22 & 12 & 6.7 & 7 & 26 & 11.5 & 4.7 & 7 & 25 & 14.1 & 6.1 \\
\hline Pimephales spp. & 7 & 8 & 7.4 & 0.6 & -- & -- & -- & -- & 7 & 14 & 8.5 & 2.1 & 7 & 10 & 8.5 & 1.1 \\
\hline Rhinichthys spp. & 7 & 8 & 7.5 & 0.5 & 7 & 13 & 10 & 1.8 & 7 & 13 & 11 & 1.8 & 8 & 13 & 10.3 & 1.6 \\
\hline Semotilus spp. & 23 & 23 & 23 & $N / A$ & 16 & 22 & 19 & 3 & 9 & 26 & 17.8 & 3.8 & 8 & 25 & 15 & 4.4 \\
\hline \multicolumn{17}{|l|}{ Percidae } \\
\hline Etheostoma spp. & 9 & 9 & 9 & 0 & 10 & 15 & 12.5 & 2.2 & 15 & 15 & 15 & 0 & 10 & 15 & 13.1 & 1.7 \\
\hline All taxa & 7 & 23 & 8.8 & 3.2 & 7 & 22 & 11 & 3.2 & 7 & 26 & 13.8 & 4.8 & 7 & 25 & 13.2 & 5.0 \\
\hline
\end{tabular}




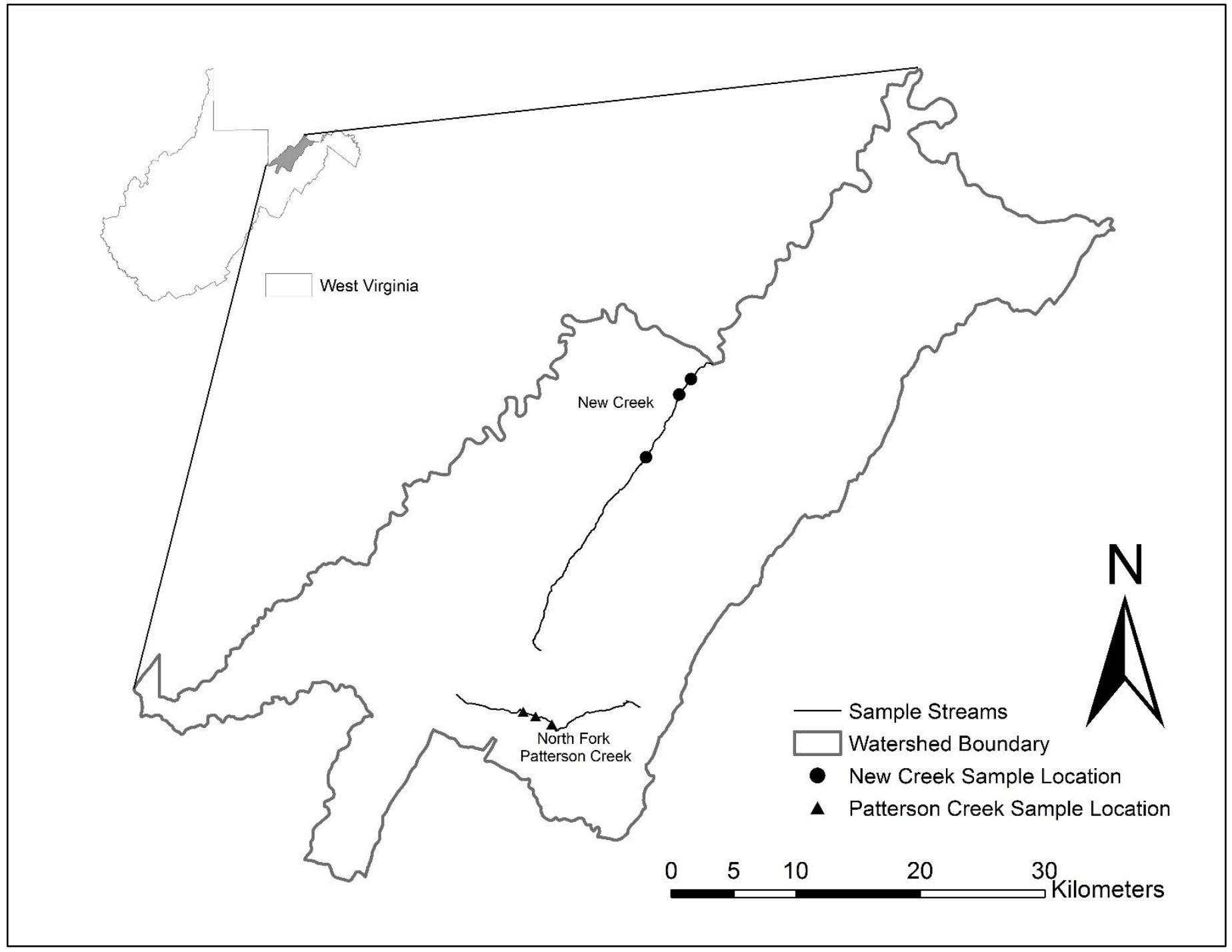

Figure 1. Location of sample streams and sites. Solid circles and solid triangles represent sample sites along New Creek and Patterson Creek respectively. The inset map location of the watershed within the state of West Virginia. 


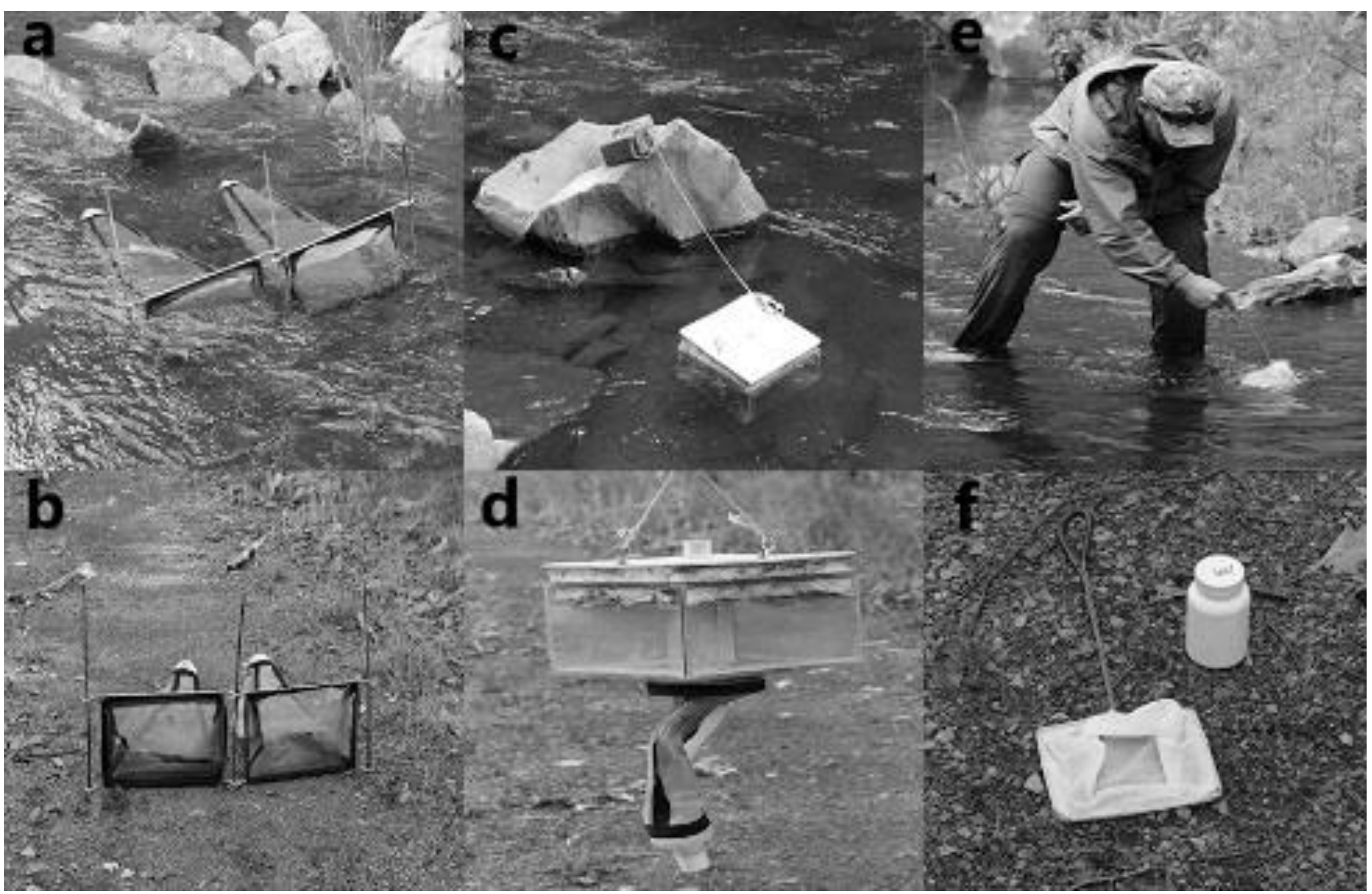

Figure 2. Images show each of the three methods - drift nets (a, b), light traps (c, d), and spot-and-sweep (e, f) - in action (a, c, and e) and on land for a clear visual representation (b, d, and f). 


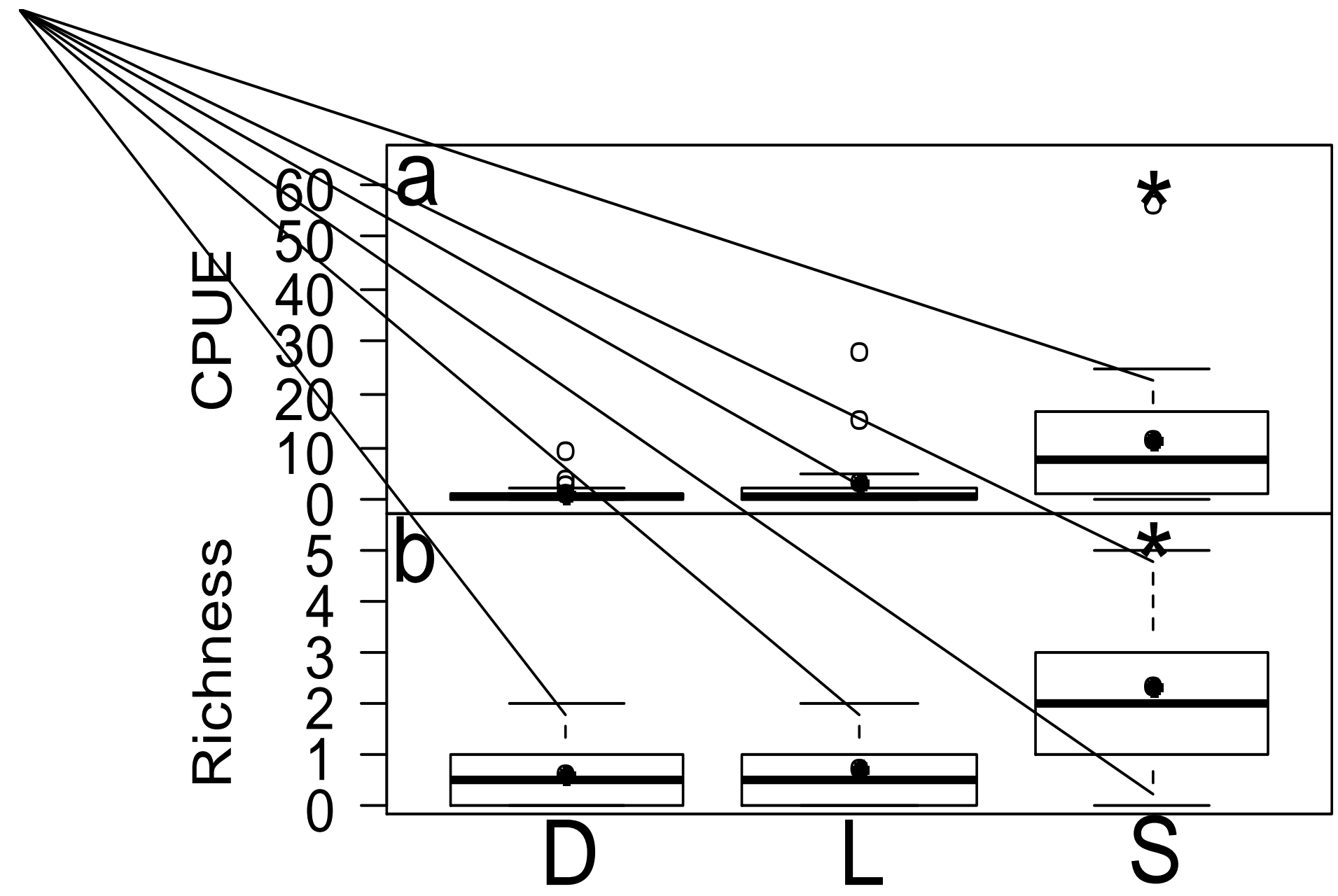

Figure 3. CPUE (a) and richness (b) for nighttime sampling for each sampling method ( $D=$ Drift Nets, L=Light Traps, S=Spot-andSweep). Solid circles represent means, asterisks designate statistical significance, open circles represent outliers, ends of whiskers represent minima and maxima, boxes represent quartiles, and lines within boxes represent medians. 


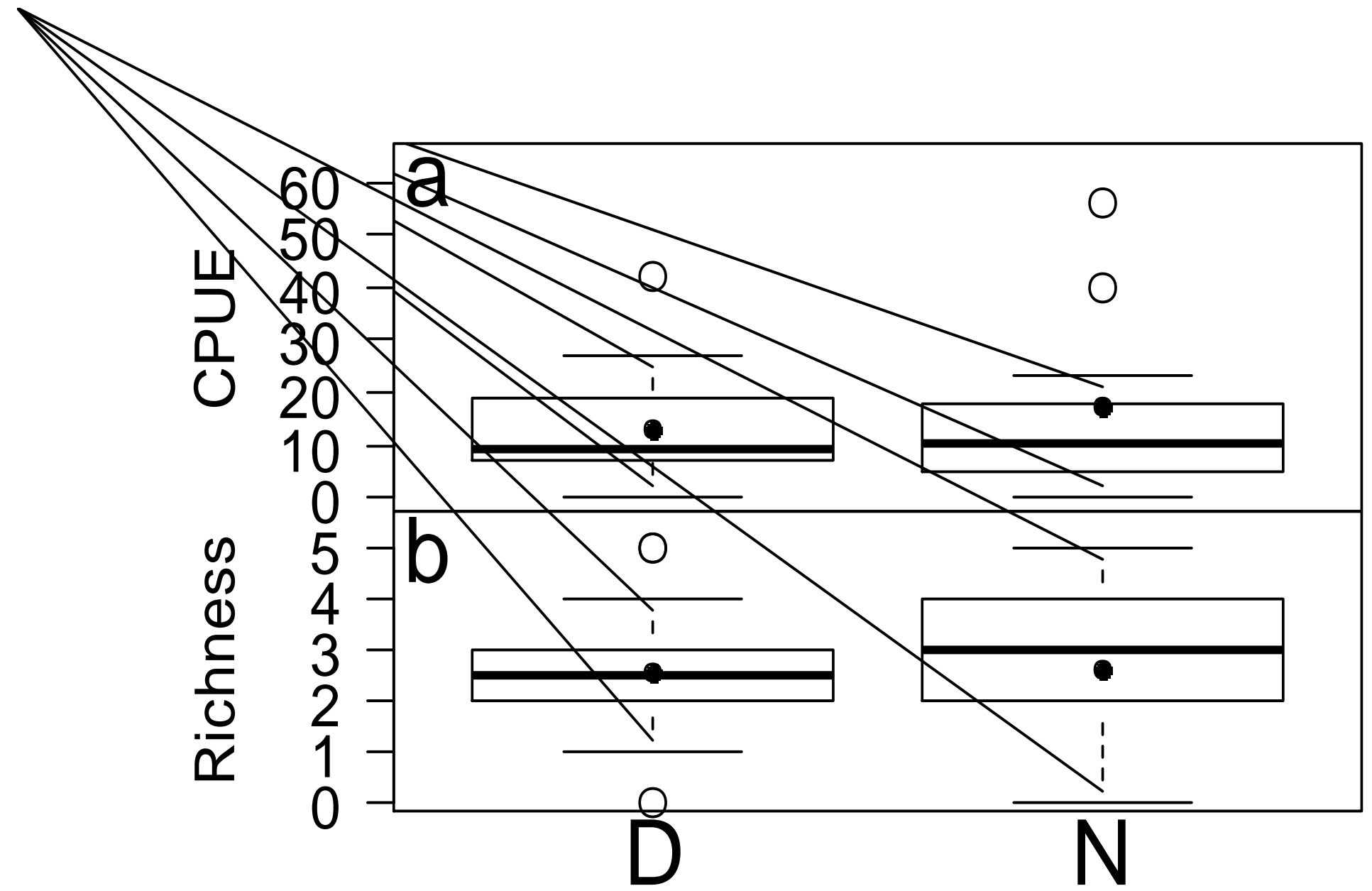

Figure 4. CPUE (a) and richness (b) for daytime and nighttime sampling periods for the spot-and-sweep sampling method (D=Day, $\mathrm{N}=$ Night). Solid circles represent means, open circles represent outliers, ends of whiskers represent minima and maxima, boxes represent quartiles, and lines within boxes represent medians. 
Chapter 2. Identifying Impacts from Dams that may Affect Abundance, Richness, Diversity, and Community Structure for Larval and Juvenile Fish

\author{
Abstract \\ The influence of dams on downstream biotic and abiotic components of aquatic \\ ecosystems has been largely studied within the context of the River Continuum (RCC) and Serial \\ Discontinuity Concepts (SDC). Few of these studies have sufficiently investigated how these \\ variables change along the longitudinal gradient below the impoundments in a systematic \\ manner, especially for early life stage fishes. We systematically evaluated patterns of abiotic and \\ biotic (larval and juvenile fish; <30 mm total length) along the longitudinal gradient at two \\ spatial scales in both systems with hypolimnetic and those with epilimnetic releases, and \\ compared impounded systems to a reference stream. Generalized additive models indicated a \\ general increase for abundance, genus richness, and Shannon diversity with increasing distance \\ from dams and at two spatial scales: one near dam gradient where rapid changes occurred within \\ the first 1,100-m sample reach and a second more gradual gradient that appears to extend beyond \\ the 5,100-m sample reach. Principal component analysis (PCA) indicated three influential PC's \\ that were structured by landcover, habitat and water quality, and disturbance. Nonmetric \\ multidimensional scaling (NMDS) indicated larval and juvenile fish communities were \\ structured differently between epilimnetic and hypolimnetic releases and that habitat variables \\ structuring those communities were more variable in epilimnetic releases than hypolimnetic \\ releases. Generally, our findings agreed with that of the SDC but we believe future studies \\ should be more systematic in their evaluation of the SDC and further studies are required to \\ understand the two recovery gradients that exist below impoundments.
}




\section{Introduction}

River ecosystems are often conceptualized as continuous entities along their longitudinal gradient. At large scales where such a concept may be applicable, the River Continuum Concept (RCC) proposes that the physical and chemical features continually change along the stream gradient from headwaters to sea; thereby structuring the associated biological communities (Vannote et al. 1980). Scale refers to the extent relative to the size of the sampling unit of a variable of interest in both space and time (Schnieder, 1989; Weins, 1989). Scale also has three relevant subcategories: extent, grain, and lag. Whereas, extent describes the limits of the study, grain describes the size of the sampling unit (e.g., 100-m transect, 5-m quadrat, 500-m stream reach, etc.), and lag describes the distance or interval between sampling units (Sutherland 2006). As scale is reduced, these changes become less prominent and may not appear to follow the RCC but rather seem somewhat random (Ward et al., 2001).

However, due largely to anthropogenic influences, the majority of lotic ecosystems no longer act as continuous entities and instead are influenced by discontinuities along their longitudinal gradient (Ward and Stanford 1983), of which dams are likely the most influential. Ward and Stanford (1983) developed the Serial Discontinuity Concept (SDC) which created the theoretical framework to understand how discontinuities modify physiochemical and biological components upstream and downstream of dams. These changes have been shown to adversely influence biological components (e.g., fish, aquatic macroinvertebrates, etc.) of stream communities (Katano et al. 2009; Ellis and Jones, 2013; Freedman et al., 2013). Discontinuities within a stream can reset or shift a variable in either the upstream or downstream direction (Ward and Stanford, 1983). The distance of this shift is termed the discontinuity distance. In order to further understand the nature of biological recovery gradients along these longitudinal 
discontinuities, empirical approaches are necessary (Stanford and Ward 2001). Studies of regulated rivers should be performed at the appropriate scale, including considerations of extent, grain, and lag, in order to sufficiently assess biotic and abiotic recovery gradients.

The size and relative location of dams along the length of a stream may have differential effects on downstream physiochemical and biological attributes (Ward and Stanford, 1983) and should be considered when evaluating a dam's impact on the abiotic and biotic components of that system. The nature of the water released from a dam and its downstream impacts on both physiochemical and biological components are influenced by whether the water is of hypolemnetic or epilimnetic origin (Yeager 1993). The SDC was proposed as using a series of thought experiments based on hypothetical dams with hypolemnetic water releases (Ward and Stanford 1983, Stanford and Ward 2001).

Dams have been shown to disrupt sediment transport thereby reducing downstream sediment loads and modifying sediment composition (Jones, 2010). Shifts in thermal regimes are also a product of impoundments and the magnitude of change above and below the dam is dependent on whether the dam release is hypolimnetic or epilimnetic. The rate at which temperature changes as the distance from dam increases is dependent on multiple factors (e.g., the number, size, and temperature of tributaries, latitude, canopy cover, etc.) (Rice et al., 2001). The velocity and depth close to impoundments are often substantially different from what would be expected at the location along the stream continuum were the dam absent (Freedman et al., 2013), due to the ability for dams to trap nutrients and sediment (Graff, 1999; Poff and Hart, 2002). Water quality can be influential in structuring the biotic communities (Storey et al., 1991; Freedman et al., 2013). Large substrate has been found to be characteristic of sites in close proximity to dams (Storey et al., 1991; Cortes et al., 2002; Katano et al., 2009). Reservoirs may 
act to trap sediment, thereby starving areas downstream of dams of this key resource causing an armoring of the substrate as the streambed and banks are eroded (Jones, 2010).

The biotic components, adult fish and aquatic macroinvertebrates, of river ecosystems in the context of the SDC have been largely studied (Ellis and Jones 2013); yet there have been few studies to evaluate dam influences on larval and juvenile fish. This is especially true of efforts to understand the response of early life stage fish to impounded systems along the longitudinal gradient. Furthermore we could find no other studies that evaluated the impacts of dams on larval and juvenile fish under epilimnetic and hypolimnetic dam release conditions while comparing them to a reference stream. Land use practices have been shown to influence aquatic ecosystems (Allan, 2004) in regards to both their biotic and abiotic components (Allan and Johnson 1997, Johnson et al., 1997; Roy et al., 2003). Johnson et al. (1997) found agricultural land use to be an effective predictor of water chemistry variables in central Michigan's Saginaw River basin.

Urbanization and forested landcover had opposite effects on various benthic invertebrate biotic indices, with higher values associated with forested areas; whereas urbanization resulted in higher proportions of tolerant taxa and reduced diversity (Roy et al., 2003). Within the context of the SDC, land use practices should be considered as potentially influential in structuring water quality, habitat, and biotic indices. The objectives of this study were to systematically: 1) evaluate general relationships of abundance, richness, and diversity with habitat (instream, landcover, and water quality) along the longitudinal gradient below dams; and 2) investigate potential differences in the structure of communities and associated habitat variables between epilimnetic and hypolimnetic dam releases and a reference stream. We hypothesized, concurrent 
with the SDC, that the aforementioned response variables and community structure will show a strong relationship with increasing distance from dams.

\section{Materials and Methods}

Study Sites

Sampling occurred in six dammed streams (Beaver Run, Pennsylvania; Big Walnut Creek, Ohio; East Branch of the Clarion River, Pennsylvania; Evitts Creek, Pennsylvania; Savage River, Maryland; Two Lick Creek, Pennsylvania; Yellow Creek, Pennsylvania) and one reference stream (New Creek, West Virginia) during 2012 and 2013, of the six dams three were epilimnetic and three were hypolimnetic releases (Figure 1, Table 1). New Creek was selected as a reference stream based on data from previous work (Hanks unpublished) where it had high richness and diversity and based on the fact that the stream is unimpounded within the near proximity of the study reach. New Creek (i.e., reference stream) was assigned a starting location (i.e., a hypothetical dam location) and sampled from that point downstream in the same fashion as our dammed sites. The 2012 sampling occurred in Savage River, MD; yet we were unable to replicate sampling in Savage River during 2013 due to agency concerns. The Savage River was replaced in 2013 with East Branch of the Clarion, PA during 2013. Sampling locations (distance below dams) within each stream were selected a priori. Beginning as close to the tailwaters of each dam as was safely possible (assigned zero distance) we sampled larval fish and physiochemical variables every $100-\mathrm{m}$ for the first $600-\mathrm{m}(\mathrm{n}=7)$, thereafter we sampled every 500-m to 5,100-m below the dam $\left(\mathrm{N}_{\text {total }}=16\right.$ for each stream). Preliminary data (Hanks unpublished 2011) suggested very low taxa richness within the first 600-m below the dam and we therefore sampled at a finer spatial scale within the first $600-\mathrm{m}$ below the dam. Due to 
logistical and resource constraints we decided to sample 5,100-m below dams to assess the discontinuity distance associated with each dam along the stream continuum.

\section{Sampling: Larval fish and physicochemical variables}

Larval fish were sampled two times during both 2012 and 2013 between mid-May and mid-June, as prior sampling for larval fish (Hanks unpublished data) and work by Niles (2004) indicated there are high numbers of individual larvae captured and high taxa richness between these dates in this region. Sampling twice during this timeframe allowed for capture of what we believe was the majority of larval richness in our research streams. At each sampling location, we sampled larval fish for a total of 25 minutes (i.e., five, five minute sample periods) using a modified sweep net technique (Falke et al. 2010; Hanks 2016), where small aquarium dip nets $($ mesh size $=500-\mu \mathrm{m})$ were used. This modified sweep net technique is a modified adaptive cluster sampling technique where personnel wade the stream while looking for larval fish (Greenwood and Robinson 2006). Once larval fish are seen they are swept into the net (Hanks 2016). Captured larvae were washed into sample jars, labeled, and preserved with $10 \%$ buffered formalin (Kelso et al. 2013). Larvae were returned to the lab for identification. Due to logistical constraints we could not sample site locations within each stream randomly and therefore we randomly selected either 5,100-m or 0-m as our starting location, sampled either upstream or downstream from that starting location, and sampled each site consecutively along the stream's longitudinal gradient. All sampling occurred during daylight hours (0900-2000).

Microhabitat and water quality variables were measured once per year at each sampling location. Water quality variables (conductivity $(\mu \mathrm{S} / \mathrm{cm})$, dissolved oxygen $(\mathrm{mg} / \mathrm{L}), \mathrm{pH}$, and temperature $\left({ }^{\circ} \mathrm{C}\right)$ were recorded once at each sampling location $\left(\mathrm{N}_{\text {total }}=16\right.$ per stream $)$ with a YSI 
meter (Yellow Springs Instruments computer module: 650MDS, Yellow Springs, Ohio). Channel and bankful widths were measured at five transects per sampling location (sixteen sampling locations per stream) and at five points along each transect width, depth, flow, percent embeddedness, and substrate were measured (400 point locations per stream). Flow measurements were recorded with a Marsh-McBirney flow meter (Marsh-McBirney Inc., Frederick, Maryland). Substrata were coded based on size class categories as follows: $1=$ bedrock $(>4000 \mathrm{~mm}), 2=$ fines $(<0.06 \mathrm{~mm}), 3=$ sand $(0.06-2 \mathrm{~mm}), 4=$ fine gravel $(2-16 \mathrm{~mm}), 5$ $=$ coarse gravel $(16-64 \mathrm{~mm}), 6=$ cobble $(64-250 \mathrm{~mm})$, and $7=$ boulder $(250-4000 \mathrm{~mm})$. Average substrate coarseness (Katano et al. 2009) at each sampling location was used in models and calculated as:

\section{Coarseness $=\Sigma$ (Size category code $x \%$ of a given category at a given transect $)$}

Additionally, average substrate diversity (Shannon diversity) and overall habitat diversity (Shannon diversity for substrate, depth, and flow) was calculated for each site.

\section{Landscape habitat variables}

Using spatial analyst functions in ArcMap 10.2.1 (Environmental Systems Research Institute, Redlands, California) we generated watersheds for each site on a respective stream. Landcover (from the 2011 National Landcover Dataset [NLCD]) attributes from each watershed were then subtracted serially in order to get the percent landcover type within each respective sub-watershed. We then combined landcover types into three categories (developed, forested, and agricultural/grassland) for analysis. We also calculated road density (i.e., density = (road 
length/sub-watershed area) x 100) as an additional method of calculated development within a sub-watershed. For each sampling location stream distance to nearest upstream and downstream tributary was measured in ArcMap 10.2.1 using the measure tool.

\section{Laboratory processing of samples}

All samples were washed through a 500- $\mu \mathrm{m}$ sieve and transferred to a dissecting tray. Larval fish were identified to lowest possible taxa (typically genus) using various references (Auer, 1982; Holland-Bartels et al., 1990; Wallus et al., 1990). An advantage of the modified sweep net technique is that larvae are not damaged during the capture and fixation process and therefore we had no unidentified larvae due to damage from handling, etc. Larvae were identified using a Leica MZ6 dissecting microscope (Buffalo Grove, Illinois) aided with a ColeParmer light ring and polarizing lens (Court Vernon Hills, Illinois).

\section{Statistical analysis}

We evaluated differences in the change along the longitudinal gradient in abundance, richness, and diversity between years (2012 and 2013) with an ANCOVA and community similarity with Adonis (package vegan). Due to the species area relationship (MacArthur and Wilson 1967) streams with larger drainage area are expected to have higher taxonomic richness; therefore we regressed total genus richness on drainage area $\left(\mathrm{km}^{2}\right)$. Drainage area was assessed using each respective stream's dam as a pour point and total genus richness was calculated as the average of all genera captured within each stream's 5,100 m stream reach for 2012 and 2013. We also tested for differences in abundance, richness, and diversity between our reference 
stream, epilimnetic, and hypolimnetic dam releases with an ANCOVA and community similarity with Adonis.

We investigated the influence of physicochemical habitat variables (in stream and landscape level) on abundance and genus level richness and diversity along the stream continuum below dams using Generalized Additive Models (GAMs). Generalized Additive Models allow for response variables to vary in a non-linear fashion as predictor variables change. Using factors in the models allow for these changes to vary with the factor term (e.g., dam release type). GAMs were applied using package mgcv (Wood 2006) in Program R and we applied a cubic regression spline with shrinkage, allowing for smoothing terms to have zero degrees of freedom (Zuur et al. 2009). Generalized additive models were developed using a smoothing term for distance and treating release type (epilimnetic and hypolimnetic) as factors. Prior to model development and selection we used variance inflation factors (VIF) to assess collinearity between predictor variables. Variables with a VIF greater than 3 were removed from subsequent models, with year (2012 and 2013) treated as a factor. There was a significant effect of release type (epilimnetic and hypolimnetic) on temperature while controlling for distance $(\mathrm{F}=291.87, \mathrm{p}<0.001)$; however, we decided to remove release type and retain temperature in our models, which was significant along the longitudinal gradient $(F=4.85, p<0.05)$, because we felt that temperature contained release type information as well as additional non-categorical information. Richness was modeled with a Poisson distribution because it is count data; while diversity and abundance were modeled using a Gaussian distribution. Final models are a result of fitting the data to all measured and calculated habitat variables, dropping nonsignificant terms and selecting the model with the lowest Akaike Information Criterion (AIC). 
We used principal component analysis (PCA) to reduce the dimensionality of our water quality, in stream habitat, and landcover variables and further investigate changes along the longitudinal gradient below dams. Large multivariate data sets can be dimensionally reduced using PCA into a new smaller set of derived orthogonal variables called principal components (PCs) where PCs are ordered in proportion of the variance they explain. Prior to PCA analysis, correlation matrices were employed and where correlations were greater than 0.60 one of the variables was removed; additionally, where appropriate all variables were normalized with either natural logarithm or square root transformations because PCA assumes variables are normally distributed.

Principal component analysis was performed with package vegan (Oksanen et al. 2016) where the PCA was performed with function pca, and scores were used to calculate factor loadings. Principal component analysis assumes multivariate normality and in order to approximate normality we transformed variables where necessary. Water quality, land use, and habitat variables were considered significant constituents of the PCA where factor loadings were $>|0.05|$. Principal components with eigenvalues $>2.0$ were considered significant and were interpreted and considered in further analyses. Principal component analysis constituents that were included in the analysis were stream wetted width, embeddedness, dissolved oxygen, conductivity, $\mathrm{pH}$, temperature, substrate categories (boulder, cobble, coarse gravel, fine gravel, sand, fines, and bed rock), depth, flow, coarseness, and land use categories (road density, \% developed land, \% forested land, and \% grassland) (Table 1).

We used nonmetric multidimensional scaling (NMDS) to summarize larval fish community structure among sites based on genus-level abundance data (Bray-Curtis distance metric). Nonmetric multidimensional scaling is an ordination technique that plots sites based on 
similarities in multidimensional space, where sites plotting closer together are more similar (McCune and Grace 2002). Abundance data were $\sqrt{ }(\mathrm{x})$-transformed and Wisconsin doublestandardized prior to analysis (Oksanen et al. 2016). To ensure a final convergent solution with the lowest possible stress, we used multiple random starts. Nonmetric dimensional scaling solutions were determined in 2 through 5 dimensions; however, only the three dimensional solution was used as stress was not reduced substantially in higher dimensions. We correlated individual community metrics with the ordination through vector fitting in order to determine the multivariate structure of the NMDS solution. Vector lengths are representative of correlation strength to the ordination and distance represents the direction of most rapid change within the multivariate space. We overlaid individual stream sites on the ordination to allow us to investigate community level changes that were associated with stream type and distance from dam. All analyses were performed using the $\mathrm{R}$ language and environment for statistical computing (R Development Core Team, Vienna, Austria).

Additionally we correlated habitat variables to the NMDS ordination to assess the relative influence of habitat variable on larval and juvenile fish community structure. Statistical strength $\left(r^{2}\right)$ of the linear vector of each variable was determined with 1000 permutations using the envfit function in package vegan (Oksanen et al. 2016); however, linear interpretation is not always appropriate so we used generalized additive models to fit variables with thin plate splines in 2 dimensions (Wood 2003, Oksanen et al. 2016). Model complexity was determined via crossvalidation to select the degree of smoothing and we used the coefficient of determination $\left(r^{2}\right)$ to assess the significance of 1000 permutations. This approach allowed us to evaluate whether a response variable responded in a linear or curvilinear fashion, depending on which method had the higher $r^{2}$ value (Oksanen et al. 2016). Such an approach enabled us to evaluate which habitat 
variables most strongly correlated with changes in the larval and juvenile fish community structure and to understand if the communities responded in a linear or curvilinear manner with changing habitat variables.

\section{Results}

Drainage area was unrelated to genera richness $\left(R^{2}=0.05 ; p>0.05\right)$ for the streams we surveyed. Community similarity was not significantly different between years (Adonis: $F=7.25$, $\mathrm{p}>0.05, \mathrm{df}=1)$. When the longitudinal gradient was considered there was a significant difference for distance from dam for both factors year and impoundment type/reference condition (epilimnetic, hypolimnetic, and reference streams) for abundance, richness, and diversity. Abundance and diversity differed between years (ANCOVA: $F=9.1, p<0.05, \mathrm{df}=1$ and $\mathrm{F}=5.9$, $\mathrm{p}<0.05, \mathrm{df}=1$ respectively) while richness did not (ANCOVA: $\mathrm{F}=0.01, \mathrm{p}>0.05, \mathrm{df}=1$ ).

Differences existed between dam release type and reference stream for abundance, richness, and diversity (ANCOVA: $\mathrm{F}=16.31, \mathrm{p}<0.05, \mathrm{df}=2 ; \mathrm{F}=116.9, \mathrm{p}<0.05, \mathrm{df}=2 ; \mathrm{F}=78.9, \mathrm{p}<0.05, \mathrm{df}=2$ respectively). Post hoc tests revealed differences for richness and diversity existed between all pairwise comparisons $(\mathrm{p}<0.05)$ but significant differences in abundance existed between our reference stream and each of the release types $(\mathrm{p}<0.05)$ but not between the release types $(p>0.05)$. This suggests that dams affect richness and diversity in a predictable manner regardless of type of release.

Twice each year (2012 and 2013) we sampled five, five-minute periods at each of the 16 sites on each respective stream. Henceforth, one five minute sampling period represents one unit of effort in our catch per unit effort (CPUE). Therefore each stream's 16 sample sites were sampled 20 times during the duration of the study for a total of 100-minutes per site. In total we 
sampled 2,240 periods for a combined 11,200-minutes and collected a total of 9,733 larvae and juveniles (fish < $30 \mathrm{~mm}$ total length) (mean CPUE 4.35) comprised of 14 different genera. From our reference stream we collected 2,667 larvae and juveniles (mean CPUE 8.33), which were comprised of 11 genera. Our samples from dammed streams resulted in the capture of 7,066 larvae and juveniles (mean CPUE 3.68) comprised of 14 genera. At dammed sites with epilimnetic releases we captured 4,200 larvae and juveniles (mean CPUE 4.38) and 13 genera; while those with hypolimnetic releases resulted in the capture of 2,866 larvae and juveniles (mean CPUE 2.99) and 10 genera. Our sampling of dammed streams resulted in the capture of three genera (Ambloplites, Micropterus, and Oncorhynchus) that were not captured in our reference stream. We captured five genera (Ambloplites, Campostoma, Etheostoma, and Hypentelium) in streams with epilimnetic releases which were not captured in streams with hypolimnetic releases; however, we captured Oncorhynchus sp. in Two Lick Creek, a stream with a hypolimnetic release which was a genus not captured in streams with epilimnetic releases (Table 1). Taxa were first captured at varying distances from dams in impounded streams and distance at first capture differed between epilimnetic and hypolimnetic releases for Cottus, Micropterus, Notropis, Percina, and Semotilus but distance first found was the same for Catostomus, Nocomis, Pimephales, and Rhinichthys (Table 2).

Within each sample site abundance in dammed streams ranged from zero to 304 individuals and had a higher maximum value in streams with epilimnetic releases than those with hypolimnetic releases (304 and 164 respectively). Richness in dammed streams ranged from zero to nine and also had a higher maximum value in streams with epilimnetic releases than those in hypolimnetic releases (nine and six respectively). Generally, abundance, richness, and diversity increased with distance from dam. 
Abundance showed a general increase with downstream distance from dams and reached its maximum value between 4,000 and 4,500-m; however, significant variables $(\mathrm{p}<0.05)$ differentially affected abundance along the stream continuum. The final GAM for abundance where all smoothing terms were significant $(\mathrm{p}<0.05)$ was

Abundance $\approx \mathrm{s}($ distance $)+\mathrm{s}($ dissolved oxygen $)+\mathrm{s}(\%$ development $)+\mathrm{s}(\%$ forested $)+$ factor(year)

Where abundance varied as a smooth function of distance, dissolved oxygen, percent development, percent forested area and year. The GAM for abundance explained 53\% of the deviance in the data and resulted in an adjusted $\mathrm{R}^{2}$ value of 0.47 (Table 3). Abundance decreased with increasing dissolved oxygen, was generally lower where $\%$ development was low (below 10\%), and showed a steady peak where \% forested area was approximately 80\% (Table 3; Figure 2).

Richness, as with abundance, displayed a general increasing trend with increasing distance from dams and important variables were also variable in their effect on richness along the stream continuum. There were also two spatial recovery gradients that were evident with richness. The final GAM for richness where all smoothing terms were significant $(\mathrm{p}<0.05)$ was

Richness $\approx \mathrm{s}($ distance $)+\mathrm{s}($ depth $)+\mathrm{s}($ temperature $)+\mathrm{s}(\%$ development $)+\mathrm{s}(\%$ forested $)$

Where richness varied as a smooth function of distance, depth, temperature, percent development, and percent forested area. The GAM explained $67 \%$ of the deviance in the data 
and had an $\mathrm{R}^{2}$ value of 0.62 (Table 3). The first spatial recovery gradient, where richness increased rapidly, occurred between the dam's tail waters and approximately 1,100-m downstream where the second, and more gradual, gradient began and richness continued to increase throughout the 5,100-m sampled stream reach. Richness was somewhat variable with depth and temperature but was highest in shallow waters and appeared to have multiple peaks with temperature. Increasing \% development negatively influenced richness; while richness peaked where sub-watersheds ranged from $50-65 \%$ forested area (Table 3, Figure 3).

Shannon diversity followed a similar pattern to that of richness as it increased with downstream distance along two distinct recovery gradients and, as with both richness and abundance, significant habitat variables were differential in their effect on diversity along the stream continuum. The final GAM for diversity where all smoothing terms were significant $(\mathrm{p}<0.05)$ was

Diversity $\approx \mathrm{s}($ distance $)+\mathrm{s}($ temperature $)+\mathrm{s}(\%$ development $)$

Where Shannon diversity varied as a smooth function of distance, temperature, and percent development. The GAM explained $60 \%$ of the deviance in the data and had an $\mathrm{R}^{2}$ value of 0.55 (Table 3). The first short but rapid spatial recovery gradient occurred from sites closest to the dam to approximately 1,100-m downstream where the second more gradual gradient began and continued throughout the 5,100-m sampled stream reach. Diversity was high at low temperatures at approximately $10^{\circ} \mathrm{C}$ before rapidly declining and then again increasing to a stable temperature region ranging between $17^{\circ} \mathrm{C}$ and $23^{\circ} \mathrm{C}$. Diversity was variable with $\%$ development but was particularly low at $4 \%$ and $~ 11 \%$ developed area (Table 3, Figure 4). 
Principal component analysis (PCA) indicated that habitat (instream habitat, landcover, and water quality) parameters within hyper- and hypolimnetic streams exhibited three distinct multidimensional trends along the stream continuum below their respective dams. Additionally, these three principal components were different from our reference stream. Principal components analysis reduced the variability in habitat variables to five important principal components with eigenvalues $>1.5$ (Table 4); however we only interpreted the first three (eigenvalues $>2.0$ ). Principal components 1, 2, and 3 combined to explain $52 \%$ of the variability in our habitat data set. Principal component 1 explained $25 \%$ of the variation in habitat and represented a landcover/land use gradient (\% landcover, conductivity, and substrate coarseness). Principal component 2 explained $15 \%$ of the habitat data and represented a water quality gradient. Principal component 3 explained $12 \%$ of the variation in the habitat data and represented a subset of the landcover categories with a negative association with \% grass land, while positive values were associated with sandy substrate and embeddedness (Table 4). Principal components 4 and 5 were not significant and therefore will not be discussed further. Differences existed in community structure between epilimnetic and hypolimnetic releases (Adonis: $\mathrm{F}=8.12, \mathrm{p}<0.05, \mathrm{df}=1$ ). We therefore performed NMDS analysis on the epilimnetic and the hypolimnetic data separately (Figure 5), where select variables are presented. For the purpose of displaying a comparison of each release type to the reference stream we performed NMDS analysis on both epilimnetic and hypolimnetic data with New Creek (Figure 5 a and $b)$. However, in order to understand community structure associations with habitat variables we performed NMDS analyses for both epilimnetic and hypolimnetic data sets separately but without inclusion of the data for the reference stream (Figure $5 \mathrm{c}-\mathrm{f}$ ). 
Nonmetric multidimensional scaling indicated streams with epilimnetic dam releases had strong distance and richness gradients which were most strongly structured by landcover variables. For dams with epilimnetic releases NMDS distinguished site types based on larval and juvenile fish community structure where there was a strong distance gradient (Figure 5c) where richness (Figure 5a) also increased along axis 1 and moving from right to left. As distance and richness increased these streams with warmwater releases became similar to our reference stream and displayed a large amount of overlap with reference sites (Figure 5A). Sites close to dams (right side of Figure 5a) were not strongly associated with any fish genera and were strongly characterized by higher values of the disturbed landcover (road density, \% development, and \% grassland; only road density (Rd_dens) is shown.) as well as higher conductivity. Sites towards the left side of axis 1 were associated with higher $\%$ forest and cobble substrates; and as mentioned previously these sites also had high richness and were more distant from dams (Figure 5c).

The fish communities in streams with epilimnetic releases were most strongly structured by a disturbance gradient followed by a water quality gradient. The majority of genera were negatively related to high levels of disturbance and positively associated with increased distance and richness gradient. Semotilus, Pimephales, and Notropis loaded heavily on the left side of axis 1 and were therefore most associated with decreased disturbance (i.e., road density, \% development, \% grassland, and conductivity). Other taxa that showed a similar but not as strong of a relationship with the left side of axis 1 were Rhinichthys, Nocomis, and Cottus (Figure 5e). Along axis 2 for the epilimnetic data temperature loaded in the negative direction, while $\mathrm{pH}$ and dissolved oxygen were positively associated with the NMDS solution (Figure 5c). Hypentelium, Ambloplites, Micropterus and Rhinichthys were associated strongly with increasing temperature 
along axis 2. Of these four taxa, Ambloplites, Hypentelium, and Micropterus were found in relatively high numbers in Yellow Creek, which had the highest average temperature $\left(26.8^{\circ} \mathrm{C}\right)$ of our sites.

The NMDS for streams with hypolimnetic releases performed poorly in its ability to aid in understanding changes along the stream continuum and fish communities in these streams were poorly structured by the habitat (in stream, landcover, and water quality) variables that we measured. Streams where water was released hypolimnetically also showed a strong relationship with distance and richness along NMDS axis 1 but unlike in the epilimnetic ordination the linear model for distance performed poorly compared to that of the surface fit model (Table 5). The surface fit model (graphically not displayed) indicated a distance gradient from right to left along NMDS axis 1 and another from bottom to top along axis 2. As with streams with epilimnetic releases, those with hypolimnetic releases became more similar to the reference stream as distance increased but unlike the epilimnetic condition sites in streams with hypolimnetic releases showed little overlap with the reference stream (Figure 5b). Habitat variables for the streams with hypolimnetic releases generally showed less variability than those with epilimnetic releases (Figure 5c vs 5d). Unlike streams with epilimnetic releases, landcover had little importance in structuring communities in streams with hypolimnetic releases (Figure 5d). Along NMDS axis 1 in stream habitat (sandy substrate and boulders along the left side of the plot and gravel fines along the right side) and temperature (along the right side of the axis) were most influential in structuring the coldwater communities. Nonmetric multidimensional scaling axis 2 was most strongly influenced by cobble (top of the axis 2) and gravel fines and dissolved oxygen (bottom of axis 2) (Figure 5d). Hypolimnetic sites near dams indicated no strong association of larval and juvenile fish. Larval and juvenile fish became more strongly associated with sites that 
were mid-reach and those most distant from the dam as is indicated with Semotilus along NMDS axis 1 and Percidae, Oncorhynchus, and Catostomus along NMDS axis 2 (Figure 5f).

Non-metric multidimensional scaling showed that the community structure of larval and juvenile fish responded differently among epilimnetic, hypolimnetic, and reference streams (Table 5). Distance was statistically correlated with the NMDS solution in epilimnetic, hypolimnetic, and reference streams. Although correlations were relatively weak $\left(r^{2}\right.$ values for linear relationships ranged from 0.29 to 0.34 ), landcover variables were some of the strongest indicators (higher $r^{2}$ and significant $\mathrm{p}$ value) for both epilimnetic and reference conditions but not for hypolimnetic streams, where only $\%$ grass covered area was significant $\left(r^{2}=0.06\right)$. Of the channel morphology habitat variables boulder, fines, gravel fines, and sand were significantly correlated with streams with hypolimnetic releases, but only boulder and sandy substrate were significantly correlated with epilimnetic streams and bedrock was the only substrate category significantly correlate with the reference condition. In both epilimnetic and hypolimnetic conditions conductivity, dissolved oxygen, and temperature were significantly correlated and in the reference condition significant correlations existed for conductivity and depth.

Surface fitting resulted in improved correlations with the NMDS solution and distance for impounded streams but not our reference stream. In streams with epilimnetic releases surface fits improved the $r^{2}$ for statistically significant variables over the linear models for $\%$ development, \% forest, \% grassland, road density, boulders substrate, sandy substrate, conductivity, $\mathrm{pH}$, and temperature. Cobble substrate was not significant in the linear model but it was in the surface fit although the correlation was low $\left(r^{2}=0.07\right)$. Only dissolved oxygen had a higher correlation coefficient in the linear model than the surface fit model; however the values were very similar $\left(r^{2}=0.17\right.$ and $r^{2}=0.16$ respectively). Streams with hypolimnetic releases 
responded somewhat differently in that the linear models outperformed the surface fit models for four out of five of the channel morphology variables (boulder substrate, fines, gravel fines, and sand), albeit improvements in $r^{2}$ were small. Surface fitting improved $r^{2}$ for $\%$ grassland, flow, conductivity, $\mathrm{pH}$, dissolved oxygen, and temperature and in some cases it did so substantially. For example, although the $r^{2}$ value was still low, the linear model for $\mathrm{pH}$ resulted in an $r^{2}=0.02$ $(\mathrm{p}=0.47)$ while the $r^{2}$ for the surface fit model was $0.14(\mathrm{p}<0.01)$. In our reference stream all statistically significant habitat variables were improved with surface fitting over linear models and two variables ( $\mathrm{pH}$ and dissolved oxygen) which were not significant with the linear models were with the surface fitting. Often, in our reference stream, the surface fitting improved $r^{2}$ substantially (e.g., the linear model for dissolved oxygen resulted in $r^{2}=0.00(\mathrm{p}=0.97)$ while $r^{2}=0.26(\mathrm{p}=0.03)$ for the model with a surface fit. $)$. Generally, landcover variables were important in impounded streams with epilimnetic releases and our reference stream where $r^{2}$ values were $>0.30$. All water quality variables were important in both epilimnetic and hypolimnetic releases and our reference stream (except temperature in the reference stream) but $r^{2}$ were relatively low in impounded streams (i.e., ranging from 0.13 to 0.27 ) but had higher correlation in the reference stream (i.e., ranging from 0.26 to 0.73). Additionally, the correlations for significant variables for the reference stream were higher (i.e., ranging from 0.26 to 0.73 ) than those for impounded streams with epilimnetic or hypolimnetic releases (i.e., ranging from 0.07 to 0.39 for epilimnetic and 0.07 to 0.34 for hypolimnetic releases).

\section{Discussion}

Various studies have been performed in the context of the Serial Discontinuity Concept (SDC) on how fish are affected downstream of dams (Moog 1992; Parasiewicz et al. 1998) and 
dam effects on downstream habitat (Harvey 1987; Thompson et al. 2011). We found no other studies that evaluated the effects of dams on larval and juvenile fish abundance, richness, diversity, and community structure that compared both epilimnetic and hypolimnetic releases to a reference stream. Additionally, in a systematic manner, we evaluated 16 sites per stream and at two spatial scales (near dam sites were spaced 100-m apart for 600-m and thereafter sites were spaced every 500-m to 5,100-m downstream of each respective dam). Removing the effect of the reference stream we investigated the longitudinal effect of dams on downstream water quality, instream habitat, and land use and how those habitat variables influenced abundance, richness, and diversity of larval and juvenile fish through generalized additive models (GAMs); afterwards we used principle components analysis (PCA) to visualize habitat associations and non-metric multidimensional scaling (NMDS) to visualize community structure and community/habitat associations. Our results generally agreed with the SDC (Ward and Stanford 1983).

Abundance, genus richness, and genus diversity all increased with distance from the dam (Figures 2a, 3a, 4a). Abundance of captured individuals increased steadily from sites nearest dams to approximately 4,100-m where it peaked prior to showing a slight decrease to our most downstream site, 5,100-m below each respective dam. Genus richness, defined as the number of different taxa captured at a given site (in both epilimnetic and hypolimnetic release types), and genus diversity of larval and juvenile fish displayed two distinct gradients. In the first 1,100-m there was a rapid increase in richness and diversity, subsequently followed by a more gradual but steadily increasing trend to our most downstream site, 5,100-m below each respective dam. These findings are congruent with the theoretical construct of the SDC (Ward and Stanford 1983). 
Along with distance, our final GAM for abundance indicated that dissolved oxygen, $\%$ developed area, and \% forested area were significant variables. Lower dissolved oxygen was associated with epilimnetic releases and abundance was highest in areas with lower dissolved oxygen. Abundance differences between our hypolimnetic and epilimnetic releases likely explains this, as our streams with hypolimnetic releases had lower average abundance than those with epilimnetic releases. This is congruent with other findings by Wolf et al. (1996) where they found reduced abundance of larval fish below the Garrison Dam, North Dakota which releases water hypolimnetically. Additionally, dissolved oxygen showed a negative relationship with increasing distance from dams and it is difficult to separate the influence of dams and dissolved oxygen under these circumstances. Abundance was highest where \% developed area ranged between $10-14 \%$ and \% forested area was approximately $80 \%$. Moderately disturbed areas (e.g., moderate levels of development) have been shown to have elevated abundance due to tolerant taxa performing well in these areas (Schade and Bonar, 2005).

In addition to distance, our final GAM for genus richness indicated depth, temperature, $\%$ developed area, and \% forested area were significantly influential. Intermediate depths displayed high variability for richness but shallower waters tended to have the highest richness and deeper waters the lowest. Larval and juvenile fish are likely restricted to common habitat (Schlosser 1987; Schlosser 1991) where the costs associated with predators and environmental variables are minimized (Werner and Gilliam 1984; Schlosser 1988) but the benefit of prey abundance is maximized (Wilbur 1980). Shallow water habitats, especially lateral stream margins, may be most suitable for larval and juvenile life stages (Power 1987; Moore and Gregory 1988; Schlosser 1991) as these areas present refugia from predation by larger fish and higher flows in mid-channel habitats (Schlosser 1987). Albeit anecdotal, evidence from our study suggests that 
larval and juvenile fish were most commonly seen and captured in shallow, slow moving stream margins.

Stream ecosystems are often considered to be structured by various scale dependent processes (Fausch et al. 2002) where the reach scale is most influenced by the surrounding landscape (Allan 2004). We found that subwatersheds with lower \% developed area had higher richness ( $\sim 6 \%$ developed area was highest), while richness was highest where subwatersheds were $30 \%$ and $60 \%$ forested area. This is not surprising as it has been shown that agricultural practices (i.e., \% grassland), developed lands, and roadways negatively impact stream biota (Roy et al. 2003; Perkin et al. 2016) and furthermore these multiple stressors may have additive effects (Merriam et al. 2011). Some disturbance of the surrounding landscape within a subwatershed may result in no biological response (Ward and Stanford 1983) or even a slight increase in biological response (e.g., richness or diversity) (Townsend et al. 1997). Intermediate disturbances may allow for the inclusion of tolerant taxa at the expense of intolerant taxa; thereby not displaying a negative response for overall richness and/or diversity. Other studies have found that streams that have dams with hypolimnetic releases negatively impact richness of adult fish (Lessard and Hayes 2003), aquatic macroinvertebrates (Maynard and Lane 2012), and larval fish (Wolf et al. 1996). In the streams that we sampled richness was generally lower where dams released water hypolimnetically. Surprisingly, richness was high for our lowest recorded temperatures, which were from East Branch of the Clarion. Richness in East Branch of the Clarion was higher than other streams with hypolimnetic releases and similar to those with epilimnetic releases. The late sampling period for East Branch of the Clarion may have corresponded with timing of larval hatching events in a hypolimnetic system, resulting in high 
richness. Otherwise, richness was consistently high where temperatures ranged from $18-24{ }^{\circ} \mathrm{C}$ and began to decrease at higher temperatures (Figure 3c).

Our final GAM for genus diversity suggested that other than temperature, only \% developed area significantly influenced diversity. Temperatures in the range of $18-24{ }^{\circ} \mathrm{C}$ consistently had higher diversity than temperatures ranging from $14-18{ }^{\circ} \mathrm{C}$ and temperatures ranging from $25-28{ }^{\circ} \mathrm{C}$. Hypolimnetic releases of cold water may act as a form of thermal pollution (Olden and Naiman 2010) negatively affecting the warmwater fish community that would normally reside in the impacted stream. Diversity, as was also the case for richness, was high for our lowest recorded temperatures, which were recorded in East Branch of the Clarion. Diversity in East Branch of the Clarion was higher than other streams with hypolimnetic releases and similar to those with epilimnetic releases. Wolf et al. (1996) found many of the genera they captured in the Missouri River below Garrison Dam, North Dakota had spawning periods that were extended or delayed in relation to what literature suggested. East Branch of the Clarion was sampled last during 2013 (June 3 and 18, 2013) and this late sampling period may have corresponded with timing of larval hatching events in a hypolimnetic system, resulting in high diversity. Diversity was somewhat variable with \% developed area but areas that had the highest \% development (>10\%) in our data consistently had low diversity, while those areas with intermediate to low \% developed area generally exhibited high genus diversity.

\section{Conclusion}

Regulated rivers have been studied extensively and the successful management of these systems demands a full understanding of their impact on both abiotic and biotic components of 
the ecosystems they influence. We found only two other studies that systematically investigated the response of physicochemical and biological components of dams, which both dealt with aquatic macroinvertebrates as their biological component (Ellis and Jones, 2014; Hanks, 2016). Ellis and Jones (2014) sampled between six and eight sites that were not spaced equidistant along each of their four sample streams and of which two were impounded hydropeaking systems and two were natural flowing. We sampled 16 sites on six impounded streams where sample sites were spaced equidistant along the stream continuum below each respective dam. Furthermore, our study, as with Hanks (2016), compared both epilimnetic and hypolimnetic dam releases to a reference condition and our study is the first to investigate dam impacts on larval and juvenile fish in such a systematic manner.

We found a clear pattern of two recovery gradients for larval and juvenile fish richness and diversity. Only the present study and Hanks (2016) used study designs that allowed them to investigate the rapidly changing gradient near dams. The second, more gradual recovery gradient that extended beyond our 5,100-m sampling reach has been studied extensively but not using larval and juvenile fish as the biological indicator. Temperature influenced both richness and diversity, where lower temperatures (i.e., streams with hypolimnetic releases) generally resulted in lower values for richness and diversity; however, as was what appeared to be the case with East Branch of the Clarion, fish in streams with hypolimnetic dam releases likely reproduce later in the season. Genus richness and diversity were also influenced by landcover where disturbance at low levels increased values for both richness and diversity. Abundance of individuals did not respond in the same fashion as richness and diversity and only displayed a single gradient that increased steadily from the dam and peaked prior to our most downstream sampling site, 5,100-m downstream of dams. Landcover was also important in our model for 
abundance where sites with intermediate disturbance typically had higher abundance.

Abundance also responded to release type, as areas with higher values for dissolved oxygen had higher abundance than those with lower dissolved oxygen and there is a clear link between temperature and dissolved oxygen. Changes that occur below dams may occur rapidly (our near dam gradient), while others may take much greater distance to recover (e.g., thermal recovery). Ellis and Jones (2015) suggested, and we agree, that future studies investigating the SDC should be designed to systematically evaluate variables of interest at various spatial and temporal scales.

Our results suggest that differences exist in community structure between streams with epilimnetic and hypolimnetic releases, as well as in the importance of factors that control community structure. In the streams that we evaluated, the communities with an epilimnetic release were structured largely by landcover where higher percent forested area was shown to be associated with sites most similar to a reference stream, while sites with higher values for disturbance (i.e., percent development, road density, percent grassland, and conductivity) were associated with sites closest to dams and with lower genus richness. To a lesser extent the communities in these streams were influenced by water quality (i.e., $\mathrm{pH}$, dissolved oxygen, and temperature). In contrast, landcover showed almost no influence in structuring communities in streams with hypolimnetic releases. Communities of streams with hypolimnetic releases were mostly structured by in stream habitat (i.e., sand, boulders, and gravel fines) and water quality (temperature, conductivity, and dissolved oxygen) variables. Furthermore, habitat variables in streams with epilimnetic releases had more variability than those in streams with hypolimnetic releases. Additionally, it may be that streams with hypolimnetic releases show more stream to stream variability in regards to habitat variables that control larval and juvenile fish community structure than those with epilimnetic releases. Distance and richness were strong indicators of 
communities shifting towards a reference condition and while richness was highly linear in both situations, distance was only linear in the streams with epilimnetic releases. Whereas our models with smooth surface splines for distance greatly improved fit in the hypolimnetic condition over the linear model (Table 5).

There is a dearth of studies that investigate responses of larval and juvenile fish in the context of the SDC. The importance of successful reproduction for continued success of fisheries in riverine systems is obvious and we suggest that more effort should be made to understand how reproduction is impacted in impounded systems. Such studies should include the two spatial gradients discussed here and in Ellis and Jones (2014), as well as include temporally longitudinal aspects. Further understanding of land use practices and tributary influences, as well as the inclusion of various scales (spatiotemporal and biotic) should be included in studies and will aid in further understanding of the SDC and how to best manage impounded systems. 


\section{References}

Allan, J. D. 2004. Landscapes and riverscapes: the influence of land use on stream ecosystems. Annual Review of Ecological and Evolutionary Systems 35:257-284.

Allan, J. D. and L. B. Johnson. 1997. Catchment-scale analysis of aquatic ecosystems. Freshwater Biology 37:107-111.

Auer, N. A. 1982. Identification of larval fishes of the Great Lakes basin, with emphasis on the Lake Michigan drainage. University of Michigan, Special Publication 82-3, Ann Arbor.

Cortes, R., M. Ferreira, S. Oliveira, and D. Oliveira. 2002. Macroinvertebrate community structure in a regulated river segment with different flow conditions. River Research and Applications 18(4):367-382.

Ellis, L. E. and N. E. Jones. 2013. Longitudinal trends in regulated rivers: a review and synthesis within the context of the serial discontinuity concept. Environmental Reviews 21(3):136148.

Falke, J. A., Fausch, K. D., Bestgen, K. R., and Baily L. L. 2010. Spawning phenology and habitat use in a Great Plains, USA, stream fish assemblage: an occupancy estimation approach. Canadian Journal of Fisheries and Aquatic Sciences 67:1942-1956.

Fausch, K. D., C. E. Torgersen, C. V. Baxter, and H. W. Li. 2002. Landscapes to riverscapes: bridging the gap between research and conservation of stream fishes. BioScience 52:483-498.

Freedman, J. A., B. D. Lorson, R. B. Taylor, R. F. Carline, and J. R. Stauffer Jr. 2013. River of the dammed: longitudinal changes in fish assemblages in response to dams. Hydrobiologia 727(1):19-33.

Graf, W. L. 1999. Dam nation: A geographic census of American dams and their large-scale hydrologic impacts. Water Resources Research 35(4):1305-1311.

Greenwood, J. J. D. and R. A. Robinson. 2009. Principles of Sampling. Pages 11-86 in W. J. Sutherland, editor. Ecological Census Techniques, $2^{\text {nd }}$ edition. Cambridge University Press, New York.

Hanks, R. D. 2016. The Influence of Dams on Downstream Larval and Juvenile Fish and Benthic Macroinvertebrate Community Structure and Associated Physicochemical Variables. Doctoral Dissertation. West Virginia University, Morgantown.

Harvey, B. C. 1987. Susceptibility of young-of-the-year fishes to downstream displacement by flooding. Transactions of the American Fisheries Society 116:851-855. 
Holland-Bartels, L. E., S. K. Littlejohn, and M. L. Huston. 1990. Guide to larval fishes of the upper Mississippi River. U.S. Fish and Wildlife Service Publication, LaCrosse, Wisconsin.

Jones, N. E. 2010. Erratum: Incorporating lakes within the river discontinuum: longitudinal changes in ecological characteristics in stream-lake networks. Canadian Journal of Fisheries and Aquatic Sciences 67(12):2058-2058.

Johnson, L B., C. Richards, G. E. Host, and J W. Arthur. 1997. Landscape influences on water chemistry in Midwestern stream ecosystems. Freshwater Biology 37:193-208.

Katano, I., J. Negishi, T. Minagawa, H. Doi, Y. Kawaguchi, and Y. Kayaba. 2009. Longitudinal macroinvertebrate organization over contrasting discontinuities: effects of a dam and a tributary. Journal of the North American Benthological Society 28(2):331-351.

Kelso W. E., M. D. Kaller, and A. Rutherford. 2013. Collection, processing, and identification of fish eggs and larvae and zooplankton. Pages 363-413 in A. V. Zale, D. L. Parrish, and T. M. Sutton, editors. Fisheries techniques, $3^{\text {rd }}$ edition. The American Fisheries Society, Bethesda, Maryland.

Lessard, J. L. and D. B. Hayes. 2003. Effects of water temperature on fish and macroinvertebrate communities below small dams. River Research and Applications 19:721-732.

MacArthur, R. H. and E. O. Wilson. 1967. The theory of island biogeography. Princeton University Press, Princeton, New Jersey.

Maynard, C M. and S. N. Lane. 2012. Reservoir compensation releases: impact on the macroinvertebrate community of Derwent River, Northumberland, United Kingdom-a longitudinal study. River Research and Applications 28:692-702.

McCune B. and J. B. Grace. 2002. Analysis of ecological communities. MjM Software Design, Gleneden Beach, Oregon.

Merriam, E. R., J. T. Petty, G. T. Merovich Jr, J. B. Fulton, and M. P. Strager. 2011. Additive effects of mining and residential development on stream conditions in a central Appalachian watershed. Journal of the North American Benthological Society 30(2):399418.

Moog, O. 1993. Quantification of daily peak hydropower effects on aquatic fauna and management to minimize environmental impacts. Regulated Rivers: Research and Management 8:5-14.

Moore, K. M. S. and S. V. Gregory. 1988. Summer habitat utilization and ecology of cutthroat trout fry (Salmo clarki) in Cascade Mountain streams. Canadian Journal of Aquatic Sciences 45:1921-1930. 
Niles, J. M. 2004. Examination of experimentally engineered larval fish habitat in the Marmet Pool, Kanawha River, West Virginia. Master's thesis. West Virginia University, Morgantown, West Virginia.

Oksanen, J., F. G. Blanchet, R. Kindt, P. Legendre, P. R. Minchin, R. B. O’Hara, G. L. Simpson, P. Solymos, M. H. H. Stevens, and H. Wagner. 2016. Vegan: Community Ecology Package. R package version 2.3-3.

Olden, J. D. and R. J. Naiman. 2010. Incorporating thermal regimes into environmental flows assessments: modifying dam operations to restore freshwater ecosystem integrity. Freshwater Biology 55:86-107.

Parasiewicz, S., S. Schmutz, and O. Moog. 1998. The effect of managed hydropower peaking on the physical habitat, benthos and fish fauna in the River Bregenzerach in Austria. Fisheries Management and Ecology 5(5):403-417.

Perkin J. S., M. J. Troia, D. Shaw, J. E. Gerken, and K. B. Gido. 2016. Multiple watershed alterations influence fish community structure in Great Plains prairie streams. Ecology of Freshwater Fish 25(1):141-155.

Poff, N. L., and D. D. Hart. 2002. How Dams Vary and Why It Matters for the Emerging Science of Dam Removal. BioScience 52(8):659-668.

Power, M. E. 1987. Predator avoidance by grazing fishes in temperate and tropical streams: importance of stream depth and prey size. Pages 333-351 in W. C. Kerfoot and A. Sih, eds. Predation: Direct and Indirect Impacts on Aquatic Communities. University of New England Press, Hanover, NH.

R Core Team (2015). R: A language and environment for statistical computing. R Foundation for Statistical Computing, Vienna, Austria. ISBN 3-900051-07-0, URL http://www.Rproject.org/

Rice, S. P., M. T. Greenwood, and C. B. Joyce. 2001. Tributaries, sediment sources, and the longitudinal organisation of macroinvertebrate fauna along river systems. Canadian Journal of Fisheries and Aquatic Sciences 58(4):824-840.

Roy, A. H., A. D. Rosemond, M. J. Paul, D. S. Leigh, and J. B. Wallace. 2003. Stream macroinvertebrate response to catchment urbanisation (Georgia, U.S.A.). Freshwater Biology 48(2):329-346.

Schade, C. B. and S. A. Bonar. 2005. Distribution and abundance of nonnative fishes in streams of the western United States. North American Journal of Fisheries Management 25:1386-1394. 
Schlosser, I. J. 1987. The role of predation in age and size related habitat use by stream fishes. Ecology 68:651-659.

Schlosser, I. J. 1988. Predation risk and habitat use by two size classes of stream cyprinid: experimental test of a hypothesis. Oikos 52:36-40.

Schlosser, I. J. 1991. Stream fish ecology: a landscape perspective. BioScience 41(10):704-712.

Schnieder D.C. 2001. The rise of the concept of scale in ecology. Bioscience. 51(7):545-553.

Storey, A. W., D. H. Edward, and P. Gazey. 1991. Recovery of aquatic macroinvertebrate assemblages downstream of the Canning Dam, Western Australia. Regulated Rivers: Research and Management 6:213-224.

Sutherland W. J. ed. 2006. Ecological Census Techniques. $2^{\text {nd }}$ ed. Cambridge University Press. New York.

Thompson, L.C., S. A. Cocherell, S. N. Chun, J. J. Cech, and A. P. Klimley. 2011. Longitudinal movement of fish in response to a single-day flow pulse. Environmental Biology of Fish 90: 253-261.

Townsend, C. R. and M. R. Scarsbrook. 1997. The intermediate disturbance hypothesis, refugia, and biodiversity in streams. Limnology and Oceanography 42(5):938-949.

Vannote, R.L., G.W. Minshall, K.W. Cummins, J.R. Sedell, and C.E. Cushing. 1980. The river continuum concept. Canadian Journal of Fisheries and Aquaculture Science 37:130-137.

Wallus, R., L. K. Kay, T. P. Simon, and B. L. Yeager. 2008. Reproductive biology and early life history of fishes in the Ohio River drainage: Series. CRC Press, 2008.

Ward, J.V. and J.A. Stanford. 1983. The serial discontinuity concept of lotic eco- systems. In Dynamics of Lotic Ecosystems, Fontaine TD, Bartell SM (eds). Ann Arbor Scientific Publishers: Ann Arbor, MI; 29-42.

Ward, J. V., K. Tockner, U. Uehlinger, and F. Malard. 2001. Understanding natural patterns and processes in river corridors as the basis for effective river restoration. Regulated Rivers: Research \& Management 17(4 5):311-323.

Weins J.A. 1989. Spatial scaling in ecology. Functional Ecology. 3:385-397.

Werner, E. E. and J. F. Gilliam. 1984. The ontogenetic niche and species interactions in size structured populations. Annual Review of Ecological Systems 15:395-425.

Wilbur, H. M. 1980. Complex life cycles. Annual Review of Ecological Systems 11:67-93. 
Wolf, A. E., D. W. Willis, and G. J. Power. 1996. Larval fish community in the Missouri River below Garrison Dam, North Dakota. Journal of Freshwater Ecology 11(1):11-19.

Wood, S. 2006. Generalized additive models: an introduction with R. Chapman and Hall, Boca Raton, Florida.

Yeager, B. L. 1993. Dams. Pages 57 - 113. In C. F. Bryan and D. A. Rutherford, editors. Impacts on warmwater streams: Guidelines for evaluation, Second Edition. Southern Division, American Fisheries Society, Little Rock, Arkansas.

Zuur, A. F., E. N. Leno, N. J. Walker, A. A. Saveliev, and G. M. Smith. 2009. Mixed effects models and extensions in ecology with R. $1^{\text {st }}$ edition. Springer, New York. 
Table 1. Abundance, richness, and catch per unit effort as well as total captures of each genera are displayed for each of reference stream, epilimnetic, and hypolimnetic dam releases. Total abundance and average CPUE and richness are displayed in the first row of each sub-category. Rows represent total abundance and total genus captures and average CPUE and richness for each distance within a respective sub-category. Abun=abundance; $\mathrm{CPUE}=$ catch per unit effort; $\mathrm{Rich}=$ richness, $\mathrm{AMBL}=$ Ambloplites; $\mathrm{CAT}=$ Catostomus;

$\mathrm{CAMP}=$ Campostoma $; \mathrm{COT}=$ Cottus $; \mathrm{ETH}=$ Etheostoma $; \mathrm{HYP}=$ Hypentelium $; \mathrm{MICR}=$ Micropterus $;$ NOC=Nocomis; NOTR=Notropis; $\mathrm{ONC}=$ Oncorhynchus $; \mathrm{PERC}=$ Percina $; \mathrm{PIM}=$ Pimephales $; \mathrm{RHY}=$ Rhinichthys $; \mathrm{SEM}=$ Semotilus .

\begin{tabular}{|c|c|c|c|c|c|c|c|c|c|c|c|c|c|c|c|c|c|c|}
\hline & Distance & Abun & CPUE & Rich & AMBL & CAT & CAMP & COT & ETH & HYP & MICR & NOC & NOTR & ONC & PERC & PIM & RHY & SEM \\
\hline \multicolumn{19}{|l|}{ Reference } \\
\hline & 0 & 95 & 4.8 & 7 & -- & 3 & -- & 1 & -- & -- & -- & 19 & 17 & -- & -- & 13 & 15 & 27 \\
\hline & 100 & 99 & 5.0 & 9 & -- & 2 & 1 & 2 & 3 & -- & -- & 16 & 14 & -- & -- & 4 & 28 & 29 \\
\hline & 200 & 147 & 7.4 & 10 & -- & 7 & 1 & 2 & -- & 2 & -- & 23 & 19 & -- & 1 & 15 & 38 & 39 \\
\hline & 300 & 166 & 8.3 & 10 & -- & 6 & 8 & 4 & 1 & -- & -- & 50 & 22 & -- & 1 & 10 & 27 & 37 \\
\hline & 400 & 101 & 5.1 & 10 & -- & -- & 3 & 5 & 3 & 1 & -- & 28 & 9 & -- & 3 & 10 & 17 & 22 \\
\hline & 500 & 78 & 3.9 & 9 & -- & 9 & -- & 3 & 4 & -- & -- & 19 & 7 & -- & 1 & 7 & 16 & 12 \\
\hline & 600 & 244 & 12.2 & 10 & -- & 31 & 1 & 7 & 4 & 1 & -- & 54 & 36 & -- & -- & 1 & 54 & 55 \\
\hline & 1100 & 152 & 7.6 & 8 & -- & 18 & -- & 6 & 3 & -- & -- & 24 & 7 & -- & -- & 7 & 40 & 47 \\
\hline & 1600 & 146 & 7.3 & 9 & -- & 16 & 2 & 6 & 1 & -- & -- & 21 & 30 & -- & -- & 14 & 22 & 34 \\
\hline & 2100 & 350 & 17.5 & 9 & -- & 12 & 2 & 8 & 1 & -- & -- & 31 & 37 & -- & -- & 5 & 134 & 120 \\
\hline & 2600 & 300 & 15.0 & 9 & -- & 20 & -- & 9 & 2 & -- & -- & 32 & 87 & -- & 2 & 29 & 33 & 86 \\
\hline & 3100 & 174 & 8.7 & 10 & -- & 4 & 1 & 3 & 2 & -- & -- & 15 & 45 & -- & 2 & 45 & 30 & 27 \\
\hline & 3600 & 138 & 6.9 & 9 & -- & 4 & 6 & 10 & -- & -- & -- & 6 & 41 & -- & 3 & 16 & 35 & 17 \\
\hline & 4100 & 171 & 8.6 & 9 & -- & -- & 1 & 15 & 8 & -- & -- & 34 & 55 & -- & 5 & 1 & 25 & 27 \\
\hline & 4600 & 133 & 6.7 & 10 & -- & 1 & 4 & 3 & 4 & -- & -- & 13 & 26 & -- & 2 & 13 & 42 & 25 \\
\hline & 5100 & 173 & 8.7 & 10 & -- & -- & 1 & 8 & 3 & 2 & -- & 22 & 25 & -- & 2 & 8 & 49 & 53 \\
\hline & Total & 2667 & 8.3 & 11 & 0 & 133 & 31 & 92 & 39 & 6 & 0 & 407 & 477 & 0 & 22 & 198 & 605 & 657 \\
\hline \multicolumn{19}{|l|}{ Epilimnetic } \\
\hline & 0 & 41 & 0.7 & 5 & -- & -- & 1 & -- & -- & -- & -- & 7 & 8 & -- & -- & 14 & -- & 11 \\
\hline & 100 & 34 & 0.6 & 6 & -- & 3 & -- & -- & -- & 3 & -- & 5 & 3 & -- & -- & 11 & -- & 9 \\
\hline & 200 & 29 & 0.5 & 6 & -- & 1 & -- & -- & -- & -- & 1 & -- & 12 & -- & -- & 6 & 1 & 8 \\
\hline & 300 & 41 & 0.7 & 6 & -- & -- & -- & -- & -- & 1 & -- & -- & 12 & -- & 2 & 4 & 20 & 2 \\
\hline
\end{tabular}




$\begin{array}{rccccccccccccccccc}400 & 164 & 2.7 & 8 & 62 & 16 & -- & -- & -- & -- & 3 & 5 & 17 & -- & -- & 43 & 6 & 12 \\ 500 & 147 & 2.5 & 7 & -- & 41 & 2 & -- & -- & -- & 53 & 3 & 14 & -- & -- & 18 & -- & 16 \\ 600 & 129 & 2.2 & 11 & 26 & 29 & 1 & 1 & -- & 4 & 10 & 8 & 13 & - & -- & 7 & 3 & 27 \\ 1100 & 167 & 2.8 & 10 & 50 & 3 & 4 & -- & -- & 2 & 18 & 13 & 36 & - & -- & 18 & 7 & 16 \\ 1600 & 99 & 1.7 & 7 & 12 & 49 & -- & -- & -- & 2 & 3 & -- & 19 & -- & -- & 8 & -- & 6 \\ 2100 & 393 & 6.6 & 11 & -- & 156 & -- & 1 & 1 & 3 & 6 & 54 & 91 & - & 1 & 29 & 8 & 43 \\ 2600 & 196 & 3.3 & 11 & -- & 78 & -- & 1 & 1 & 2 & 11 & 27 & 25 & - & 6 & 11 & 7 & 27 \\ 3100 & 455 & 7.6 & 8 & -- & 123 & -- & 1 & -- & 2 & -- & 51 & 169 & -- & -- & 22 & 21 & 66 \\ 3600 & 688 & 11.5 & 9 & -- & 74 & 1 & 2 & -- & 3 & -- & 77 & 383 & -- & -- & 65 & 14 & 69 \\ 4100 & 638 & 10.6 & 10 & -- & 189 & 2 & 2 & 1 & -- & -- & 53 & 230 & -- & 10 & 66 & 28 & 57 \\ 4600 & 583 & 9.7 & 9 & -- & 51 & 2 & -- & 3 & -- & 2 & 75 & 281 & -- & -- & 90 & 13 & 66 \\ 5100 & 396 & 6.6 & 10 & -- & 72 & 2 & -- & 1 & 6 & 28 & 39 & 146 & -- & -- & 33 & 23 & 46 \\ \text { Total } & 4200 & 4.4 & 13 & 150 & 885 & 15 & 8 & 7 & 28 & 135 & 417 & 1459 & 0 & 19 & 445 & 151 & 481\end{array}$

Hypolimnetic

\begin{tabular}{|c|c|c|c|c|c|c|c|c|c|c|c|c|c|c|c|c|c|}
\hline 0 & 28 & 0.5 & 3 & -- & 1 & -- & -- & -- & -- & -- & 23 & -- & -- & -- & 4 & -- & -- \\
\hline 100 & 29 & 0.5 & 3 & -- & 17 & -- & -- & -- & -- & -- & 6 & -- & -- & -- & 6 & -- & -- \\
\hline 200 & 75 & 1.3 & 6 & -- & 51 & -- & -- & -- & -- & -- & 1 & -- & 3 & -- & 15 & 2 & 3 \\
\hline 300 & 200 & 3.3 & 6 & -- & 156 & -- & -- & -- & -- & -- & 12 & 11 & 8 & -- & 10 & -- & 3 \\
\hline 400 & 120 & 2.0 & 8 & -- & 71 & -- & -- & -- & -- & 1 & 1 & 5 & 6 & -- & 26 & 2 & 8 \\
\hline 500 & 254 & 4.2 & 6 & -- & 163 & -- & -- & -- & -- & -- & 18 & 22 & 5 & -- & 37 & -- & 9 \\
\hline 600 & 233 & 3.9 & 7 & -- & 159 & -- & -- & -- & -- & 1 & 4 & 6 & -- & -- & 59 & 1 & 3 \\
\hline 1100 & 201 & 3.4 & 7 & -- & 138 & -- & 1 & -- & -- & -- & 6 & 15 & 3 & -- & 29 & -- & 9 \\
\hline 1600 & 400 & 6.7 & 6 & -- & 261 & -- & -- & -- & -- & -- & 60 & 24 & -- & -- & 41 & 1 & 13 \\
\hline 2100 & 168 & 2.8 & 3 & -- & 125 & -- & -- & -- & -- & -- & 3 & -- & -- & -- & 40 & -- & -- \\
\hline 2600 & 104 & 1.7 & 6 & -- & 97 & -- & -- & -- & -- & -- & 2 & 1 & -- & -- & 1 & 1 & 2 \\
\hline 3100 & 178 & 3.0 & 7 & -- & 98 & -- & -- & -- & -- & -- & 26 & 19 & 2 & -- & 28 & 1 & 4 \\
\hline 3600 & 213 & 3.6 & 6 & -- & 186 & -- & -- & -- & -- & -- & 9 & 5 & 2 & 1 & 10 & -- & -- \\
\hline 4100 & 240 & 4.0 & 7 & -- & 175 & -- & -- & -- & -- & -- & 19 & 12 & 5 & 1 & 18 & -- & 10 \\
\hline 4600 & 247 & 4.1 & 6 & -- & 151 & -- & -- & -- & -- & -- & 19 & 19 & -- & -- & 40 & 4 & 14 \\
\hline 5100 & 176 & 2.9 & 6 & -- & 92 & -- & -- & -- & -- & -- & 14 & 20 & -- & -- & 16 & 1 & 33 \\
\hline Total & 2866 & 3.0 & 10 & 0 & 1941 & 0 & 1 & 0 & 0 & 2 & 223 & 159 & 34 & 2 & 380 & 13 & 111 \\
\hline
\end{tabular}


Table 2. Distance $(\mathrm{m})$ where each genera was first captured in reference stream and epilimnetic and hypolimnetic dam releases. $\mathrm{AMBL}=$ Ambloplites $; \mathrm{CAT}=$ Catostomus $; \mathrm{CAMP}=$ Campostoma $; \mathrm{COT}=$ Cottus $; \mathrm{ETH}=$ Etheostoma $; \mathrm{HYP}=$ Hypentelium; $\mathrm{MICR}=$ Micropterus $; \mathrm{NOC}=$ Nocomis $;$ NOTR=Notropis $; \mathrm{ONC}=$ Oncorhynchus $; \mathrm{PERC}=$ Percina $; \mathrm{PIM}=$ Pimephales $; \mathrm{RHY}=$ Rhinichthys; SEM=Semotilus

\begin{tabular}{lcccccccccccccc}
\hline & AMBL & CAT & CAMP & COT & ETH & HYP & MICR & NOC & NOTR & ONC & PERC & PIM & RHY & SEM \\
\hline Reference & NA & 0 & 100 & 0 & 100 & 200 & NA & 0 & 0 & NA & 200 & 0 & 0 & 0 \\
Epilimnetic & 400 & 0 & 0 & 600 & 2100 & 100 & 200 & 0 & 0 & NA & 300 & 0 & 200 & 0 \\
Hypolimnetic & NA & 0 & NA & 1100 & NA & NA & 400 & 0 & 300 & 200 & 3600 & 0 & 200 & 200 \\
\hline
\end{tabular}


Table 3. Generalized additive model summary statistics for the best model to explain abundance, richness, and diversity using habitat variables listed in table $2 . \mathrm{R}^{2}$ and deviance explained are for the model as a whole. Dist=Distance from dam, $\%$ For $=\%$ forested area within a subwatershed, $\% \mathrm{Dev}=\%$ developed area within a subwatershed, Temp=Temperature, $\mathrm{f}($ Year $)=y e a r$ as a factor.

\begin{tabular}{|c|c|c|c|c|c|c|c|c|c|c|c|}
\hline Overall Model & & & Coarse & Depth & Dist & DO & Flow & $\%$ For & \% Dev & Temp & f(Year) \\
\hline \multicolumn{12}{|l|}{ Abundance } \\
\hline $\mathrm{R}^{2}$ & 0.47 & $\mathrm{P}$ & -- & -- & $<0.01$ & $<0.01$ & -- & $<0.01$ & $<0.01$ & -- & $<0.01$ \\
\hline Deviance Explained & $53 \%$ & & & & & & & & & & \\
\hline \multicolumn{12}{|l|}{ Richness } \\
\hline $\mathrm{R}^{2}$ & 0.62 & $\mathrm{P}$ & -- & $<0.01$ & $<0.01$ & -- & -- & $<0.01$ & $<0.01$ & $<0.01$ & -- \\
\hline Deviance Explained & $67 \%$ & & & & & & & & & & \\
\hline \multicolumn{12}{|l|}{ Diversity } \\
\hline $\mathrm{R}^{2}$ & 0.55 & $\mathrm{P}$ & -- & -- & $<0.01$ & -- & -- & -- & $<0.01$ & $<0.01$ & -- \\
\hline Deviance Explained & $60 \%$ & & & & & & & & & & \\
\hline
\end{tabular}


Table 4. Results of principal component analysis on in stream habitat and landcover data. Eigenvalues, \% variance explained, cumulative \% variance explained, and factor loadings of the variables for the first 5 principal components (PC) are given. - indicates loadings $<|0.4|$.

\begin{tabular}{lccccc}
\hline & PC 1 & PC 2 & PC 3 & PC 4 & PC 5 \\
\hline Eigenvalue & 5.0 & 3.0 & 2.3 & 1.9 & 1.5 \\
\% variance explained & 25.2 & 15.0 & 11.5 & 9.3 & 7.6 \\
Cumulative variance explained & 25.2 & 40.2 & 51.7 & 61.0 & 68.6 \\
Habitat Variables & & & & & \\
\% development & 0.75 & -- & -- & -- & -- \\
\% forested area & 0.63 & -- & -0.47 & -- & -- \\
\% grass & 0.76 & -- & -0.52 & -- & -- \\
Bedrock & -- & -- & -- & -- & -- \\
Boulder & -0.51 & -- & -0.46 & -0.40 & -- \\
Coarse gravel & -- & -- & -- & 0.67 & -- \\
Coarseness & -0.79 & -- & -0.34 & -- & -- \\
Cobble & -0.56 & -- & -- & -- & -- \\
Conductivity & 0.54 & 0.60 & -- & -- & 0.42 \\
Depth & 0.42 & -0.44 & -- & -- & -- \\
Dissolved oxygen & -- & -0.59 & -- & 0.42 & 0.49 \\
Embeddedness & 0.56 & -- & 0.64 & -- & -- \\
Fine gravel & -- & -- & -- & 0.67 & -- \\
Fines & 0.82 & -- & -- & -- & -- \\
Flow & -- & -- & -0.48 & -- & -- \\
pH & -- & 0.80 & -- & -- & -- \\
Road density & 0.59 & 0.44 & -- & -- & -- \\
Sand & -- & -- & 0.58 & -- & -- \\
Temperature & -- & 0.63 & -- & -- & -0.61 \\
Wetted width & -0.52 & -- & -- & -- & -- \\
\hline
\end{tabular}


Table 5. Relationships of distance and habitat (landcover type, channel morphology, and water quality) to nonmetric multidimensional scaling (NMDS) ordination of larval and juvenile fish genera in 3 dimensions by vector fitting (linear model) and surface fitting (nonlinear generalized additive model). Corresponding $\mathrm{r}^{2}$ and $\mathrm{p}$-values are given. $\mathrm{p}$-values are estimated from 1000 randomizations of the data. $\mathrm{BL}=$ boulder; $\mathrm{BR}=$ bedrock; $\mathrm{CB}=$ cobble; $\mathrm{FN}=$ fines; $\mathrm{GC}=$ coarse gravel; $\mathrm{GF}=$ fine gravel; $\mathrm{SA}=\mathrm{Sand}$; Cond=conductivity; $\mathrm{DO}=$ dissolved oxygen; Temp=temperature.

\begin{tabular}{|c|c|c|c|c|c|c|}
\hline Variable & value) & Surface $r^{2}$ ( $p$-value & Vector $r^{2}$ ( $p$-value) & Surface $r^{2}(p$-value & Vector $r^{2}$ ( $p$-value) & Surface $r^{2}(p$-value \\
\hline \multicolumn{7}{|l|}{ Landcover } \\
\hline$\%$ Development & $0.34(<0.001)^{*}$ & $0.39(<0.001)^{*}$ & $0.03(0.31)$ & $0.01(0.29)$ & $0.31(<0.01)^{*}$ & $0.33(<0.001)^{*}$ \\
\hline$\%$ Forest & $0.29(<0.001)^{*}$ & $0.35(<0.001)^{*}$ & $0.01(0.72)$ & $0.03(0.13)$ & $0.32(<0.01)^{*}$ & $0.34(<0.01)^{*}$ \\
\hline$\%$ Grassland & $0.29(<0.001)^{*}$ & $0.35(<0.001)^{*}$ & $0.06(0.04)^{*}$ & $0.11(<0.01)^{*}$ & $0.33(<0.01)^{*}$ & $0.35(<0.01)^{*}$ \\
\hline Road density & $0.29(<0.001)^{*}$ & $0.36(<0.001)^{*}$ & $0.01(0.84)$ & $0.01(0.26)$ & $0.28(<0.01)^{*}$ & $0.30(<0.01)^{*}$ \\
\hline \multicolumn{7}{|l|}{ Channel morphology } \\
\hline $\mathrm{BL}$ & $0.07(0.04)^{*}$ & $0.08(0.02)^{*}$ & $0.09(<0.02)^{*}$ & $0.08(0.02)^{*}$ & $0.01(0.83)$ & $0.06(0.25)$ \\
\hline $\mathrm{BR}$ & $0.02(0.39)$ & $0.00(0.33)$ & $0.03(0.26)$ & $0.01(0.29)$ & $0.19(0.03)^{*}$ & $0.36(<0.01)^{*}$ \\
\hline $\mathrm{CB}$ & $0.06(0.06)$ & $0.07(0.02)^{*}$ & $0.04(0.17)$ & $0.02(0.18)$ & $0.07(0.35)$ & $0.01(0.33)$ \\
\hline FN & $0.03(0.3)$ & $0.02(0.23)$ & $0.08(0.03)^{*}$ & $0.05(0.03)^{*}$ & $0.01(0.92)$ & $0.00(0.99$ \\
\hline GC & $0.00(0.91)$ & $0.00(0.90)$ & $0.03(0.24)$ & $0.01(0.24)$ & $0.11(0.21)$ & $0.15(0.12)$ \\
\hline GF & $0.02(0.43)$ & $0.06(0.06)$ & $0.34(<0.001)^{*}$ & $0.33(<0.001)^{*}$ & $0.09(0.30)$ & $0.06(0.26)$ \\
\hline SA & $0.14(<0.01)^{*}$ & $0.17(<0.001)^{*}$ & $0.07(0.04)^{*}$ & $0.05(0.04)^{*}$ & $0.05(0.44)$ & $0.17(0.10)$ \\
\hline Coarse & $0.03(0.32)$ & $0.03(0.16)$ & $0.05(0.11)$ & $0.03(0.11)$ & $0.12(0.17)$ & $0.10(0.14)$ \\
\hline Flow & $0.03(0.26)$ & $0.02(0.23)$ & $0.05(0.10)$ & $0.17(<0.01)^{*}$ & $0.01(0.91)$ & $0.00(0.79)$ \\
\hline Depth & $0.04(0.16)$ & $0.11(<0.01)$ & $0.05(0.12)$ & $0.02(0.12)$ & $0.31(<0.01)^{*}$ & $0.47(<0.001)^{*}$ \\
\hline \multicolumn{7}{|l|}{ Water quality } \\
\hline Cond & $0.11(<0.01)^{*}$ & $0.19(<0.001)^{*}$ & $0.10(<0.01)^{*}$ & $0.13(<0.01)^{*}$ & $0.63(<0.001)^{*}$ & $0.73(<0.001)^{*}$ \\
\hline $\mathrm{pH}$ & $0.12(<0.01)^{*}$ & $0.21(<0.001)^{*}$ & $0.02(0.47)$ & $0.14(<0.01)^{*}$ & $0.14(0.11)$ & $0.34(<0.01)^{*}$ \\
\hline DO & $0.17(<0.001)^{*}$ & $0.16(<0.001)^{*}$ & $0.16(<0.01)^{*}$ & $0.27(<0.001)^{*}$ & $0.00(0.97)$ & $0.26(0.03)^{*}$ \\
\hline Temp & $0.23(<0.001)^{*}$ & $0.24(<0.001)^{*}$ & $0.10(<0.01)^{*}$ & $0.14(<0.01)^{*}$ & $0.13(0.15)$ & $0.17(0.07)$ \\
\hline
\end{tabular}




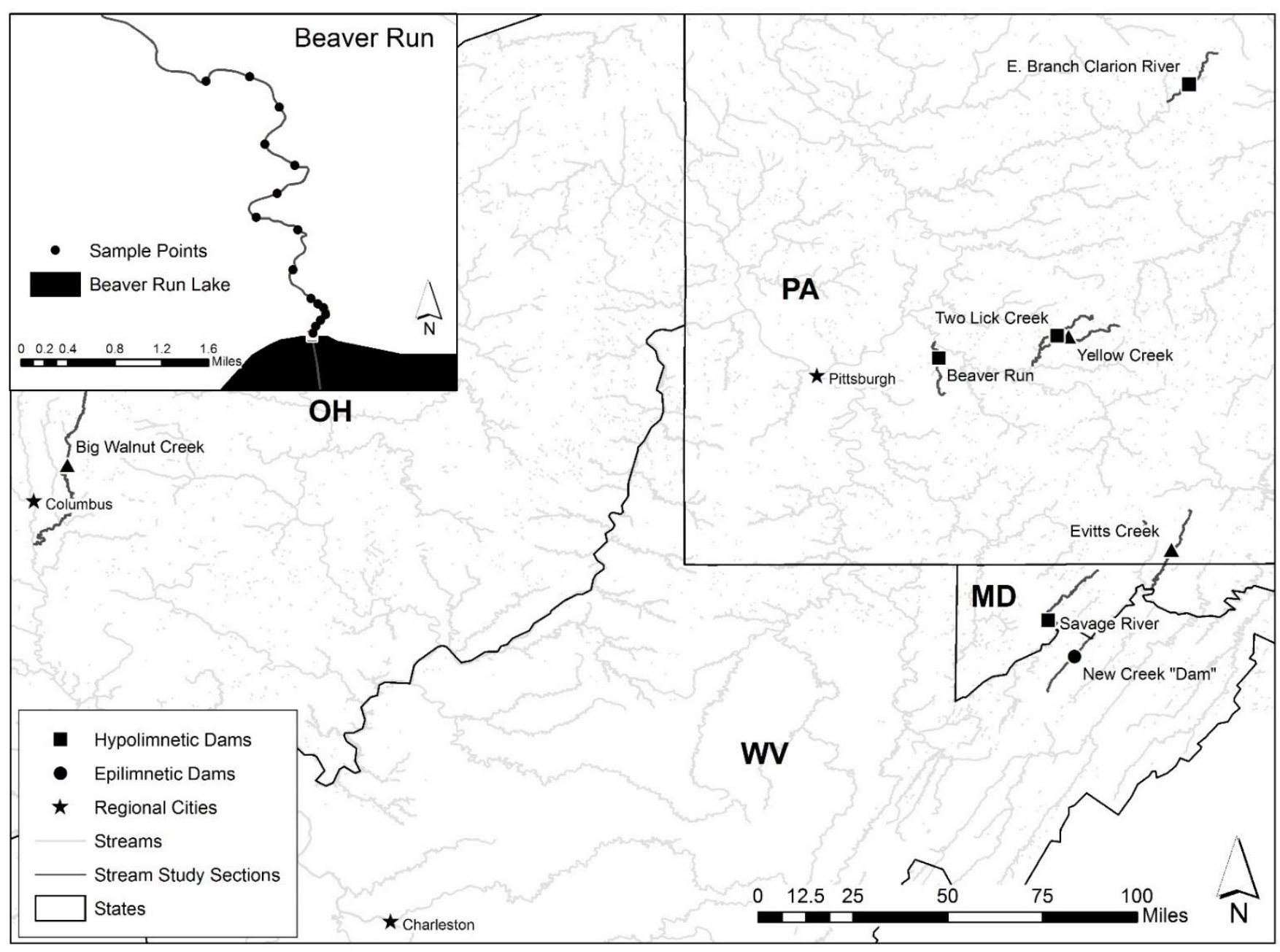

Figure 1. Location of study dams and streams. Dams with hypolimnetic releases are designated by solid squares, while solid circles represent dams with epilimnetic releases. The inset map displays the spacing of sample sites along the stream continuum below dams using Beaver Run as an example. 

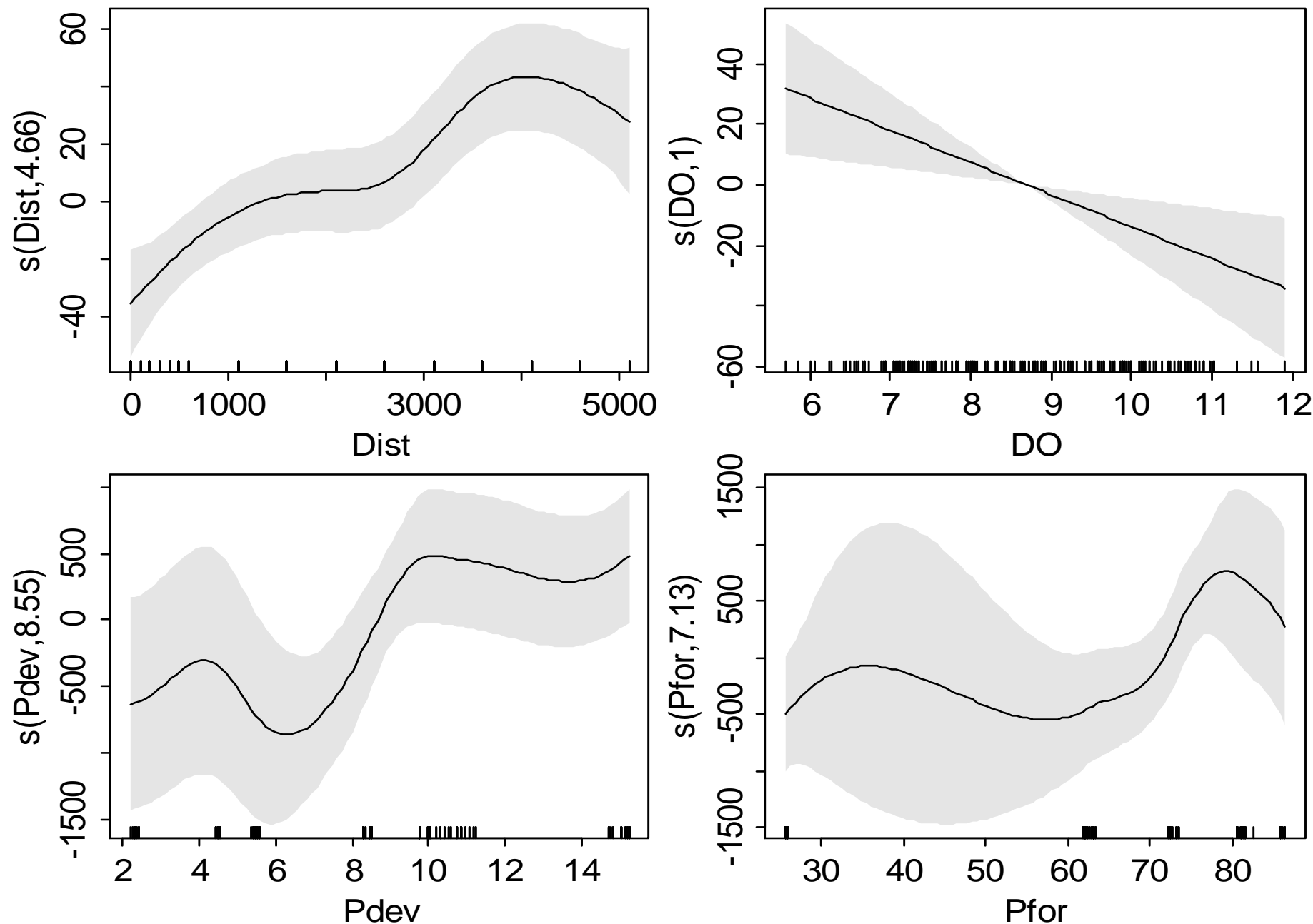

Figure 2. Estimated influence of habitat variables on abundance of larval and juvenile fish from our model (see text and Table 3). Approximate $95 \%$ pointwise confidence intervals are given by the shaded regions. Variables displayed were significant in the model and are scaled and mean-centered. 

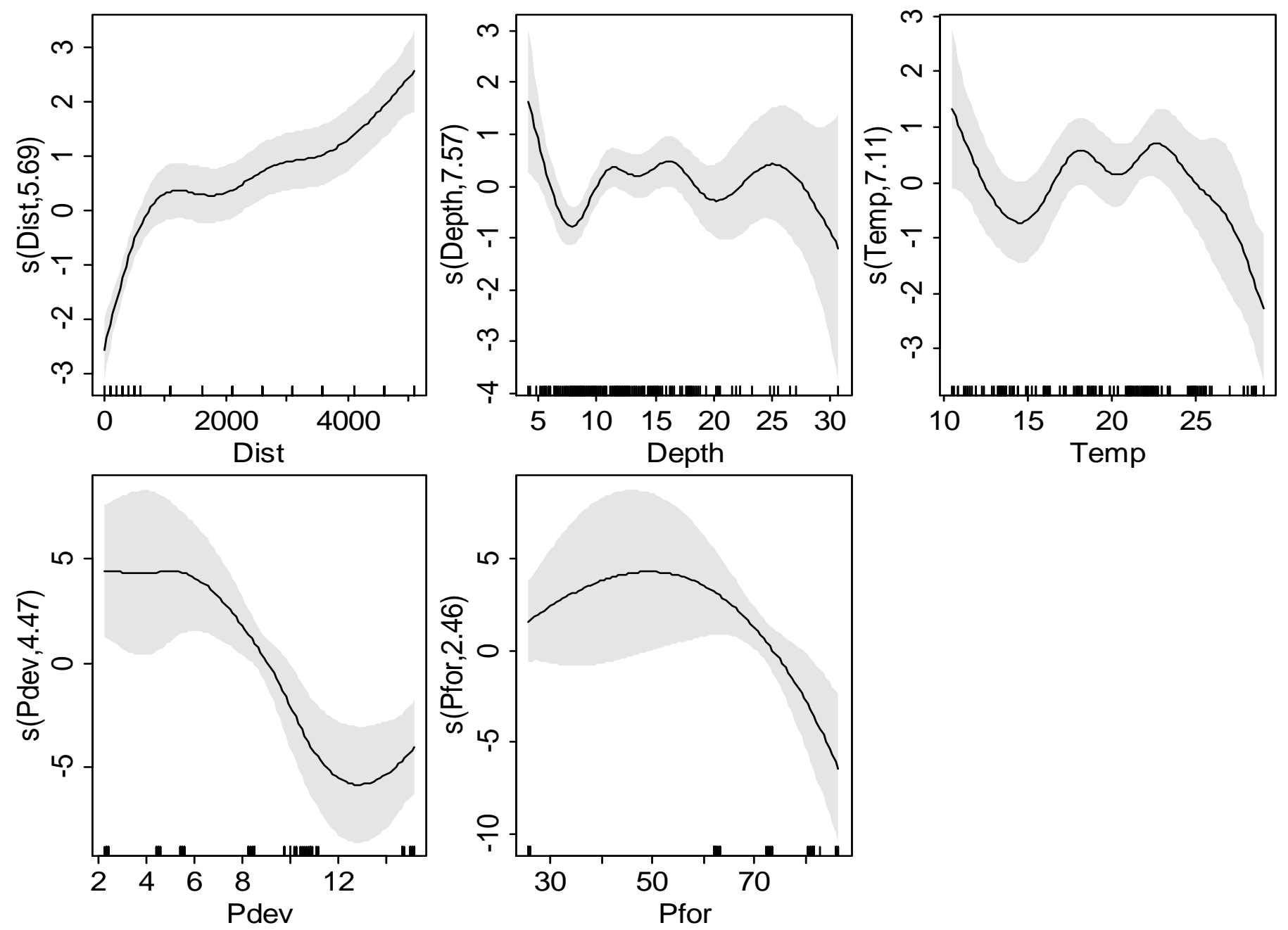

Figure 3. Estimated influence of habitat variables on taxonomic richness of larval and juvenile fish from our model (see text and Table 3). Approximate $95 \%$ pointwise confidence intervals are given by the shaded regions. Variables displayed were significant in the model and are scaled and mean-centered. 

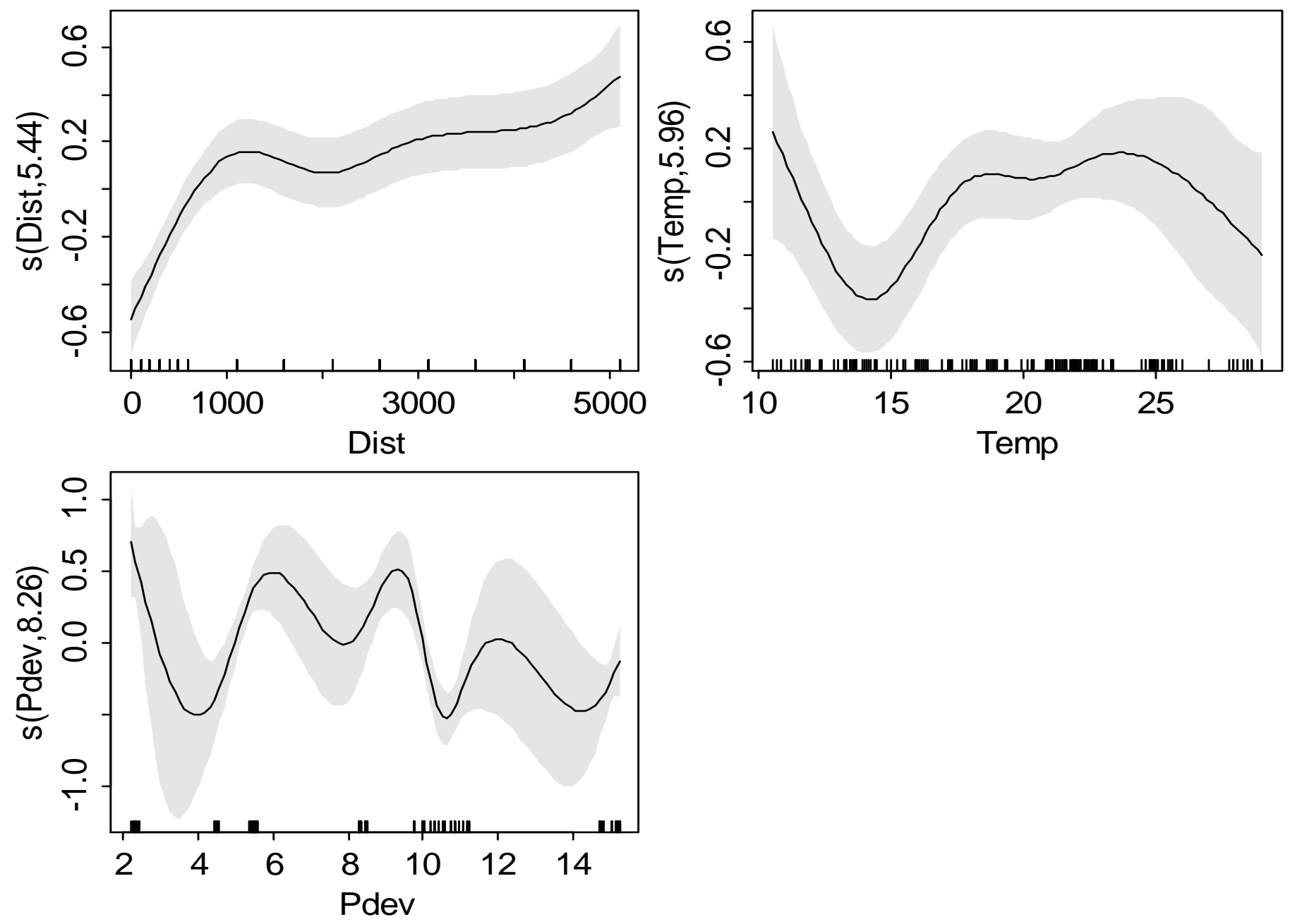

Figure 4. Estimated influence of habitat variables on diversity (Shannon) of larval and juvenile fish from our model (see text and Table 3). Approximate $95 \%$ pointwise confidence intervals are given by the shaded regions. Variables displayed were significant in the model and are scaled and mean-centered. 


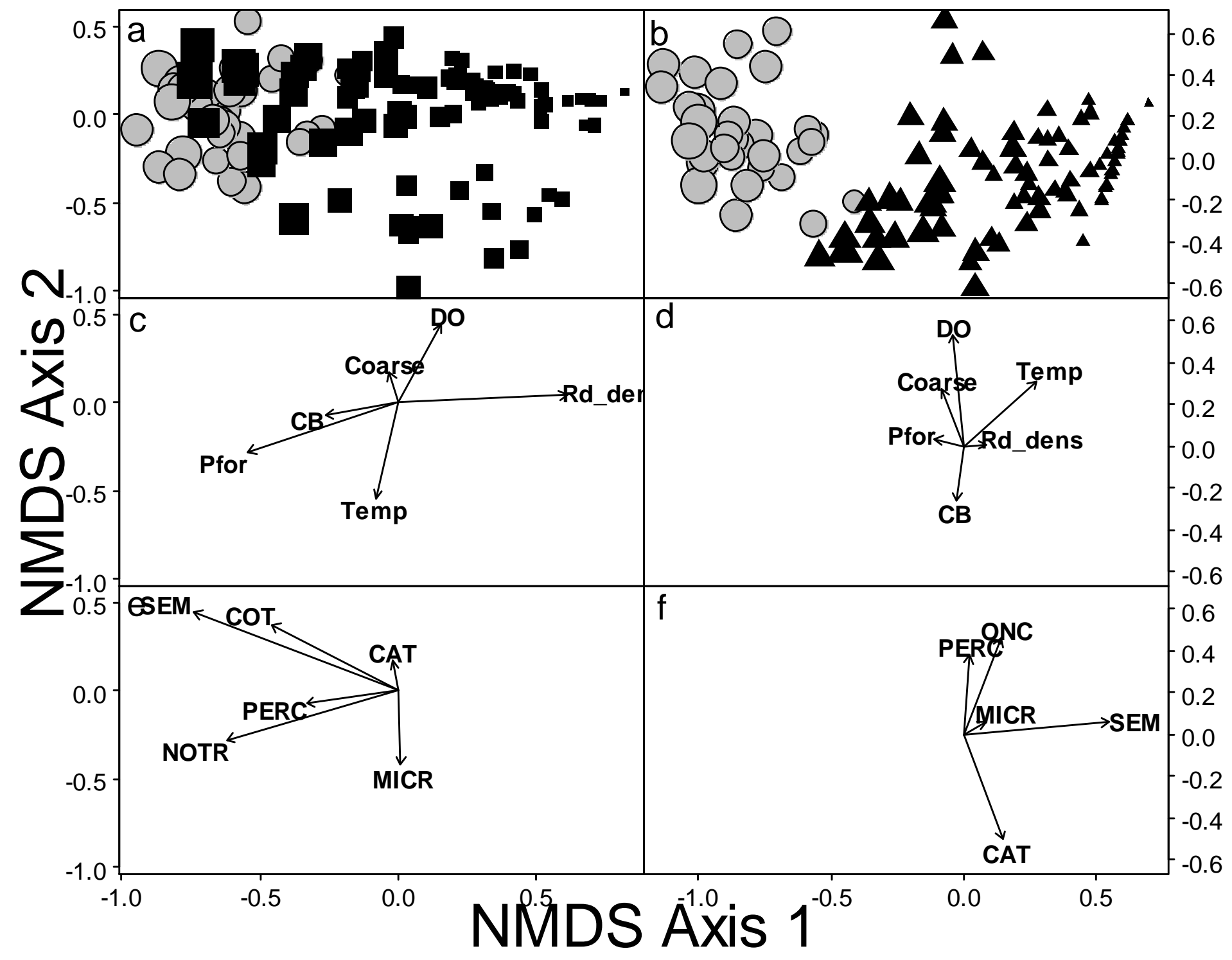


Figure 5. Nonmetric multidimensional scaling (NMDS) ordination of larval and juvenile fish samples (Bray-Curtis coefficient) in 2 dimensions labeled by release type (epilimnetic, hypolimnetic, and reference condition as denoted by squares, triangles, and circles respectively) ( $a$ and b), habitat variables (instream, landcover, and water quality) (c and d), and weighted mean position of genera of larval and juvenile fish. Stress = 11.0 and 8.7 for epilimnetic (c and e) and hypolimnetic ( $\mathrm{d}$ and f) dam releases respectively in the 3dimensional solution. Two convergent solutions were found after one and 20 runs for epilimnetic dam releases respectively. DO $=$ dissolved oxygen, Cond = conductivity, Temp $=$ temperature, Dist $=$ distance, Pgrass $=\%$ grassland, Pdev $=\%$ development, Pfor $=\%$ forested land, Rd_dens = Road density, Coarse $=$ substrate coarseness, $\mathrm{BL}=$ boulder, $\mathrm{BR}=$ bedrock, $\mathrm{CB}=$ cobble, $\mathrm{GC}=$ coarse gravel, GF = fine gravel, $\mathrm{SA}=$ sandy substrate, $\mathrm{SEM}=$ Semotilus, $\mathrm{COT}=$ Cottus, $\mathrm{PIM}=$ Pimephales, $\mathrm{CAMP}=\mathrm{Campostoma}, \mathrm{NOC}=$ Nocomis, ETH = Etheostoma, PERC = Percina, NOTR = Notropis, RHY = Rhinichthys, HYP = Hypentelium, AMBL = Ambloplites, MICR $=$ Micropterus, $\mathrm{CAT}=$ Catostomus and $\mathrm{ONC}=$ Oncorhynchus. Vectors show linear trends where the length of a vector for a specified variable is indicative of the relative correlation strength (scaled to unit length) where its direction indicates the direction of most rapid increase in ordination space. 
Chapter 3. Identifying Impacts from Dams on Downstream Microhabitat Variables that may Affect Richness, Abundance, and Diversity of Aquatic Macroinvertebrates

\author{
Abstract \\ The effect of impoundments on downstream abiotic and biotic components of aquatic \\ ecosystems in the context of the River Continuum (RCC) and Serial Discontinuity Concepts \\ (SDC) have been extensively studied. However, few of those studies have systematically \\ evaluated the changes in biotic and abiotic variables along the stream continuum in a sufficient \\ manner. We systematically evaluated both the abiotic and biotic (i.e., benthic \\ macroinvertebrates) along the stream continuum below impoundments with both epilimnetic and \\ hypolimnetic releases and compared those findings to a reference stream. Generalized additive \\ models (GAMs) identified six habitat variables (i.e., substrate coarseness, substrate diversity, \\ $\mathrm{pH}$, temperature, stream width, and stream depth) as significantly related to distance from dam. \\ GAMs also indicated that abundance was not significantly related to distance from dam but both \\ family level richness and Shannon diversity exhibited significant increases with increasing \\ distance from dams. GAMs indicated two distinct recovery gradients for both richness and \\ diversity where the first rapidly changing gradient occurred in the first 1,100-m and the second \\ more gradual gradient extended beyond the 5,100-m sample reach. Our findings were in general \\ agreement with the SDC; however, we believe a fuller understanding of the SDC could be \\ accomplished through a combination of systematic studies (as we have done here), further \\ investigations of the two recovery gradients exhibited here, and more fine scale benthic \\ macroinvertebrate metrics (e.g., functional feeding groups, etc.).
}




\section{Introduction}

River ecosystems are often conceptualized as continuous entities along their longitudinal gradient. At large scales where such a concept may be applicable, the River Continuum Concept (RCC) proposes that the physical and chemical features continually change along the stream gradient from headwaters to sea; thereby structuring the associated biological communities (Vannote et al. 1980). Scale refers to the extent relative to the size of the sampling unit of a variable of interest in both space and time (Schnieder, 1989; Weins, 1989). Scale also has three relevant subcategories: extent, grain, and lag. Whereas, extent describes the limits of the study, grain describes the size of the sampling unit (e.g., 100-m transect, 5-m quadrat, 500-m stream reach, etc.), and lag describes the distance or interval between sampling units (Sutherland 2006). As scale is reduced, these changes become less prominent and may not appear to follow the RCC but rather seem somewhat random (Ward et al., 2001).

However, due largely to anthropogenic influences, the majority of lotic ecosystems no longer act as continuous entities and instead are influenced by discontinuities along their longitudinal gradient, of which dams are likely the most influential (Ward and Stanford 1983). Ward and Stanford (1983) developed the Serial Discontinuity Concept (SDC) which created the theoretical framework to understand how discontinuities modify physiochemical and biological components upstream and downstream of dams. These changes have been shown to adversely influence biological components (e.g., fish, aquatic macroinvertebrates, etc.) of stream communities (Katano et al. 2009; Ellis and Jones, 2013; Freedman et al., 2013). Discontinuities within a stream can reset or shift a variable in either the upstream or downstream direction (Ward and Stanford, 1983). The distance of this shift is termed the discontinuity distance. Here, biological recovery gradients are defined as the change in biological parameters (e.g., taxa 
richness, taxa diversity, community structure) below dams as they progress towards the reference condition. In order to further understand the nature of biological recovery gradients along these longitudinal discontinuities, empirical approaches are necessary (Stanford and Ward 2001). Studies of regulated rivers should be performed at appropriate scale, including considerations of extent, grain, and lag, in order to sufficiently assess biotic and abiotic recovery gradients.

The size and relative location of dams along the length of a stream may have differential effects on downstream physiochemical and biological attributes and should be considered when evaluating a dam's impact on the abiotic and biotic components of that system (Ward and Stanford, 1983). The nature of the water released from a dam and its downstream impacts on both physiochemical and biological components are influenced by whether the water is of hypolemnetic or epilimnetic origin (Yeager 1993). The SDC was proposed as using a series of thought experiments based on hypothetical dams with hypolemnetic water releases (Ward and Stanford 1983, Stanford and Ward 2001).

Evaluation of dams on various physicochemical parameters has been extensively studied (see Ellis and Jones, 2013 for an extensive overview). Dams have been shown to disrupt sediment transport thereby reducing downstream sediment loads and modifying sediment composition (Jones, 2010). Shifts in thermal regimes are also a product of impoundments and the magnitude of change above and below the dam is dependent on whether the dam release is hypolimnetic or epilimnetic. The rate at which temperature changes as the distance from dam increases is dependent on multiple factors (e.g., the number, size, and temperature of tributaries, latitude, canopy cover, etc.) (Rice et al., 2001). The velocity and depth close to impoundments are often substantially different from what would be expected at the location along the stream continuum were the dam absent (Freedman et al., 2013), due to the ability for dams to trap 
nutrients and sediment (Graff, 1999; Poff and Hart, 2002). Water quality can be influential in structuring the biotic communities (Storey et al., 1991; Freedman et al., 2013). Large substrate has been found to be characteristic of sites in close proximity to dams (Storey et al., 1991; Cortes et al., 2002; Katano et al., 2009). Reservoirs may act to trap sediment, thereby starving areas downstream of dams of this key resource causing an armoring of the substrate as the streambed and banks are eroded (Jones, 2010).

Land use practices have been shown to influence aquatic ecosystems (Allan, 2004) in regards to both their biotic and abiotic (Johnson et al., 1997; Roy et al., 2003) components. Johnson et al. (1997) found agricultural land use to be an effective predictor of water chemistry variables in central Michigan's Saginaw River basin. Urbanization and forested landcover had opposite effects on various benthic invertebrate biotic indices, with higher values associated with forested areas; whereas urbanization resulted in higher proportions of tolerant taxa and reduced diversity (Roy et al., 2003). Within the context of the SDC, land use practices should be considered as potentially influential in structuring water quality, habitat, and biotic indices.

Benthic macroinvertebrates and environmental gradients in natural rivers and in response to disturbance have been largely studied. Yet there are still few studies that have examined their response to dams and their discontinuity distance in a systematic manner (Ellis and Jones 2013). The objectives of this study was to systematically: 1) identify changes in important habitat variables (i.e., in stream physical habitat, water quality, and landscape) and their potential influence on abundance, richness, and diversity of aquatic macroinvertebrates below dammed streams; and 2) to identify the distance at which these response variables (abundance, richness, diversity) stabilize below a dam along the longitudinal gradient of a stream (discontinuity distance). Concurrent with the Serial Discontinuity Concept (SDC) we hypothesize that the 
aforementioned response variables will increase at a greater rate near the dam before the rate of increase is ameliorated by stabilizing habitat variables.

\section{Materials and Methods}

Study Sites and Site Selection

Sampling occurred in six streams (Beaver Run, Pennsylvania; Big Walnut Creek, Ohio; East Branch of the Clarion River, Pennsylvania; Evitts Creek, Pennsylvania; Savage River, Maryland; Two Lick Creek, Pennsylvania; Yellow Creek, Pennsylvania) and one reference stream (New Creek, West Virginia) during 2012 and 2013 (Figure 1; Table 1). New Creek was selected as a reference stream based on data from previous work (Hanks unpublished) where it had high richness and diversity and based on the fact that the stream is unimpounded within the near proximity of the study reach. New Creek was assigned a starting location (i.e., a hypothetical dam location) and sampled from that point downstream in the same fashion as our dammed sites. During 2012 sampling occurred in Savage River, Maryland; yet we were unable to replicate sampling in Savage River during 2013 due to agency concerns. Therefore in lieu of the Savage River, sampling took place in East Branch of the Clarion, Pennsylvania during 2013. During both 2012 and 2013 we evaluated three streams with epilimnetic and three hypolimnetic release types. Dams ranged in height from 19 to 56-m and their drainage area ranged from 11,188 to 49,208-ha. Sampling locations (distance below dams) within each stream were selected a priori. Beginning as close to the tailwaters of each dam as was safely possible (assigned zero distance) we sampled larval and juvenile fishmacroinvertebrates and physiochemical variables every $100-\mathrm{m}$ for the first $600-\mathrm{m}\left(\mathrm{n}_{100}=7\right)$, thereafter we sampled every 500-m to 5,100-m below the dam $\left(\mathrm{N}_{500}=8 ; \mathrm{N}_{\text {total }}=16\right.$ for each stream). Preliminary sampling 
indicated rapid changes macroinvertebrate richness and diversity at sites near dams and we therefore sampled at a finer spatial scale (every 100-m) near the dam as we felt there may be important changes within this short (600-m) distance from the dam. Due to logistical and resource constraints we decided to sample 5,100-m below dams to assess the discontinuity distance associated with each dam along the stream continuum.

\section{Sampling: Physiochemical habitat}

Microhabitat and water quality variables were measured at each sampling location concurrent with sampling for macroinvertebrates. Water quality variables (conductivity $(\mu \mathrm{S} / \mathrm{cm})$, dissolved oxygen $(\mathrm{mg} / \mathrm{L}), \mathrm{pH}$, and temperature $\left.\left({ }^{\circ} \mathrm{C}\right)\right)$ were recorded once at each sampling location $\left(\mathrm{N}_{\text {total }}=16\right.$ per stream) with a YSI meter (Yellow Springs Instruments computer module: 650MDS, Yellow Springs, Ohio). Channel and bankful widths were measured at five transects per sampling location (sixteen sampling locations per stream) and at five points along each transect width, depth, flow, percent embeddedness, and substrate were measured (400 point locations per stream). Flow measurements were recorded with a Marsh-McBirney flow meter (Marsh-McBirney Inc., Frederick, Maryland). Substrata were coded based on size class categories as follows: $1=$ bedrock $(>4000 \mathrm{~mm}), 2=$ fines $(<0.06 \mathrm{~mm}), 3=$ sand $(0.06-2 \mathrm{~mm}), 4$ = fine gravel $(2-16 \mathrm{~mm}), 5=$ coarse gravel $(16-64 \mathrm{~mm}), 6=$ cobble $(64-250 \mathrm{~mm})$, and $7=$ boulder (250-4000 mm). Average substrate coarseness (Katano et al. 2009) at each sampling location was used in models and calculated as:

Coarseness $=\Sigma$ (Size category code $x \%$ of a given category at a given transect $)$ 
Additionally, we calculated average substrate diversity (Shannon diversity substrate categories;

e.g., boulder, cobble, fine gravel, etc.) and overall habitat diversity (Shannon diversity for substrate, depth, and flow) for each site.

Sampling: Landscape habitat variables

Using spatial analyst functions in ArcMap 10.2.1 (Environmental Systems Research Institute, Redlands, California) we generated watersheds for each site on a respective stream. Landcover (from the 2011 National Landcover Dataset [NLCD]) attributes from each watershed were then subtracted serially in order to get the percent landcover type within each respective sub-watershed. We then combined landcover types into three categories (developed, forested, and agricultural/grassland) for analysis. We also calculated road density (i.e., density = (road length/sub-watershed area) x 100) as an additional method of calculated development within a sub-watershed. For each sampling location stream distance to nearest upstream and downstream tributary was measured in ArcMap 10.2.1 using the measure tool.

\section{Sampling: Aquatic macroinvertebrates}

Benthic macroinvertebrates were sampled once at each sampling location during both 2012 and 2013 between mid-May and mid-June. At each sampling location, macroinvertebrates were sampled following the USEPA Rapid Bioassessment Protocols for wadeable streams (Barbour et al. 1999). Four 0.25- $\mathrm{m}^{2}$ kick net samples were collected at each site from riffle habitat. All materials from each of the four samples were combined into a composite sample (1$\mathrm{m}^{2}$ ) and preserved in $95 \%$ ethanol. In the laboratory samples were washed and filtered through a 0.25-mm sieve. All remaining organisms were subsampled randomly via a $200(+/-10 \%)$ 
organism fixed count (Barbour and Gerritsen, 1996) whereupon they were enumerated and identified to Family (2012 and 2013) and genus (2013) (when possible and excepting Chironomidae, Hirudinia, Hydracarina, and Oligochaetae) using keys found in Peckarsky et al. (1990) and Merritt and Cummins (1996). The count of individuals was scaled up to the original total sample $\left(1-\mathrm{m}^{2}\right)$ to give an estimate of the total number of individuals present in a given sample.

\section{Statistical analysis}

We investigated changes in habitat variables along the stream gradient (i.e., distance below dams) using both linear models and Generalized Additive Models (GAMs). Generalized Additive Models allow for response variables to vary in a non-linear fashion as predictor variables change. Using factors in the models allow for these changes to vary with the factor term (e.g., individual streams). GAMs were applied using package mgcv (Wood 2006) in Program $\mathrm{R}$ and we applied a cubic regression spline with shrinkage, allowing for smoothing terms to have zero degrees of freedom (Zuur 2009). Generalized additive models were developed using a smoothing term for distance and treating release type (hyperlimnetic and hypolimnetic) and individual streams as factors. For example:

coarseness $\approx \mathrm{s}($ distance $)$

coarseness $\approx \mathrm{s}($ distance $)+$ factor(release type $)$

coarseness $\approx \mathrm{s}($ distance $)+$ factor(stream $)$

Table 2 displays model $\mathrm{R}^{2}$ and its associated $\mathrm{P}$ value for the model for each habitat variable. 
Using GAMs we investigated the influence of habitat variables (in stream and landscape level) on family richness and diversity below dams. Prior to model development and selection we used variance inflation factors (VIF) to assess collinearity. Variables with a VIF greater than 3 were removed from subsequent models. Year (2012 and 2013) was treated as a factor. While there was a significant effect of release type (epilimnetic and hypolimnetic) on temperature while controlling for distance $(\mathrm{F}=291.87, \mathrm{P}<0.001)$; however, we decided to remove release type and retain temperature in our models because temperature contained release type information as well as additional non-categorical information. Richness was modeled with a Poisson distribution because it is count data; while diversity and abundance were modeled using a Gaussian distribution. Final models are a result of fitting the data to all measured and calculated habitat variables, dropping nonsignificant terms and selecting the model with the lowest Akaike Information Criterion (AIC). Final models for abundance, richness, and diversity were as follows:

Abundance $\approx \mathrm{s}($ depth $)+\mathrm{s}($ dissolved oxygen $)+\mathrm{s}($ flow $)+\mathrm{s}($ percent forest $)$

Where abundance varies as a smooth function of depth, dissolved oxygen, flow, and percent forest.

Richness $\approx \mathrm{s}($ coarseness $)+\mathrm{s}($ distance $)+\mathrm{s}($ dissolved oxygen $)+\mathrm{s}($ percent forest $)+\mathrm{s}($ temperature $)$ + factor(year) 
Where richness varies as a smooth function of distance, coarseness, dissolved oxygen, percent forest, and temperature and is allowed to shift with the factors of year.

Diversity $\approx \mathrm{s}($ coarseness $)+\mathrm{s}($ distance $)+\mathrm{s}($ dissolved oxygen $)+\mathrm{s}($ percent forest $)+$ $\mathrm{s}($ percent developed $)+\mathrm{s}($ temperature $)$

Analyses were performed using the $\mathrm{R}$ language and environment for statistical computing (R Development Core Team, Vienna, Austria).

\section{Results}

Dissolved oxygen, conductivity, flow, habitat diversity, and embeddedness were not significant in any of our models that investigated changes of habitat variables along the stream continuum below dams. The remaining instream habitat variables that we measured were all significant $(\mathrm{p}<0.05)$ (Table 2; Figure 2). Generalized additive models (using a smoothing term for distance) with stream as a factor were the best models (i.e., lowest AIC) and had $\mathrm{R}^{2}$ values ranging between 0.30 (depth) and 0.83 (temperature) (Table 2). Substrate coarseness was high near dams, dropped dramatically until about 1,000-m below the dam where it began rising until about 3,000-m mark and remained relatively stable from that point on $\left(\mathrm{R}^{2}=0.36, \mathrm{p}<0.05\right)$.

Substrate diversity was low near the dam, increased until peaking around 2000-m from the dam, and then returned to levels to those immediately below the dam at around 5000-m from the dam $\left(\mathrm{R}^{2}=0.34, \mathrm{p}<0.05\right)$. Average $\mathrm{pH}$ dropped from $\sim 8$ to $\sim 7.75$ in the first $600-\mathrm{m}$ and then steadily rose throughout the stream reach to $\sim 8.15\left(\mathrm{R}^{2}=0.69, \mathrm{p}<0.05\right)$. Instream temperature was lowest near dams $\left(\bar{x} \sim 18^{\circ} \mathrm{C}\right)$ and gradually increased throughout the sampled stream reach $\left(\mathrm{R}^{2}=0.83\right.$, 
$\mathrm{p}<0.05)$. Streams were widest at sites near the dam and narrowed steadily until about 1,500-m below the dam where width stabilized $\left(\mathrm{R}^{2}=0.38, \mathrm{p}<0.05\right)$. Depth increased in the downstream distance until about 1,500-m where it peaked and then gradually declined until about 2,100-m where it remained relatively constant $\left(\mathrm{R}^{2}=0.30, \mathrm{p}<0.05\right)$.

From dammed streams there were a total of 192 samples taken and 34,254 individual macroinvertebrates were identified. At each sample site enumerated family richness ranged from 2 to 26 , while estimated abundances ranged from 95 to 5800 . Generally, richness and diversity increased while abundance decreased with distance from dam. Generalized additive models with a smoothing term for distance and stream treated as a factor had the higher $\mathrm{R}^{2}$ value for richness, diversity, and abundance where diversity varies as a smooth function of distance, coarseness, dissolved oxygen, percent forested land, and percent developed land.

Richness $\left(\mathrm{R}^{2}=0.39, \mathrm{p}<0.05\right)$ and diversity $\left(\mathrm{R}^{2}=0.36, \mathrm{p}<0.05\right)$ both increased most rapidly near the dam, up to approximately 2,000-m where the rate of increase declined. However, both richness and diversity continued to increase thereafter but at a reduced rate. Abundance $\left(\mathrm{R}^{2}=0.24, \mathrm{p}<0.05\right)$ was highest near dams, decreased up to approximately $2,000-\mathrm{m}$ below the dam at which point it began to increase steadily to our most downstream site $(5,100$-m below the dam).

The final model for abundance explained $43 \%$ of the deviance in the data and resulted in an adjusted $\mathrm{R} 2$ of 0.38 . The smoothing term for dissolved oxygen was significant at $\mathrm{p}<0.05$, while all other smoothing terms were significant at $\mathrm{p}<0.01$ (Table 3; Figure 3). Our model for family richness explained $71 \%$ of the deviance in the data and resulted in an adjusted $\mathrm{R}^{2}$ of 0.68 . All smoothing terms and the factor year were significant $(\mathrm{p}<0.01)$ (Table 3; Figure 4). Our Family diversity model explained $63 \%$ of the deviance in the data and resulted in an adjusted $\mathrm{R}^{2}$ 
value of 0.59 . All smoothing terms were significant but the factors year and release type were not significant (Table 3; Figure 5).

\section{Discussion}

The evaluation of dam influences on downstream aquatic macroinvertebrates has previously been studied (Lemkuhl, 1972; Gore, 1977; Kraft and Mundahl, 1984; Rader and Ward, 1988; Voelz and Ward, 1990; Valentin et al., 1995; Katano et al., 2009; Jones, 2011; Ellis and Jones, 2014) but we found only one other empirically based systematic test of the Serial Discontinuity Concept (SDC) besides our own (see Ellis and Jones 2014). However, our work on the effects of dams on longitudinal changes downstream include seven dammed streams and both epilimnetic and hypolimnetic releases. Additionally we evaluated 16 sites per stream and at two spatial scales (near dam sites were spaced 100-m apart for 600-m and thereafter sites were spaced every 500-m to 5,100-m downstream of each respective dam). We investigated the longitudinal effect of dams on instream habitat and water quality; followed subsequently with models to identify significant effects of these parameters and land use on biological measures of abundance, richness, and diversity of benthic macroinvertebrates. Our results generally agreed with the SDC (Ward and Stanford 1983).

Substrate was coarser (i.e., larger) on average at sites near dams. This is likely due to impoundments acting as sinks for smaller substrata, starving areas below dams, riprap being placed below dams to reduce erosion in tailwater areas, and high flows flushing smaller substrata from these areas immediately below dams; thereby having an overall effect of highly armored substrate below dams (Gore et al. 1989; Story et al. 1991; Katano et al. 2009). Low substrate diversity in areas immediately below dams confirms these findings and is likely due to the same 
factors. Overall habitat diversity followed the same pattern as that of substrate coarseness indicating that overall habitat is somewhat diverse but quickly decreasing in areas immediately below dams (up to approximately 1,000-m) at which point it is the most homogenous. This is likely due to the large size of substrate in this area creating high variability (i.e., diversity) in both depth and flow, where boulders create both shallow and deep habitat, and flow is more variable where boulders create eddy currents downstream.

The decrease in both habitat diversity and substrate coarseness subsided approximately 1,000-m below dams. This may be an area of substrate deposition where energy from high flows has dissipated. Substrate diversity was at its highest approximately 1,500-m below the dams indicating a lag of approximately 500-m below where coarseness and habitat diversity were lowest. This may be a point at which the influence of dams on instream habitat is beginning to diminish; yet it is dependent on factors such as dam size, flow regime, land use, and geomorphology (e.g., slope and geology). Dam construction is likely the reason for streams being widest and shallowest in areas near dams. However, the change in width was much more rapid than that of depth (approximately 500-m and 1,000-m respectively).

Temperature rose steadily as distance from dam increased; however, release type had an important influence and the final model (Figure 3e) was dominated by hypolimnetic discharge, whereas dams with an epilimnetic discharge showed little to no change in temperature downstream of the dam. The streams we studied which have epilimnetic releases showed no apparent temperature gradient and the recovery gradient for hypolimnetic streams appears to be beyond our 5,100-m stream reach, which is supported by previous studies where thermal recovery gradients were shown to require greater than 100-km (Preece and Jones, 1983; Paller and Saul, 1996). Additionally our temperature recordings were snapshots in time where we 
recorded temperature at each sampling location during the time we were performing other sampling on four separate occasions during each of 2012 and 2013 between mid-May and lateJune. It is possible that longitudinal temperature changes would be different during other parts of the year and that daily fluctuations may show greater variability during certain times of the year and at different locations along the stream continuum due in part to physical attributes of the streams regulated by dams (e.g., shallow reaches near the dam). Variability in thermal regimes across varying temporal scales have been shown to influence the macroinvertebrates in a variety of ways (Ward and Stanford, 1983; Rader et al., 2007). Phenological timing of important life stages in macroinvertebrates may be affected by reduced daily fluctuations in hypolimnetic releases where thermal cues are depended upon for timing of emergence, growth, reproduction and the success of populations (Ward, 1982; Byren and Davies, 1989).

Family richness, defined as the number of different taxa at each site, of benthic invertebrates was lowest at sites near dams, increased relatively quickly to approximately 1,000$\mathrm{m}$, where the rate of increase slowed but still exhibited an upward trend to our most downstream site, 5,100-m below each respective dam. This finding is congruent with the theoretical construct of the SDC and has been corroborated with other studies (Gore, 1977; Rader and Ward, 1988; Munn and Brusven, 1991; Volz and Ward, 1991; Stevens et al., 1997; Cortes et al., 2007; Jones, 2012; Ellis and Jones, 2014). There appears to be a "sweet spot" where substrate coarseness relatively high but not extremely high. Extremely high values of substrate coarseness were common at sites with almost exclusively boulder habitat, as were prevalent as riprap immediately below dams. Sites with very low substrate coarseness were dominated by either fine sediment or bedrock/armored substrate. Previous studies have reported reduced taxonomic richness due to very coarse substrate (Katano et al. 2009) and fine sediment (Kaller and 
Hartman, 2004; Jones et al. 2011), whereas cobble and pebble substrate are known to increase richness (Erman and Erman, 1984; Grubaugh et al., 1996)

Percent forested area within a watershed has been positively related to richness (Roy et al. 2003). In our study, richness peaked at approximately $60 \%$ forested area and declined at sites with sub-watersheds with either more or less percent forested area. It is likely that sites with low percent forest are impaired with other land use practices and thereby result in low richness. More interesting is the decrease in richness as percent forest increased beyond $60 \%$. The $60 \%$ "sweet spot" may be the result of non-exclusion, where both tolerant and intolerant taxa are present (Mackey and Currie, 2001). Katano et al. (2009) found substrate to be coarser below dams in streams they studied in Japan and that richness was lower in these areas. Our study indicates there may be two recovery gradients that exist for richness. The first gradient is demonstrated by a rapid increase in richness taking place within the first 1,000-m below the dam. The second, and more subtle gradient, appears to continue beyond the 5,100-m stream reach and is the gradient most often discussed in the literature. Ellis and Jones (2014) found the most rapid change in richness to be within the first $5 \mathrm{~km}$ and seemed to have recovered within $10 \mathrm{~km}$ below one of their study dams and to have peaked at $10 \mathrm{~km}$ below before again decreasing another impounded system they investigated. Year was significant in our model indicating that yearly variability in richness may be expected but it is likely attributed to normal variability from yearto-year in local rainfall, temperature, etc. that interacts with the timing of various life history stages of benthic macroinvertebrates.

Although distance was not significant in our final model, and in contrast to richness, estimated abundance was highest at sites near dams and steadily decreased until approximately 2,000-m below impoundments where it began nearly an equally steady increase and continued on 
this trajectory through our 5,100-m sample reach (Figure 3). Abundance, in the systems that we studied was best explained as a function of depth, flow, dissolved oxygen, temperature, and percent forest. Abundance was highest at sites considered to be of poor environmental quality (low dissolved oxygen, shallow, low flow, low \% forest). While Ward (1984) proposed abundance may either increase or decrease below dams depending on the consistency of flow, it has been generally shown to increase where flow is most consistent. Abundance fluctuated along the temperature gradient but showed a general trend of decrease as temperature increased. Streams that have hypolimnetic dam releases have been shown to have high abundance (Jones 2013) and the negative trend in abundance with increasing temperature that we saw agrees with these findings. The fluctuation in abundance along the temperature gradient is due to streams that we sampled having their own distinct thermal ranges, showing little overlap with the other streams that we sampled. Jones (2011) also found abundance to be highest at a near dam site in the Magpie River on the northern side of Lake Michigan. High abundance and low taxonomic richness at sites near dams is likely the result of highly tolerant (e.g., Chironomidae, Crangonyctidae, etc.) or highly specialized taxa (e.g., trichoptera) dominating areas near dams. As richness increases downstream due to improving and diversification of environmental conditions competition for resources also increases thereby reducing total abundance. This is corroborated with our finding that substrate diversity was highest in areas between 1,600-m and 3,600-m and overall habitat diversity was highest approximately 3,100-m below impoundments. Taxonomic diversity was predicted by Ward and Stanford (1983) to be reduced below dams and show gradual increase with distance from dams and this has been largely the case in other studies (Cortes et al., 2002; Jones 2011; Jones, 2013; Jones and Ellis, 2015) as it was in ours. As with richness, we believe there may be two important gradients for diversity along the 
stream longitudinal continuum. The first, shorter "recovery" occurs near the dams and shows a rapid increase in diversity within the first 1,000-m before becoming relatively stable, even dropping slightly, before continuing an upward trend as distance from dam increases. Diversity was highest in areas where percent forested area was approximately $75 \%$ and percent development ranged between $8-12 \%$ in sub-watersheds. Intermediate disturbance in land use has been shown to increase richness and diversity. While taxonomic richness and diversity are often used as proxies for stream health, this may not be the case below impoundments, as tolerant taxa often dominate near dam sites and give way to increasingly more intolerant taxa downstream as habitat conditions improve (Ward and Stanford, 1979; Ward and Stanford, 1989; Zhang, 1998; Ellis and Jones, 2015). During this transition there is likely an area of mixing of tolerant and intolerant taxa where richness and diversity increase and give a false indication of progression towards recovery.

\section{Conclusion}

Understanding the dynamics that exist in regulated rivers, downstream of dams, is paramount for successful management of these systems. This is the second study that examines the effects of dams on downstream physiochemical and biotic components in the context of the SDC in a systematic manner. Jones (2012) and Ellis and Jones (2013) noted that studies of regulated rivers, in large part, are lacking in their description and inclusion in analyses of dam characteristics as well as reservoir and tributary influences. Without the inclusion of these variables studies likely miss important factors that aid in the assessment of longitudinal recovery gradients of abiotic and biotic parameters. 
Our study clearly shows two recovery gradients for benthic invertebrate richness and diversity. We found no other studies that examined the rapidly changing gradient near dams. The more gradual recovery gradient extended beyond our 5,100-m sampling reach and has been described extensively, yet not tested formally. Dam release type influences both richness and diversity with hypolimnetic releases having lower values overall. In stream habitat (i.e., substrate coarseness) is an important factor to consider when investigating biotic indices. Landcover has an essential role in driving richness and diversity and intermediate disturbance encourages higher richness and diversity; although it may be that the higher values do not indicate ecological recovery or integrity as there may be a mixing of tolerant and intolerant taxa in these intermediately disturbed area. Further understanding of the SDC will benefit from inclusion of functional diversity of benthic invertebrates (e.g., functional feeding groups, tolerance, etc. (See Ellis and Jones, 2014) and future studies should focus on inclusion of these finer scale metrics. Changes that occur below dams may occur rapidly (our near dam gradient), while others may take much greater distance to recover (e.g., thermal recovery). We concur with Ellis and Jones (2014) that future studies should approach investigating the SDC systematically and at various spatial and temporal scales.

This study supports the Serial Discontinuity Concept and suggests that along with the traditional longer recovery gradient there is an additional near dam gradient that should be considered when investigating the SDC. Temporally longitudinal studies will aid in understanding how management of systems with dams change through time and with manipulated flow and temperature below impoundments. An understanding of land use practices and tributary influences, as well as the inclusion of various scales (spatiotemporal and biotic) 
should be included in studies and will aid in further understanding of the SDC and how to best manage impounded systems. 


\section{References}

Allan, J. D. 2004. Landscapes and riverscapes: the influence of land use on stream ecosystems. Annual Review of Ecology, Evolution, and Systematics 35:257-284.

Barbour, M. T., J. Gerritsen, B. D. Snyder, and J. B. Stribling. 1999. Rapid bioassessement protocols for use in streams and wadeable rivers: periphyton, benthic macroinvertebrates and fish. $2^{\text {nd }}$ edition. EPA 841-B-022. Office of Water, US Environmental Protection Agency, Washington, DC.

Byren, B. A. and B. R. Davies. 1989. The effect of stream regulation on the physicochemcical properties of the Palmiet River, South Africa. Regulated Rivers: Research and Management 3: 107-121.

Cortes, R., M. Ferreira, S. Oliveira, and D. Oliveira. 2002. Macroinvertebrate community structure in a regulated river segment with different flow conditions. River Research and Applications 18(4):367-382.

Ellis, L. E. and N. E. Jones. 2013. Longitudinal trends in regulated rivers: a review and synthesis within the context of the serial discontinuity concept. Environmental Reviews 21(3):136148.

Ellis, L. E. and N. Jones. 2014. A test of the serial discontinuity concept: longitudinal trends of benthic invertebrates in regulated and natural rivers of northern Canada. River Research and Applications 32(3):462-472.

Freedman, J. A., B. D. Lorson, R. B. Taylor, R. F. Carline, and J. R. Stauffer Jr. 2013. River of the dammed: longitudinal changes in fish assemblages in response to dams. Hydrobiologia 727(1):19-33.

Gore, J. 1977. Reservoir manipulations and benthic macroinvertebrates in a Prairie River. Hydrobiologia 55(2):113-123.

Gore, J., J. M. Nestler, and J. B. Layzer. 1989. Instream flow predictions and management options for biota affected by peaking-power hydroelectric operations. Regulated Rivers: Research and Management 3:35-48.

Graf, W. L. 1999. Dam nation: A geographic census of American dams and their large-scale hydrologic impacts. Water Resources Research 35(4):1305-1311.

Grubaugh, J. W., J. B. Wallace, and E. S. Houston. 1996. Longitudinal changes of macroinvertebrate communities along an Appalachian stream continuum. Canadian Journal of Fisheries and Aquatic Sciences 53:896-909. 
Jones, N. E. 2010. Incorporating lakes within the river discontinuum: longitudinal changes in ecological characteristics in stream-lake networks. Canadian Journal of Fisheries and Aquatic Sciences 67(11):1350-1362.

Jones, N. E. 2011. Spatial patterns of benthic invertebrates in regulated and natural rivers. River Research and Applications 29(3)343-351.

Jones, N. E. 2013. Patterns of benthic invertebrate richness and diversity in the regulated Magpie River and neighbouring natural rivers. River Research and Applications 29(3):10901099.

Jones, N. E. 2013. Spatial patterns of benthic invertebrates in regulated and natural rivers. River Research and Applications 29(3):343-351.

Kaller, M. D. and K. J. Hartman. 2004. Evidence of a threshold level of fine sediment accumulation for altering macroinvertebrate communities. Hydrobiologia 518(1):95-104.

Katano, I., J. Negishi, T. Minagawa, H. Doi, Y. Kawaguchi, and Y. Kayaba. 2009. Longitudinal macroinvertebrate organization over contrasting discontinuities: effects of a dam and a tributary. Journal of the North American Benthological Society 28(2):331-351.

Kraft, K. J. and N. D. Mundahl. 1984. Effect of intermittent flow regulation on temperature and macroinvertebrate distribution and abundance in a Michigan River. Freshwater Invertebrate Biology 3:21-25.

Lemkuhl, D. M. 1972. Changes in thermal regime as a cause of reduction in benthic fauna downstream of a reservoir. Journal of Fisheries Research Board of Canada 29(9):13291332.

Mackey, R. L. and D. J. Currie. The diversity-disturbance relationship: is it generally strong and peaked? Ecology 82(12):3479-3492.

Merritt, R. W. and K. W. Cummins (Editors). 1996. An introduction to the aquatic insects of North America. $3^{\text {rd }}$ edition. Kendall/Hunt Publishing Co., Dubuque, Iowa.

Munn, M. D. and M. A. Brusven. 2004. The influence of Dworshak Dam on epilithic community metabolism in the Clearwater River, U.S.A. Hydrobiologia 513:121-127.

Paller M. H. and B. M. Saul. 1996. Effects of temperature gradients resulting from reservoir discharge on Dorosoma capedianum spawning in the Savannah River. Environmental Biology Fish 45: 151-160.

Peckarsky, B. L., P. R. Fraissinet, M. A. Penton, and D. J. Conklin. 1990. Freshwater macroinvertebrates of North-eastern North America. Cornell University Press, Ithaca, New York. 
Poff, N. L., and D. D. Hart. 2002. How Dams Vary and Why It Matters for the Emerging Science of Dam Removal. BioScience 52(8):659-668.

Preece R. M. and H. A. Jones. 2002. The effect of Keepit Dam on the temperature regime of the Namoi River, Australia. River Research and Applications 18: 397-414.

Rader, R. B., N. J. Voelz, and J. V. Ward. 2007. Post-flood recovery of a macroinvertebrate community in a regulated river: resilience of an anthropogenically altered ecosystem. Restoration Ecology 16:24-33.

Rader, R. B. and J. V. Ward. 1988. Influence of regulations on environmental conditions and the macroinvertebrate community in the upper Colorado River. Regulated Rivers: Research and Management 2: 597-618.

Rice, S. P., M. T. Greenwood, and C. B. Joyce. 2001. Tributaries, sediment sources, and the longitudinal organisation of macroinvertebrate fauna along river systems. Canadian Journal of Fisheries and Aquatic Sciences 58(4):824-840.

Roy, A. H., A. D. Rosemond, M. J. Paul, D. S. Leigh, and J. B. Wallace. 2003. Stream macroinvertebrate response to catchment urbanisation (Georgia, U.S.A.). Freshwater Biology 48(2):329-346.

Schnieder D.C. 2001. The rise of the concept of scale in ecology. Bioscience. 51(7):545-553.

Stanford, J., and J. V. Ward. 2001. Revisiting the serial discontinuity concept. Regulated Rivers: Research \& Management 17(4-5):303-310.

Stevens, L. E., J. P. Shannon, and D. W. Blinn. 1997. Colorado River benthic ecology in Grand Canyon, Arizona, USA: dam, tributary and geomorphological influences. Regulated Rivers: Research and Management 13:129-149.

Storey, A. W., D. H. Edward, and P. Gazey. 1991. Recovery of aquatic macroinvertebrate assemblages downstream of the Canning Dam, Western Australia. Regulated Rivers: Research and Management 6:213-224.

Sutherland W. J. ed. 2006. Ecological Census Techniques. $2^{\text {nd }}$ ed. Cambridge University Press. New York.

Valentin, S., J. G. Wasson, and M. Philippe. 1995. Effects of hydropower peaking on epilithon and invertebrate community trophic structure. Regulated Rivers: Research and Management 10:105-119.

Vannote, R.L., G.W. Minshall, K.W. Cummins, J.R. Sedell, and C.E. Cushing. 1980. The river continuum concept. Canadian Journal of Fisheries and Aquaculture Science 37:130-137. 
Voelz, N., and Ward. 1991. Biotic responses along the recovery gradient of a regulated stream. Canadian Journal of Fisheries and Aquatic Sciences 48(12).

Ward, J. V. 1982. Ecological aspects of stream regulation: responses in downstream lotic reaches. Water Pollution Management Review 2:1-26.

Ward, J. V. and J. A. Stanford. 1979. Ecological Factors Controlling Stream Zoobenthos with Emphasis on Thermal Modification of Regulated Streams. In The Ecology of Regulated Streams, Ward, J. V. and J. A. Stanford (eds). Plenum Press: New York; 35-55.

Wiens J.A. 1989. Spatial scaling in ecology. Functional Ecology. 3:385-397.

Wood, S. 2006. Generalized additive models: an introduction with R. Chapman and Hall, Boca Raton, Florida.

Ward J.V. and J.A. Stanford. 1983. The serial discontinuity concept of lotic eco- systems. In Dynamics of Lotic Ecosystems, Fontaine TD, Bartell SM (eds). Ann Arbor Scientific Publishers: Ann Arbor, MI; 29-42.

Ward, J. V., K. Tockner, U. Uehlinger, and F. Malard. 2001. Understanding natural patterns and processes in river corridors as the basis for effective river restoration. Regulated Rivers: Research \& Management 17(4 5):311-323.

Yeager, B. L. 1993. Dams. Pages 57 - 113. In C. F. Bryan and D. A. Rutherford, editors. Impacts on warmwater streams: Guidelines for evaluation, Second Edition. Southern Division, American Fisheries Society, Little Rock, Arkansas.

Zhang, Y., B. Malmqvist, and G. Englund. 1998. Ecological processes affecting community structure of blackfly larvae in regulated and unregulated rivers: a regional study. Journal of Applied Ecology 35:367-686.

Zuur, A. F., E. N. Leno, N. J. Walker, A. A. Saveliev, and G. M. Smith. 2009. Mixed effects models and extensions in ecology with R. $1^{\text {st }}$ edition. Springer, New York. 
Table 1. Characteristics of the seven streams sampled including dam release type, year of dam completion, dam height (m), and drainage area (ha).

\begin{tabular}{rllcccc}
\hline \multicolumn{1}{l|}{ Year } & Stream & State & $\begin{array}{c}\text { Dam Release } \\
\text { Type }\end{array}$ & $\begin{array}{c}\text { Year } \\
\text { Completed }\end{array}$ & $\begin{array}{c}\text { Dam Height (m) } \\
\text { Drainage Area (ha) }\end{array}$ \\
\hline $2012 / 2013$ & New Creek & West Virginia & Reference & Reference & Reference & 8236 \\
2012 & Savage River & Maryland & Hypolimnetic & 1952 & 56 & 27194 \\
$2012 / 2013$ & Evitts Creek & Pennsylvania & Epilimnetic & 1913 & 26 & 13467 \\
$2012 / 2013$ & Yellow Creek & Pennsylvania & Epilimnetic & 1969 & 19 & 13597 \\
$2012 / 2013$ & Two Lick Creek & Pennsylvania & Hypolimnetic & 1968 & 35 & 19165 \\
$2012 / 2013$ & Beaver Run & Pennsylvania & Hypolimnetic & 1952 & 28 & 11188 \\
$2012 / 2013$ & Big Walnut Creek & Ohio & Epilimnetic & 1956 & 26 & 49208 \\
2013 & East Branch of the Clarion & Pennsylvania & Hypolimnetic & 1952 & 56 & 18647 \\
\hline
\end{tabular}


Table 2. Generalized additive model summary statistics for Richness, Diversity, and Abundance and habitat variables pertaining to the Serial Discontinuity Concept. Bold values indicate the model with the best fit. Rich=Richness, Div=Diversity, Abun=Abundance, Crs=Coarseness, SubDiv=Substrate Diversity, HabDiv=Habitat Diversity, Temp=Temperature, Cond=Conductivity, DO=Dissolved Oxygen, Emb=Embeddedness.

\begin{tabular}{|c|c|c|c|c|c|c|c|c|c|c|c|c|c|c|c|}
\hline Models & & Rich & Div & Abun & Crs & Sub Div & Hab Div & pH & Temp & Cond & DO & Width & Depth & Flow & Emb \\
\hline \multicolumn{16}{|l|}{ Linear Models } \\
\hline \multirow[t]{2}{*}{$\sim$ Distance } & $\mathrm{R}^{2}$ & 0.13 & 0.07 & 0.01 & 0.005 & 0.01 & -0.005 & 0.03 & 0.02 & -0.003 & -0.002 & 0.01 & -0.004 & -0.005 & $0 . \overline{-} 05$ \\
\hline & $\mathrm{P}$ & $<0.05$ & $<0.05$ & 0.09 & 0.84 & 0.07 & 0.84 & $<0.05$ & $<0.05$ & 0.55 & 0.5 & 0.09 & 0.59 & 0.92 & 0.78 \\
\hline \multicolumn{16}{|l|}{ Generalized Additive Models } \\
\hline \multirow[t]{2}{*}{$\sim \mathrm{s}($ Distance $)$} & $\mathrm{R}^{2}$ & 0.16 & 0.09 & 0.06 & 0.03 & 0.09 & 0.03 & 0.03 & 0.02 & $<-0.001$ & $<-0.001$ & 0.1 & 0.05 & $<-0.001$ & 0.01 \\
\hline & $P$ & $<0.05$ & $<0.05$ & $<0.05$ & 0.16 & $<0.05$ & 0.16 & 0.05 & 0.08 & 1 & 1 & $<0.05$ & $<0.05$ & 1 & 0.33 \\
\hline \multirow[t]{2}{*}{$\sim \mathrm{s}($ Distance $)+\mathrm{f}($ Dam Type $)$} & $\mathrm{R}^{2}$ & 0.15 & 0.15 & 0.07 & 0.07 & 0.09 & 0.07 & 0.42 & 0.61 & -0.004 & 0.5 & 0.1 & 0.05 & 0.01 & 0.04 \\
\hline & $P$ & $<0.05$ & $<0.05$ & $<0.05$ & 0.14 & $<0.05$ & 0.14 & $<0.05$ & $<0.05$ & 1 & 1 & $<0.05$ & $<0.05$ & 1 & 0.31 \\
\hline \multirow[t]{2}{*}{$\sim \mathrm{s}($ Distance $)+\mathrm{f}($ Stream $)$} & $\mathrm{R}^{2}$ & 0.39 & 0.36 & 0.24 & 0.36 & 0.34 & 0.18 & 0.69 & 0.83 & 0.67 & 0.68 & 0.38 & 0.3 & 0.34 & 0.14 \\
\hline & $\mathrm{P}$ & $<0.05$ & $<0.05$ & $<0.05$ & $<0.05$ & $<0.05$ & 0.43 & $<0.05$ & $<0.05$ & 0.9 & 0.56 & $<0.05$ & $<0.05$ & 1 & 0.38 \\
\hline
\end{tabular}


Table 3. Generalized additive model summary statistics for the best model to explain abundance, richness, and diversity using habitat variables listed in table $2 . \mathrm{R}^{2}$ and deviance explained are for the model as a whole. Dist=Distance from dam, \%For=\% forested area within a subwatershed, $\% \mathrm{Dev}=\%$ developed area within a subwatershed, Temp=Temperature, $\mathrm{f}($ Year $)=$ year as a factor.

\begin{tabular}{|c|c|c|c|c|c|c|c|c|c|c|c|c|}
\hline \multicolumn{4}{|c|}{ Overall Model } & Coarse & Depth & Dist & DO & Flow & $\begin{array}{c}\% \\
\text { For }\end{array}$ & $\begin{array}{c}\% \\
\text { Dev }\end{array}$ & Temp & f(Year) \\
\hline \multicolumn{13}{|l|}{ Abundance } \\
\hline & $\mathrm{R}^{2}$ & 0.38 & $\mathrm{P}$ & -- & $<0.01$ & -- & $<0.05$ & $<0.01$ & $<0.01$ & -- & $<0.01$ & -- \\
\hline & $\begin{array}{l}\text { Deviance } \\
\text { Explained }\end{array}$ & $43 \%$ & & & & & & & & & & \\
\hline \multicolumn{13}{|l|}{ Richness } \\
\hline & $\mathrm{R}^{2}$ & 0.68 & $\mathrm{P}$ & $<0.01$ & -- & $<0.01$ & $<0.01$ & & $<0.01$ & -- & $<0.01$ & $<0.01$ \\
\hline & $\begin{array}{l}\text { Deviance } \\
\text { Explained }\end{array}$ & $71 \%$ & & & & & & & & & & \\
\hline \multicolumn{13}{|l|}{ Diversity } \\
\hline & $\mathrm{R}^{2}$ & 0.59 & $\mathrm{P}$ & $<0.01$ & -- & $<0.01$ & $<0.01$ & & $<0.01$ & $<0.01$ & $<0.01$ & -- \\
\hline & $\begin{array}{l}\text { Deviance } \\
\text { Explained }\end{array}$ & $63 \%$ & & & & & & & & & & \\
\hline
\end{tabular}




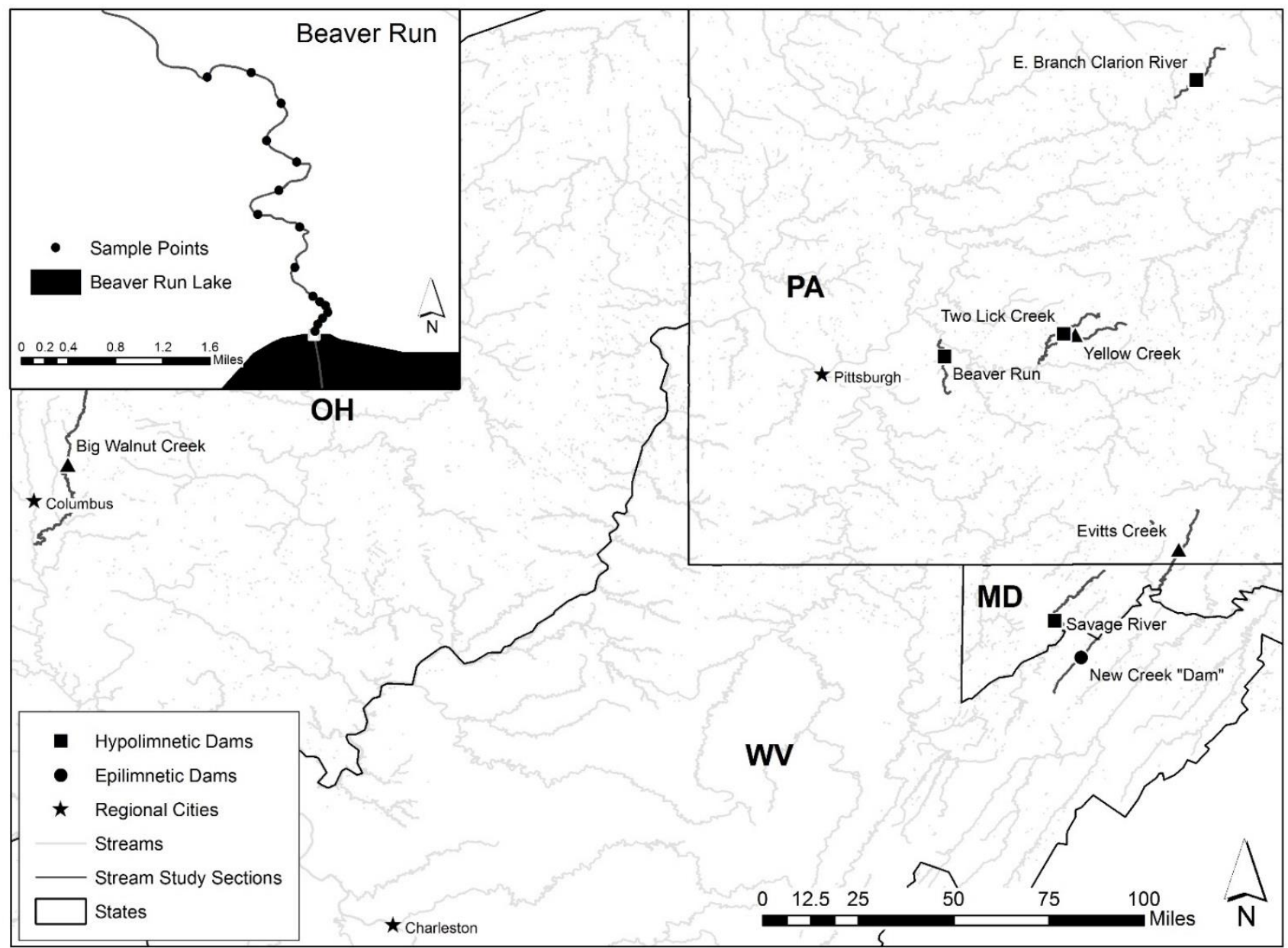

Figure 1. Location of study dams and streams. Dams with hypolimnetic releases are designated by solid squares, while solid circles represent dams with epilimnetic releases. The inset map displays the spacing of sample sites along the stream continuum below dams using Beaver Run as an example. 

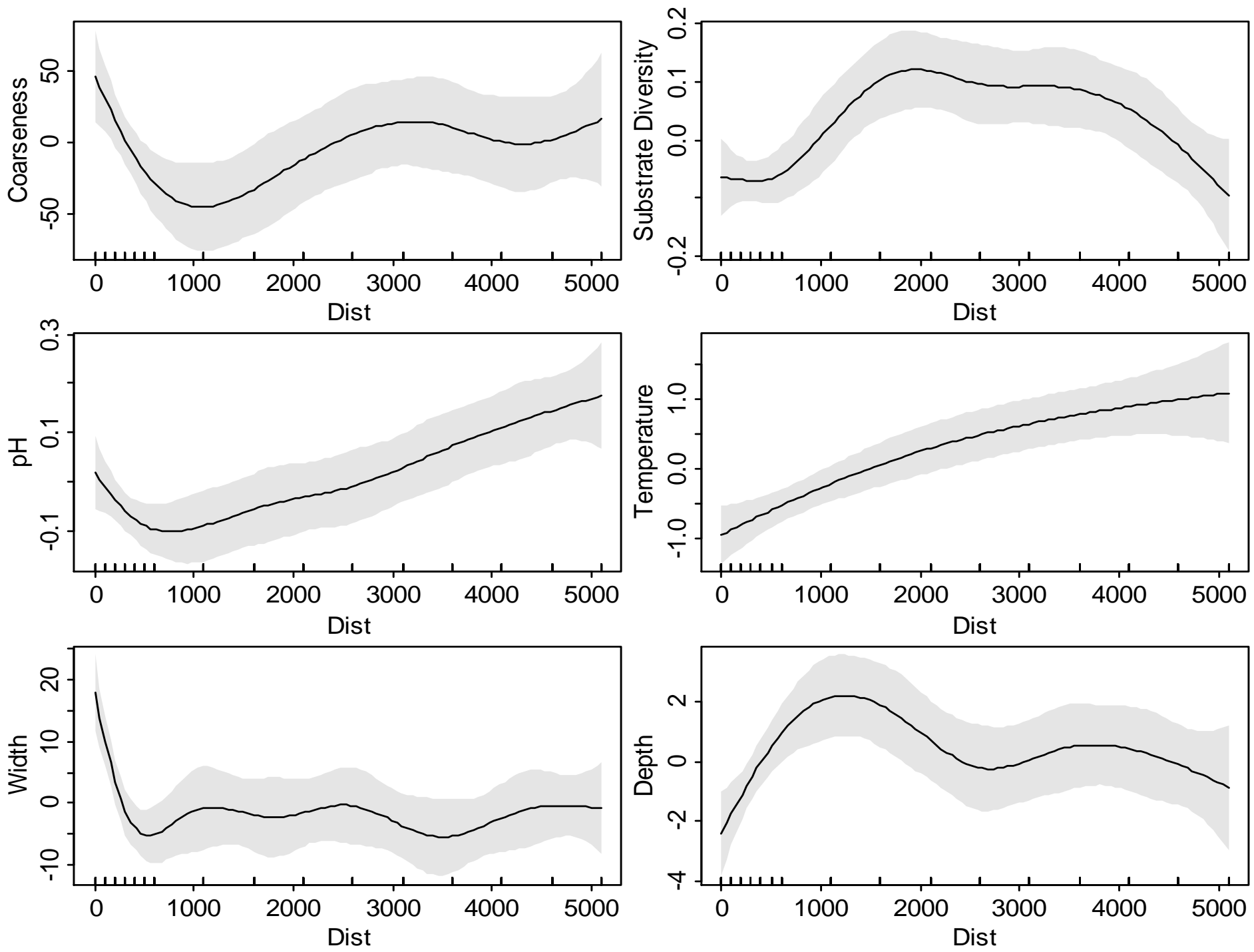

Figure 2. Estimated habitat variables along the longitudinal gradient below study dams with approximate 95\% pointwise confidence intervals given by the shaded regions. Variables are scaled and mean-centered. 

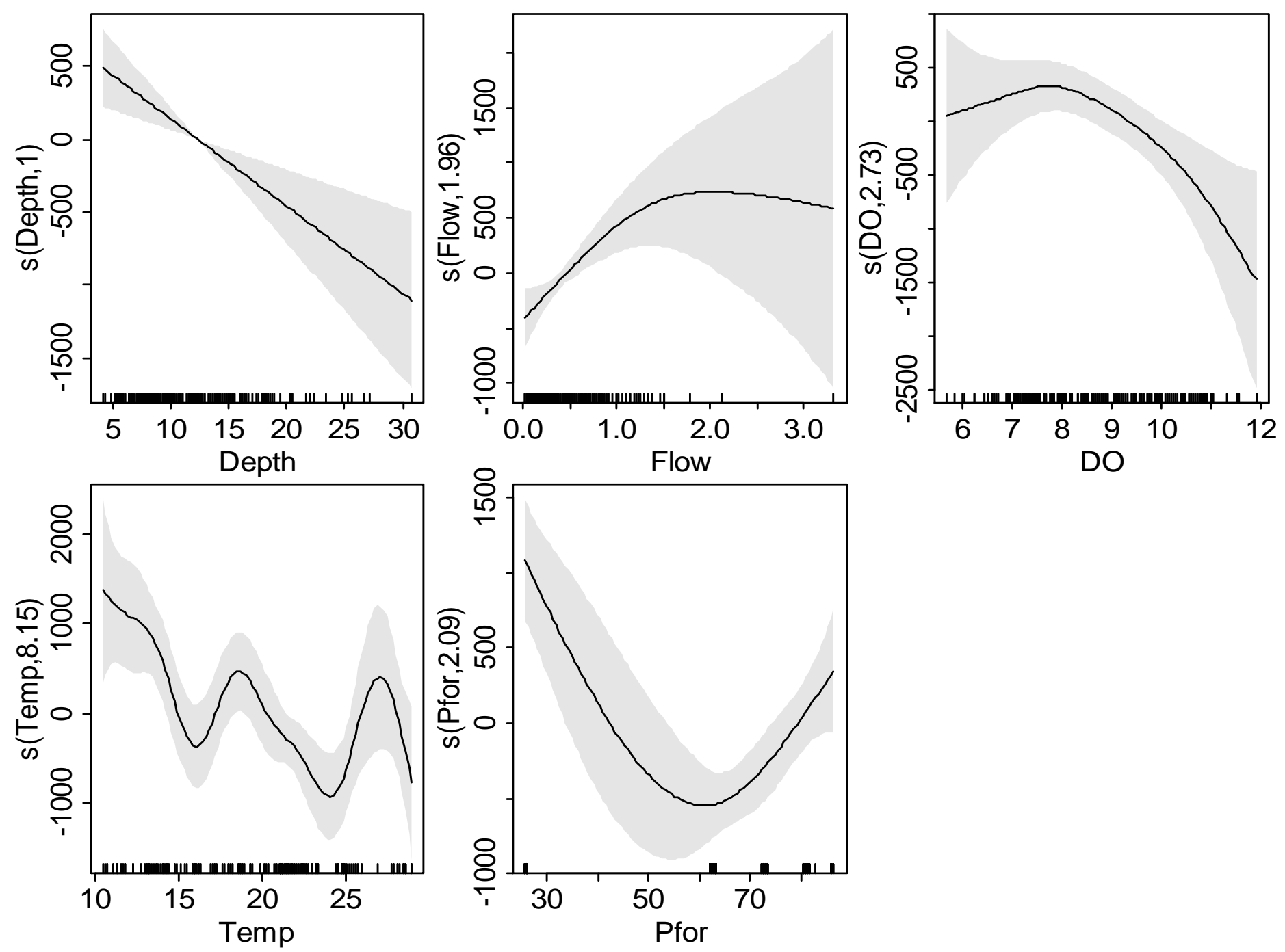

Figure 3. Estimated influence of habitat variables on abundance of benthic invertebrates from our model (see text and table 3). Approximate $95 \%$ pointwise confidence intervals are given by the shaded regions. Variables displayed were significant in the model and are scaled and mean-centered. 

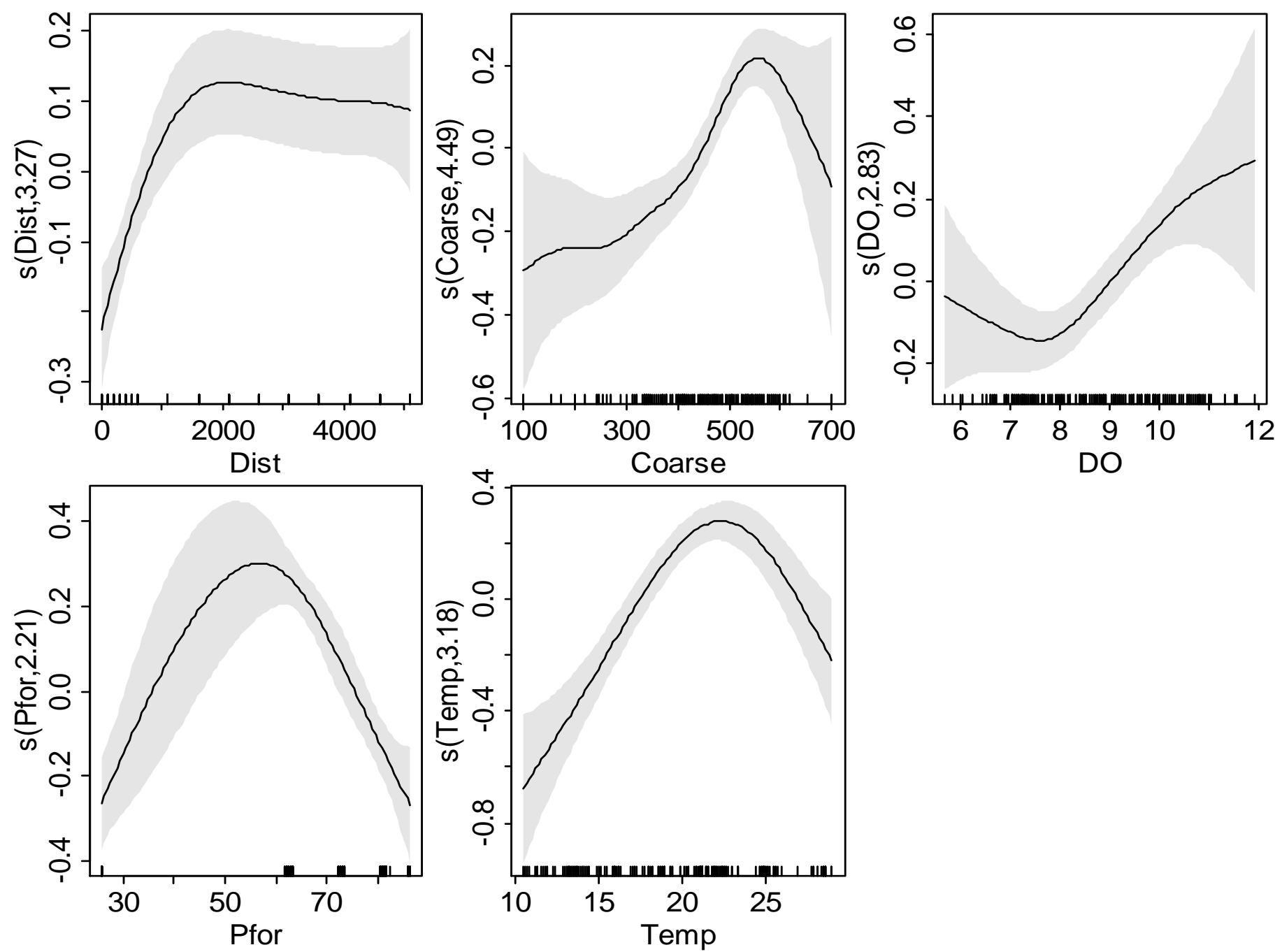

Figure 4. Estimated influence of habitat variables on taxonomic richness of benthic invertebrates from our model (see text and table 3). Approximate $95 \%$ pointwise confidence intervals are given by the shaded regions. Variables displayed were significant in the model and are scaled and mean-centered. 

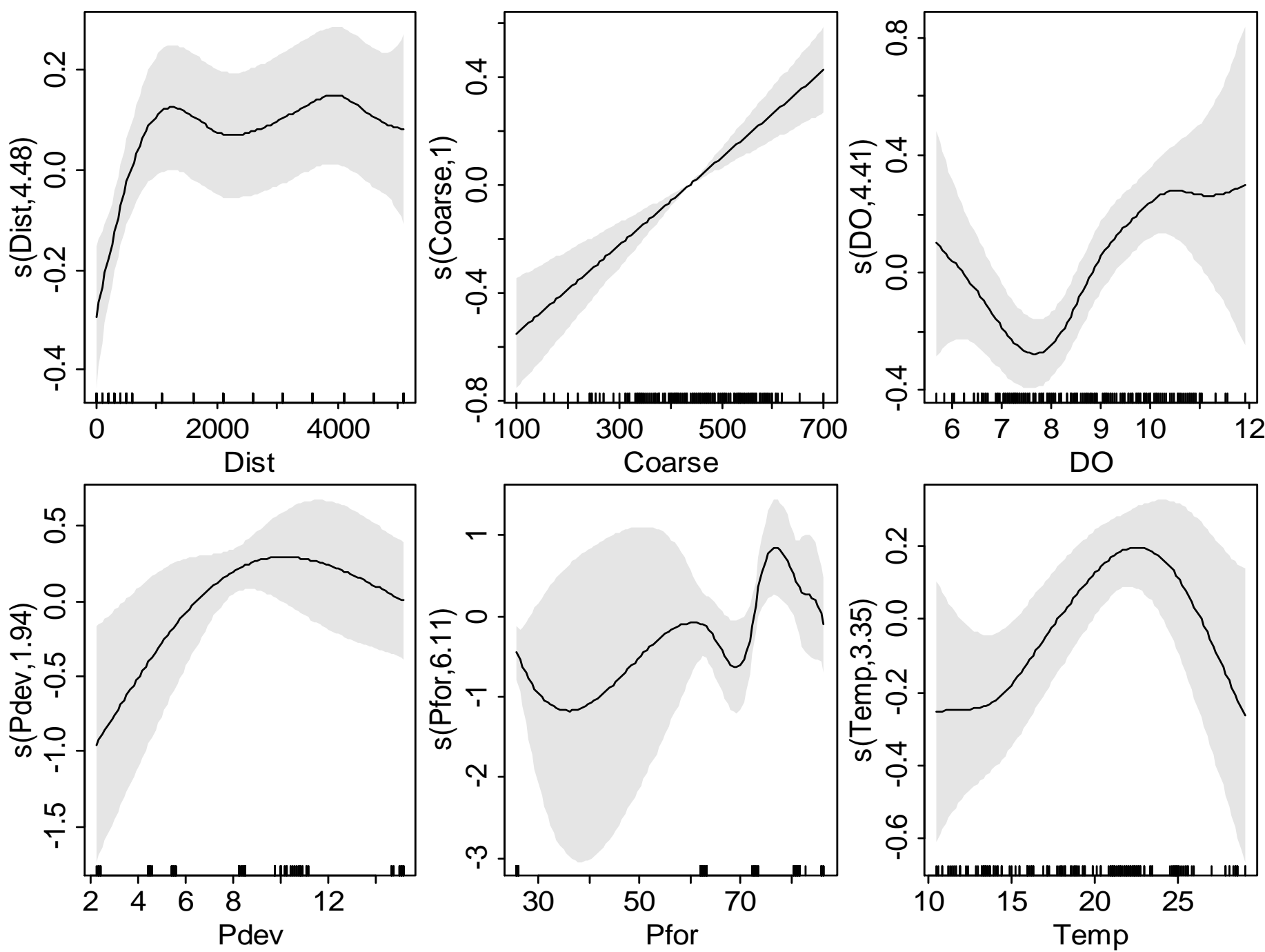

Figure 5. Estimated influence of habitat variables on diversity (Shannon) of benthic invertebrates from our model (see text and table 3). Approximate $95 \%$ pointwise confidence intervals are given by the shaded regions. Variables displayed were significant in the model and are scaled and mean-centered. 
Chapter 4. Identifying Impacts from Dams on Downstream Functional Groups and Community Structure of Aquatic Macroinvertebrates

\section{Abstract}

The influence of dams on downstream abiotic and biotic components of aquatic ecosystems has been studied extensively within the context of the River Continuum (RCC) and Serial Discontinuity Concepts (SDC). However, few of these studies have been performed in a systematic and spatially consistent manner to sufficiently address the question of how dams influence these important components along the stream continuum. This is especially true for macroinvertebrate functional groups. Here we systematically evaluated patterns of changes in abiotic and biotic (e.g., macroinvertebrate functional groups) components of aquatic systems along the longitudinal gradient below dams at two spatial scales and in systems of both epilimnetic and hypolimnetic stream releases, as compared to an undammed reference stream. Generalized additive models indicated that genus richness, functional richness, tolerance, dispersal, percent 5 dominant genera, EPT, and GLIMPSS were lower in dammed streams than in our reference stream. Genus and functional richness, percent 5 dominant genera, EPT, and GLIMPSS all increased as distance from dams increased while they remained relatively consistent within our reference stream. Tolerance and dispersal changed with distance from dams in dammed streams but showed little change in our reference stream. Percent composition of functional groups were different between dammed and reference streams and in dammed streams percent composition changed with increasing distance from dams, yet they remained relatively stable in our reference stream. Genus and functional richness also exhibited two distinct gradients within the 5,100-m that we sampled below dams where a short, rapidly changing gradient existed immediately below dams to approximately 2,000-m, followed by a 
more gradual steadily increasing gradient that appeared to continue beyond our most distant sampling location below dams (i.e., 5,100-m). Eighty five percent of our measured abiotic variables below dams had higher $\mathrm{r}$ values where curvilinear relationships were modeled as compared to linear relationships; whereas only $46 \%$ of the biotic variables had higher $\mathrm{r}$ values with curvilinear models. Nonmetric multidimensional scaling (NMDS) confirmed our GAM results indicating benthic macroinvertebrates below dams show structural changes along the stream continuum. Our findings generally agreed with the SDC but future studies should aim to sample in a spatially systematic manner, as this will improve our understanding of how dams influence abiotic and biotic components of aquatic systems. Additionally, further studies are required to understand the two recovery gradients that exist below dams and the extent of dam influences along the stream continuum. 


\section{Introduction}

Changes along the longitudinal gradients that exist in river ecosystems were

conceptualized by Vannote et al. (1980) in their well-known and well-studied River Continuum Concept (RCC), where they proposed the physical, chemical, and biological components of rivers made gradual but largely predictable changes as waterways coursed from headwaters to sea. While theoretical understanding of changes along gradients is often aided with such broad conceptual basis it is often useful when considering changes along a gradient to consider scale in order to gain a deeper understanding of the underlying factors influencing changes along these gradients. Scale refers to the extent relative to the size of the sampling unit of a variable of interests in both space and time and has three sub-components: extent, grain, and lag (Weins, 1989; Schieder, 2001; Southerland, 2006). The predictability of the changes along the river continuum may be especially noticeable at coarse scale where grain and lag are large and where one may compare, for example, headwater streams, mid-order streams, and high-order streams. However, as scale is reduced, these changes may not appear to follow the RCC and instead appear somewhat random (Ward et al., 2001). As scale is reduced, grain and lag should also be reduced in order to effectively evaluate changes along such gradients as proposed by the RCC.

Within the context of the RCC, Ward and Stanford (1983) developed the Serial Discontinuity Concept (SDC) as a means to understand how anthropogenic disturbances, of which dams are likely the most influential, modified the abiotic and biotic components of lotic ecosystems. The SDC is a broad theoretical construct where placement of hypothetical dams with hypolimnetic releases at varying locations along a river continuum, the effects of which were envisaged on both abiotic and biotic components of lotic ecosystems in both an upstream and downstream manner (Ward and Stanford 1983, Stanford and Ward 2001). Since the 
inception of the SDC such changes have been shown to adversely influence biological components (e.g., fish, aquatic macroinvertebrates, etc.) of lotic communities (Katano, 2009; Freedman et al., 2013; Ellis and Jones, 2014). Empirical approaches to understanding the nature of these biological recovery gradients below such disturbances along the river continuum are needed (Stanford and Ward, 2001; Ellis and Jones, 2014; Hanks, 2016). Adequate assessment of biological and abiotic recovery gradients should include appropriate scale, including considerations of extent, grain, and lag.

Sediment loads and composition have been shown to be disrupted by dams as they act to trap sediment up stream, thereby creating sediment starved areas downstream which exhibit abnormal sediment composition characteristics (Graf, 1999; Poff and Hart, 2002; Jones, 2010). Substrate near dams has been shown to be coarse (Storey et al., 1991; Cortes et al., 2002; Katano et al., 2009; Hanks, 2016), yet relatively homogenous (Hanks, 2016) due to rip-rap type habitat used to protect the streambed from erosion dominating the near dam habitat. Beyond the initial use of rip-rap to stabilize streambeds, and due to sediment starvation, streambeds and banks can become armored as they become eroded due to dams restricting the replacement of key portions of the sediment loads (Jones, 2010).

Land use practices have been shown to influence both biotic and abiotic components of aquatic ecosystems (Storey et al., 1991; Cortes et al., 2002; Allan, 2004; Katano et al., 2009). Agricultural land use in the Saginaw River basin of central Michigan was found to be an effective predictor of water quality (Johnson et al., 1997). Roy et al. (2003) found that urbanization and forested landcover had opposite effects on various benthic macroinvertebrate indices, where better quality macroinvertebrate communities were associated with higher forested land use and urbanization resulted in high proportions of tolerant taxa and reduced biotic 
diversity. Land use practices have the potential to influence water quality, in stream habitat, as well as biota and should be considered in studies of the SDC.

Dam size and relative location along the river continuum may differentially affect downstream physicochemical and biological attributes (Ward and Stanford, 1983) and should be considered when evaluating the impacts of dams on aquatic ecosystems. Waters released hypolimnetically or epilimnetically likely influence downstream biotic and abiotic components downstream of dams in different ways (Yeager, 1993). Research of dam influences on physicochemical variables and benthic macroinvertebrate communities within the context of the SDC has been performed on epilimnetic releases (Kraft and Mundahl, 1984; Mendoza-Lera et al., 2012), hypolimnetic releases (Lemkuhl, 1972; Gore, 1977; Rader and Ward, 1988; Volz and Ward, 1990; Voelz and Ward, 1991; Saltviet et al., 1994; Valentin et al., 1995; Camargo and Voelz, 1996; Stevens et al., 1997; Casas et al., 2000; Cortes et al., 2002; Jakob et al., 2003; Rader et al., 2007; Maynard and Lane 2012, Ellis and Jones, 2014), and both epilimnetic and hypolimnetic releases (Katano et al., 2009). The rate at which temperature changes as the distance from dam increases is dependent on multiple factors (e.g., the number, size, and temperature of tributaries, latitude, canopy cover, etc.) (Rice et al., 2001). For a full discussion of the research that has been performed on the SDC see Ellis and Jones (2013). While multiple studies have been carried out on the effects of dams on downstream aquatic systems only Ellis and Jones (2014) and Hanks (2016) have been carried out in an empirical fashion. Hanks (2016) is the only study we found that did so with the inclusion of both epilimnetic and hypolimnetic releases where a systematic sampling protocol was followed whereby sample sites were located at the same distance below dams and below a hypothetical dam on a reference stream, as we did here. 
The relationship between benthic macroinvertebrates and aquatic environmental conditions has been largely studied in both natural rivers and in disturbed systems. However, we found only two additional studies that evaluated the SDC in an empirical manner (see Ellis and Jones, 2014; Hanks, 2016) and only one that did so in a systematic manner (see Hanks, 2016). Therefore, we aimed to empirically and systematically evaluate the SDC in regards to 1) various commonly used benthic macroinvertebrate metrics (i.e., richness, functional richness, GLIMPSS, etc.) and influential abiotic variables (i.e., in stream [substrate, flow, etc.], land use, and water quality); 2) changes in functional relationships (i.e., macroinvertebrate functional feeding groups, tolerance, and dispersal) and influential abiotic variables. We hypothesize that, congruent with the SDC, the aforementioned response variables will exhibit a strong relationship with increasing distance from dams.

\section{Materials and Methods}

Study Sites and Site Selection

Sampling occurred in six dammed streams (Beaver Run, Pennsylvania; Big Walnut Creek, Ohio; East Branch of the Clarion River, Pennsylvania; Evitts Creek, Pennsylvania; Savage River, Maryland; Two Lick Creek, Pennsylvania; Yellow Creek, Pennsylvania) and one reference stream (New Creek, West Virginia) during 2013 (Figure 1). New Creek was selected as a reference stream based on data from previous work (Hanks unpublished) where it had high richness and diversity and based on the fact that the stream is unimpounded within the near proximity of the study reach. New Creek (i.e., reference stream) was assigned a starting location (i.e., a hypothetical dam location) and sampled from that point downstream in the same fashion as our dammed sites. Dammed streams were comprised of three each of epilimnetic and 
hypolimnetic release types. Dams ranged in height from 19 to 56-m and their drainage area ranged from 11,188 to 49,208-ha. Sampling locations (distance below dams) within each stream were selected a priori. Beginning as close to the tailwaters of each dam as was safely possible (assigned zero distance) we sampled aquatic macroinvertebrates and physicochemical variables every $100-\mathrm{m}$ for the first $600-\mathrm{m}\left(\mathrm{N}_{100}=7\right)$, thereafter we sampled every $500-\mathrm{m}$ to $5,100-\mathrm{m}$ below the dam $\left(\mathrm{N}_{500}=8 ; \mathrm{N}_{\text {total }}=16\right.$ for each stream). Preliminary sampling indicated rapid changes macroinvertebrate richness and diversity at sites near dams and we therefore sampled at a finer spatial scale (every $100-\mathrm{m}$ ) near the dam as we felt there may be important changes within this short (600-m) distance from the dam. Due to logistical and resource constraints we decided to sample 5,100-m below dams to assess the discontinuity distance associated with each dam along the stream continuum.

\section{Sampling: Physicochemical habitat}

Microhabitat and water quality variables were measured at each sampling location concurrent with sampling for macroinvertebrates. Water quality variables (conductivity $(\mu \mathrm{S} / \mathrm{cm})$, dissolved oxygen $(\mathrm{mg} / \mathrm{L}), \mathrm{pH}$, and temperature $\left.\left({ }^{\circ} \mathrm{C}\right)\right)$ were recorded once at each sampling location $\left(\mathrm{N}_{\text {total }}=16\right.$ per stream) with a YSI meter (Yellow Springs Instruments computer module: 650MDS, Yellow Springs, Ohio). Channel and bankful widths were measured at five transects per sampling location (sixteen sampling locations per stream) and at five points along each transect width, depth, flow, percent embeddedness, and substrate were measured (400 point locations per stream). Flow measurements were recorded with a Marsh-McBirney flow meter (Marsh-McBirney Inc., Frederick, Maryland). At each point location 10 substrate measurements were recorded (4,000 substrate measurements per stream). Substrata were coded based on size 
class categories as follows: $1=$ bedrock $(>4000 \mathrm{~mm}), 2=$ fines $(<0.06 \mathrm{~mm}), 3=$ sand $(0.06-2$ $\mathrm{mm}), 4$ = fine gravel $(2-16 \mathrm{~mm}), 5=$ coarse gravel $(16-64 \mathrm{~mm}), 6=$ cobble $(64-250 \mathrm{~mm})$, and 7 $=$ boulder (250-4000 mm). Average substrate coarseness (Katano et al. 2009) at each sampling location was used in models and calculated as:

$$
\text { Coarseness }=\Sigma(\text { Size category code } x \% \text { of a given category at a given transect })
$$

Additionally, average substrate diversity (Shannon diversity) and overall habitat diversity (Shannon diversity for substrate, depth, and flow) was calculated for each site.

\section{Sampling: Landscape habitat variables}

Using spatial analyst functions in ArcMap 10.2.1 (Environmental Systems Research Institute, Redlands, California) we generated watersheds for each site on a respective stream. Landcover (from the 2011 National Landcover Dataset [NLCD]) attributes from each watershed were then subtracted serially in order to get the percent landcover type within each respective sub-watershed. We then combined landcover types into three categories (developed, forested, and agricultural/grassland) for analysis. We also calculated road density (i.e., density = (road length/sub-watershed area) x 100) as an additional method of calculated development within a sub-watershed. For each sampling location stream distance to nearest upstream and downstream tributary was measured in ArcMap 10.2.1 using the measure tool. 


\section{Sampling: Aquatic macroinvertebrates}

Benthic macroinvertebrates were sampled once at each sampling location during 2013 between mid-May and mid-June. At each sampling location, macroinvertebrates were sampled following the USEPA Rapid Bioassessment Protocols for wadeable streams (Barbour et al. 1999). Four $0.25-\mathrm{m}^{2}$ kick net samples were collected at each site from riffle habitat. All materials from each of the four samples were combined into a composite sample $\left(1-\mathrm{m}^{2}\right)$ and preserved in 95\% ethanol. In the laboratory samples were washed and filtered through a 0.25 mm sieve. All remaining organisms were subsampled randomly via a $200(+/-10 \%)$ organism fixed count (Barbour and Gerritsen, 1996) whereupon they were enumerated and identified to genus (when possible and excepting Chironomidae, Hirudinia, Hydracarina, and Oligochaetae) using keys found in Peckarsky et al. (1990) and Merritt and Cummins (1996). The count of individuals was scaled up to the original total sample $\left(1-\mathrm{m}^{2}\right)$ to give an estimate of the total number of individuals present in a given sample or per $1-\mathrm{m}^{2}$ of stream substrata.

Recent studies have indicated benefits of using genus level taxonomic data as opposed to family-level analyses (Baily et al. 2001, Pond and McMurray 2002) depending on the objectives of the project (Pond et al. 2008). In order to evaluate functional changes of the benthic macroinvertebrate community we used the USEPA Freshwater Biological Traits Database to calculate percentage of functional groups (collector filterer, collector gatherer, predator, herbivore, and shredder), percentage of tolerance groups (high, medium, and low), and percentage of dispersal groups (high and low) for modeling and for use in multidimensional analyses. Additionally, we used the US Environmental Protection Agency (EPA) Region 3 genus level multimetric index termed the Genus Level Index of Most Probably Stream Status (GLIMPSS) to calculate commonly used aquatic macroinvertebrate community metrics 
(GLIMPSS, EPT richness, and Percent 5 Dominant Taxa) for modeling and for use in multidimensional analyses.

\section{Statistical analysis}

We investigated changes in habitat variables along the stream gradient (i.e., distance below dams) using both linear models and Generalized Additive Models (GAMs). Generalized Additive Models allow for response variables to vary in a non-linear fashion as predictor variables change. Using factors in the models allow for these changes to vary with the factor term (e.g., release type). GAMs were applied using package mgcv (Wood 2006) in Program R and we applied a cubic regression spline with shrinkage, allowing for smoothing terms to have zero degrees of freedom (Zuur, 2009). Generalized additive models were developed using a smoothing term for distance and treating release type (hyperlimnetic and hypolimnetic) and individual streams as factors. For example:

functional richness $\approx \mathrm{s}($ distance $)$

functional richness $\approx \mathrm{s}($ distance $)+$ factor(release type $)$

functional richness $\approx \mathrm{s}($ distance $)+$ factor $($ stream $)$

Using GAMs we investigated the influence of habitat variables (in stream and landscape level) on genus richness, functional richness, Genus Level Index of Most Probable Stream Status (GLIMPSS), percent functional feeding groups, percent tolerance groups, percent dispersal groups below dams, EPT richness, and \% of the 5 most dominant taxa. We selected GLIMPSS, EPT richness, and \% 5 dominant taxa to use in our analysis as they are commonly referred to in the literature and we felt they were applicable to the objectives of our study. Prior to model 
development and selection we used variance inflation factors (VIF) to assess collinearity. Variables with a VIF greater than 3 were removed from subsequent models. There was a significant effect of release type (epilimnetic and hypolimnetic) on temperature while controlling for distance $(\mathrm{F}=291.87, \mathrm{P}<0.001)$. However, we decided to remove release type and retain temperature in our models because we felt that temperature contained release type information as well as additional non-categorical information (e.g., changes in temperature as distance from dams increased). Richness and functional richness were modeled with a Poisson distribution because they are count data; while GLIMPSS and the percentages were modeled using a Gaussian distribution. Final models are a result of fitting the data to all measured and calculated habitat variables, dropping nonsignificant terms and selecting the model with the lowest Akaike Information Criterion (AIC).

We used package metaMDS (Oksanen et al. 2016) for our nonmetric multidimensional scaling (NMDS) to summarize macroinvertebrate community structure among sites based on genus-level abundance data (Bray-Curtis distance metric). Nonmetric multidimensional scaling is an ordination technique that plots sites based on similarities in multidimensional space, where sites plotting closer together are more similar (McCune and Grace 2002). Abundance data were $\sqrt{ }(\mathrm{x})$-transformed and Wisconsin double-standardized prior to analysis (Oksanen et al. 2016). To ensure a final convergent solution with the lowest possible stress, we used multiple random starts. Nonmetric dimensional scaling solutions were determined in 2 through 5 dimensions; however, only the three dimensional solution was used as stress was not reduced substantially in higher dimensions. We correlated individual community metrics with the ordination through vector fitting in order to determine the multivariate structure of the NMDS solution. Vector lengths are representative of correlation strength to the ordination and distance represents the 
direction of most rapid change within the multivariate space. We overlaid individual stream sites on the ordination to allow us to investigate community level changes that were associated with stream type and distance from dam. All analyses were performed using the R language and environment for statistical computing (R Development Core Team, Vienna, Austria). We sought to statistically evaluate community similarity (i.e., genus level) between epilimnetic and hypolimnetic releases via Bray-Curtis community and environmental similarity indices using permutation analysis of variance (PERMANOVA) with Adonis in package vegan (Oksanen et al., 2016).

Additionally we correlated habitat variables to the NMDS ordination to assess the relative influence of habitat variables on macroinvertebrate community structure. Statistical strength $(r)$ of the linear vector of each variable was determined with 1000 permutations using the envfit function in package vegan (Oksanen et al. 2016). This approach enabled us to evaluate which habitat variables, functional groups, tolerance groups, dispersal groups, and commonly used macroinvertebrate community metrics most strongly correlated with changes in the macroinvertebrate community structure.

\section{Results}

From dammed streams there were a total of 96 samples taken and 16,613 individual macroinvertebrates collected; whereas in our reference stream there were 16 samples taken and 2,737 individuals collected. Genus richness ranged from 3 to 23 in dammed sites and 15 to 25 in our reference stream; while estimated abundances ranged from 95 to 5,800 individuals in dammed streams and 494 to 3,540 in our reference stream. In general richness and functional richness were higher in our reference stream than in dammed streams (Figure 2). Genus richness 
was consistently high in our reference stream and the slope was not significantly different from zero ( $\mathrm{p}=0.58$; Figure 2a); however, in our dammed streams richness was low at sites near dams and trended upwards throughout our study reaches ( $<<0.001$; Table 1 and Figure $2 a)$. In our reference stream functional richness consistently included all five functional feeding groups $(\mathrm{p}=0.34$; Figure $2 \mathrm{~b}$ ) while functional richness in our dammed streams was lowest near dams and increased to an average of nearly five (including all five functional feeding groups) at our most downstream sites ( $\mathrm{p}=0.02$; Table 1 and Figure $2 \mathrm{~b}$ ).

Using generalized additive models (GAMs) we were able to model and evaluate fifteen selected response variables (see Table 1 for list of response and explanatory variables) both using only distance from dam as an explanatory variable and also with the inclusion of eight additional explanatory variables (full model) (Table 1). Generalized additive models with a smoothing term for distance were significant $(\mathrm{p}<0.05)$ for nine of the fifteen variables modelled and ranged in Pearson correlations $(r)$ from 0.1 to 0.66 and in percent deviance explained from $0.1 \%$ to 42.8\%. When habitat variables were included in the model (with smoothing terms) along with smoothed distance, all of the models increased both $r$ values (ranging from 0.36 to 0.87 ) and percent deviance explained (ranging from $13.9 \%$ to $80.5 \%$ ) (Table 1). Distance was an important term $(\mathrm{p}<0.05)$ in all but three $(\% 5$ dominant taxa, $\%$ collector filterer richness, and $\%$ low dispersal) of the fifteen models for response variables. Percent forested area was an important variable in our models and it was significant in all models except for functional richness and \% high dispersal. Coarseness and \% developed area were moderately important as they were each significant in eight of the 15 models. Temperature, used as a surrogate for release type, was only significant in our EPT richness model (Table 1). 
Changes in the \% composition of the macroinvertebrate community which the various functional feeding groups comprised exhibited distinct changes in the collector gatherer, herbivore, and shredder feeding groups in dammed streams while collector filterers and predators remained relatively constant (Figure 3a). Whereas these variables remained relatively consistent along the longitudinal gradient of our reference stream (Figure 3b). The percentage of collector gatherers in dammed streams was high near dams (>40\%) and continually declined throughout the study reach. Around 4,500-m the percentage of collector gatherers in our dammed streams was similar to our reference stream but it continued to decline beyond this distance. The percentage of both herbivore and shredder feeding groups was lowest at sites near dams and increased throughout our study reach (Figure 3a). The percentage of shredders in our dammed streams was similar to that of our reference stream at approximately 3,000-m downstream of dams but continued to steadily increase beyond that distance. The percentage of herbivores in our dammed streams remained well below that of our reference stream despite increasing throughout the 5,100-m study reach.

Percent changes in the composition of macroinvertebrate dispersal ability (high versus low dispersers) were relatively consistent in our reference stream (Figure 3d) while both of these variables changed in dammed streams as distance from dam increased (Figure 3c). High dispersers were found in higher percentages than low dispersers at sites near the dam ( $55 \%$ and $\sim 45 \%$ respectively). High dispersers showed a gradual decline while low dispersers gradually increased until approximately 2,500-m below the dam where both reversed their trend to levels beyond what they were at near dam sites but similar to our reference stream (Figure 3c).

Percent changes for tolerance groups (high, medium, and low tolerance) in our reference stream were also relatively consistent across space (Figure 3f). In our dammed sites, genera with 
medium tolerance to poor water quality did decrease slightly but not significantly $(\mathrm{p}=0.21)$ but changes in high tolerance (high to low percent composition) and low tolerance (low to high percent composition) were significant ( $\mathrm{p}<0.001$ for both) along the distance gradient below dams (Figure 3e).

We evaluated how three commonly used metrics, EPT richness, GLIMPSS, and \% 5 dominant taxa, change as downstream distance from dam increases. None of the three metrics were statistically related to distance in our reference stream $(\mathrm{p}=0.77, \mathrm{p}=0.72$, and $\mathrm{p}=0.48$ for EPT richness, GLIMPSS, and \% 5 dominant taxa respectively; Figure 3h). In our dammed streams $\%$ 5 dominant taxa decreased as distance from dam increased; however this change was not significant $(\mathrm{p}=0.82)$. EPT richness and GLIMPSS both showed statistically significant increases with downstream distance from dams ( $\mathrm{p}<0.001$ and $\mathrm{p}<0.01$ respectively; Figure $3 \mathrm{~g}$ ).

NMDS ordination showed that macroinvertebrate community structure in our reference stream was distinctly different than those in our dammed streams, evidenced by the tight grouping of reference sites in Figure 4a. Communities in the dammed streams became more similar to our reference stream as distance from dam increased, as is displayed with the surface fit for distance Figure 4a along NMDS axis 1 (right to left). Increasing object size in Figure 4a indicate increasing richness, which was significantly related to distance from dam in our NMDS solution (Table 2). Only dammed sites with high richness that were far from dams overlapped with our reference sites (Figure 4a). NMDS ordination showed some separation of epilimnetic and hypolimnetic sites along NMDS axis 2 and community similarity was significantly different between these two types of releases (Adonis: $\mathrm{F}=3.14, \mathrm{P}<0.05, \mathrm{df}=1$ ).

Of the 21 habitat related variables (including distance) 18 were significantly related to our NMDS solution $(\mathrm{p} \leq 0.05)$ with either a linear or surface fit. Only fine gravel, bedrock, and 
flow were not significantly related to the NMDS solution and they each had low r values as well. Surface fitting improved the relationship of variables with the NMDS solution in 15 of the 18 significant variables (Table 2), indicating many of the variables that influence community structure in our study streams were not linear. Along NDMS axis 1 there was a strong gradient associated with $\%$ forested area and $\%$ grassland area and stream depth with the macroinvertebrate community. NMDS axis 2 was dominated by a temperature and dissolved oxygen gradient, indicating some differences exist between epilimnetic and hypolimnetic dam release types but the large overlap of epilimnetic and hypolimnetic sites in the ordination suggest these differences are likely not important in how the community is structured (Figure 4d).

Functional feeding groups, tolerance groups, and dispersal groups were all significantly related to our NMDS solution $(\mathrm{p} \leq 0.05)$. Unlike the habitat variables, only two (collector gatherer and high tolerance) of the 10 groups (functional, tolerance, and dispersal groups) showed improved relationships with surface fitting (Table 2). Of the commonly used metrics that we evaluated, all had high $\mathrm{r}$ values and were statistically significant $(\mathrm{p} \leq 0.05)$; additionally, surface fitting improved the relationship each had with the NMDS solution (Table 2). NMSD axis 1 displayed a strong tolerance gradient, where high tolerant taxa were more strongly associated with near dam sites and low tolerant taxa loaded heavily in the area most distant from dams and most similar to our reference stream (Figure $4 \mathrm{~b}$ ). There was a functional feeding group gradient along NMDS axis 1 where collector gatherers were associated with sites near dams and as distance from dam increased, functional feeding groups shifted towards higher percentages of herbivores and shredders as the community became more similar to that of our reference stream. NMDS axis 2 showed a dispersal gradient where high dispersal taxa were 
more associated with colder waters and near dam sites, while taxa with low dispersal ability were found in areas further away from dams and in warmer waters.

Our NMDS solution showed strong relationships with macroinvertebrate metrics and representative taxa. GLIMPSS, EPT richness, and \% 5 dominant taxa each had high $\mathrm{r}$ values $(>0.68)$ and were significantly related to our NMDS solution $(\mathrm{p} \leq 0.05)$. Surface fitting improved the relationship of each metric; albeit not substantially (Table 2). These metrics showed a strong gradient along NMDS axis 1 where GLIMPSS and EPT richness were both associated with increasing distance from dams and our reference stream sites (left side of Figure 4c) while \% 5 dominant taxa loaded more strongly with sites close to the dam and with colder waters. Additionally, we selected six taxa (Acentrella, Baetis, Caenis, Chironomidae, Crangonyx, and Simulium) to display in Figure 4c as they loaded strongly with NMDS axes 1 and 2. Acentrella and Baetis loaded heavily in negative space on axis 1 and were strongly associated with increased distance from dam and indicative of the reference condition. Crangonyx, Simulium, and Chironomidae were strongly associated with sites near dams. Simulium loaded in negative space along axis 2 where warmer water sites were located, while Chironomidae and Crangonyx were more strongly related to cold water sites. Caenis loaded heavily in warm water sites (negative space along axis 2) and in mid-distance sites along axis 1.

\section{Discussion}

Various studies have been performed on the effects of dams on downstream aquatic fauna (fish: Moog 1992; Parasiewicz et al. 1998; aquatic macroinvertebrates: Lemkuhl 1972; Gore 1977; Rader and Ward 1988; Ellis and Jones 2014; and habitat Harvey 1987; Thompson et al. 2011) within the context of the Serial Discontinuity Concept (SDC) (Ward and Stanford 1983). 
Previous studies have failed to systematically evaluate the SDC along the longitudinal continuum below dams (except see Ellis and Jones 2014); whereas we evaluated the SDC in six dammed streams and 16 sites per stream and at two spatial scales in a systematic, empirical, and consistent manner. Near dam sites were spaced 100-m apart for the first $600-\mathrm{m}$ allowing us to evaluate community changes immediately below dams. Thereafter, sites were spaced every 500$\mathrm{m}$ to 5,100-m downstream of each respective dam allowing for a more coarse scale evaluation of dam effects on benthic macroinvertebrate communities. Additionally, we made comparisons to a reference stream (a stream sans dam), which beginning at a hypothetical dam location, was sampled identically to our dammed streams. Also, half of our dammed sites had epilimnetic releases while the other half were hypolimnetic, which allowed us to evaluate differences that between these two thermal regimes. After removing the effect of the reference stream we used generalized additive models (GAMs) to evaluate how 15 response variables changed along the distance continuum below dams and also the influence of predictor variables (in addition to distance) on those response variables. Our results generally agreed with the SDC (Ward and Stanford 1983).

Richness, functional richness, GLIMPSS, and EPT richness all showed similar trends (rapid initial increase within the first $\sim 600$-m below dams followed by a more gradual rate of change beyond $~ 600-\mathrm{m}$ from dams) with increasing distance from the dam and each was significantly related to both distance from dam and substrate coarseness. Except for functional richness, which was only significantly related to \% development, each was also affected by some combination of the three measures of land use: \% forested area, \% development, and/or road density. Roy et al. (2003) also found significant influences of land use patterns on macroinvertebrate richness and other metrics, where development and forested landcover types 
acted in contrast to one another with improved macroinvertebrate communities associated with $\%$ forested lands. In our models, temperature was only significantly related to EPT richness. Also, while each of richness, functional richness, GLIMPSS, and EPT richness all increased below dams, none of the four response variables reached the level of our reference stream. Similar trends were seen in work done by Ellis and Jones (2014) where taxa richness increased rapidly below dams in two impounded streams in Canada, which contrasted with unimpounded streams where there was no increasing trend in richness.

The SDC (Ward and Stanford 1983) hypothesized that in mid-order streams richness would decrease immediately downstream of dams and thereafter increase as distance from dams increased. Congruent with the SDC we found genus richness, defined as the number of genera at each site, of benthic macroinvertebrates in dammed streams was lowest at near dam sites and increased with distance from dams. Richness increased at a greater rate in near dam sites (first 600-m below dams) than at sites more distant from dams (>600-m to 5,100-m). The increase in richness that occurred in our reference stream did not occur at the same rate nor were there two gradients (a short and steep "near dam" gradient and a more gradual long range gradient) as was the case in our dammed streams. Our findings corroborated other studies (Gore, 1977; Rader and Ward, 1988; Munn and Brusven, 1991; Volz and Ward, 1991; Stevens et al., 1997; Cortes et al., 2002; Munn and Brusven, 2004; Jones, 2011; Jones, 2013; Ellis and Jones, 2014) which have found a clear relationship between distance below dams and richness. In our GAMs, along with distance, genus richness in our study was significantly influenced by substrate coarseness, $\%$ forested area, and road density. Areas with coarse substrate were associated with higher richness. Substrate coarseness can be important in that it allows for greater habitat heterogeneity and thereby has the potential to support a greater number of taxa (Katano et al. 2009). High 
percent forest and moderate road density were related to higher richness. Heavily forested areas are likely less disturbed and are typical of catchments with good water quality. Moderate road density may create some amount of disturbance, creating opportunities for taxa that are tolerant of disturbance to colonize streams without much negative influence on taxa that are intolerant (Townsend et al. 1997). Roy et al. (2003) found that in an urbanized catchment in Georgia macroinvertebrates responded differentially to varying levels of a land use gradient. We suggest that in addition to dam impacts on in stream habitat such as substrate coarseness, land use practices are important factors (e.g., increased sedimentation due to agricultural practices, etc.) in controlling macroinvertebrate richness and as distance from dam increases these anthropogenic influences across the landscape may become more influential than those created by the dam. However, the two (dam impacts and other land use practices) likely act in synergy with one another as they influence aquatic fauna.

Structural changes in functional groups in stream macroinvertebrates can result in modification of ecosystem function and services (Wilson, 1992; Palmer et al., 1997; Covich et al., 1999). We found a reduction in the number of functional feeding groups that were present in streams at near dam sites. Richness of functional feeding groups increased with distance from dam, while functional feeding group richness showed no relationship with distance in our reference stream. As was the case with genus richness, functional feeding group richness was related to distance and substrate coarseness. Functional feeding group richness was also related to land use but instead of \% forested area and road density being important variables, only \% development was significantly related to functional feeding group richness in our GAMs for functional richness. Again in support of the intermediate disturbance hypothesis and as was the 
case with genus richness, areas with moderate disturbance ( $\sim 6 \%$ developed area) also had the highest levels of functional feeing group richness.

GAMs for GLIMPSS scores only captured $13 \%$ of the deviance when using just distance as an explanatory variable but $80.5 \%$ when including additional explanatory variables (substrate coarseness, distance, $\%$ forested area, and $\%$ development were statistically significant in our model). GLIMPSS in our dammed streams continually increased with distance from dam and were substantially lower than those of our reference stream. A GLIMPSS score of $<52$ indicates biological impairment and while our reference stream had values below this indicator level $(\bar{x}=46.5)$ our dammed streams ranged from 20.4 at sites near dams to 33.2 at sites farthest from dams. These low GLIMPSS values suggest that while macroinvertebrate communities are greatly impacted directly below dams and while the communities continually improve downstream of dams, dams contribute to biological impairment beyond 5,100-m.

EPT richness, in our dammed streams, was lowest at near dam sites and increased with increasing distance from dams. The GAM using only distance as an explanatory variable for EPT richness explained $25.4 \%$ of the deviance in the data but increased to $70.4 \%$ when additional explanatory variables were added (coarseness, $\%$ forest, $\%$ development, and temperature were statistically significant in our model). Other than temperature being significant in our GAM, EPT richness responded similarly to richness, functional richness, and GLIMPSS in that there was an effect of both instream habitat and land use practices that were influential. EPT richness was the only one of our response variables where temperature was significant in our GAM. EPT richness was higher in streams with hyperlimnetic dam releases $(\bar{x}=7.1 \mathrm{sd}=3.9)$ than those with hypolimnetic releases $(\bar{x}=5.8 \mathrm{sd}=3.4)$ which may account for temperature being significant in our model; however, these differences were not significant ( $\mathrm{T}$ test: $\mathrm{p}=0.09, \mathrm{df}=47$ ). 
Additionally, EPT richness was lowest at both extremes of our temperatures gradient and highest between $18-24{ }^{\circ} \mathrm{C}$. Temperature in our streams with hypolimnetic releases increased with distance from dams and reached $18{ }^{\circ} \mathrm{C}$ at approximately 1,600-m downstream of dams and in our streams with hyperlimnetic releases temperature decreased and reached $24^{\circ} \mathrm{C}$ at approximately 2,000-m downstream of dams.

Our GAM with only distance as an explanatory variable for $\% 5$ dominant taxa only explained $0.1 \%$ of the deviance in the data, yet it did decrease below dams but in a linear and non-significant manner and it was higher than our reference stream. When explanatory variables, in addition to distance, were included in our model the deviance explained increased to $61.0 \%$. Explanatory variables that were significant were dissolved oxygen, $\%$ forested area, $\%$ development, and road density. Lower values of dissolved oxygen, higher \% developed area, and lower $\%$ forested resulted in higher $\% 5$ dominant taxa. Surprisingly, increased road density resulted in lower \% 5 dominant taxa.

Changes in functional feeding groups along the longitudinal continuum below dams existed for collector gatherers, herbivores, and shredders. Collector filterers and predators remained relatively consistent below dams and had similar values to those of our reference stream. Collector gatherers decreased with distance from dams and the GAM with only distance explained $18.5 \%$ of the deviance in the data; however, when additional explanatory variables were included (coarseness, depth, dissolved oxygen, flow, \% forested area, $\%$ development, and road density were all significant in addition to distance) the GAM was able to explain $61.2 \%$ of the deviance in the data set.

Herbivores exhibited a distinct increase as distance from dam increased but the GAM for herbivores was not significant $(\mathrm{p}=0.08)$ and only explained $6.5 \%$ of the deviance with distance 
alone as a predictor variable but the GAM with additional explanatory variables (in addition to distance, coarseness, dissolved oxygen, flow and \% forested area were significant) explained $64.1 \%$ of the deviance. The pattern for shredders was similar to that of herbivores in that they increased with distance from dam. The GAM for shredders with only distance explained $19.4 \%$ of the deviance while the GAM with additional explanatory variables (in addition to distance, only $\%$ forested area was significant) explained $36.7 \%$ of the deviance in the data. Ellis and Jones (2014) found filter feeders to be in high abundance at sites near dams. Only collector gatherers were found in high abundance in our sites near dams but they precipitously decreased with distance from dam.

Our results of changes in \% tolerance below dams suggest that dams may act in a similar fashion as other disturbances on the landscape (Roy et al., 2003; Cuffney et al., 2010; Bernhardt et al., 2012; Pond et al., 2014) in regards to the ability of variously tolerant taxa to occupy a given site. GAMs for \% tolerance indicated that genera with high and medium tolerance values were indicative of near dam sites ( 44\% each); whereas individuals with low tolerance only comprised about $12 \%$ of the taxonomic composition at sites closest to dams. Medium tolerant genera were relatively stable throughout the stream reach but did show a slight decrease with distance from dams. High and low tolerant taxa exhibited an inverse relationship where low tolerant genera increased and high tolerant genera decreased below dams. Impounded streams were in sharp contrast to our reference stream where \% tolerance was relatively stable throughout the study reach with low tolerant individuals consistently comprising $>45 \%$ of the taxa and high tolerant genera comprising $<22 \%$ of the taxa. Taxa that exhibit medium tolerance were consistently $>36 \%$ and $<41 \%$, which was similar to our reference stream. 
NMDS results suggested clear biotic and abiotic gradients that were associated with distance and progressed from near dam sites towards a reference condition. Additionally, NMDS results confirmed our results of modeling via GAMs. Near dam sites were dominated by collector gatherer macroinvertebrates that had high tolerance to perturbations (e.g., Crangonyx), while sites further from dams were dominated by shredders with medium to low tolerance (e.g., Acentrella and Baetis). The absence of shredders at near dam sites is likely a result of the absence of food materials (i.e., coarse particulate organic matter) due to dams disrupting sediment and nutrient transport (Rader and Ward, 1988). While taxonomic richness and diversity are often used as proxies for stream health, this may not be the case below impoundments, as tolerant taxa often dominate near dam sites and give way to increasingly more intolerant taxa downstream as habitat conditions improve (Ward and Stanford, 1979; Zhang, 1998; Ellis and Jones, 2015). High and low dispersers were also associated with this distance gradient (near to far respectively) but the relationship was not as strong. High values for EPT richness and GLIMPSS were also strongly associated with sites similar to a reference condition (i.e., far from dams), while \% five dominant taxa showed a strong relationship with near dam sites. In stream habitat variables (e.g., those associated with dam impacts), with the exception of depth, were less strongly related with near dam and distant from dam sites than were variables associated with land use practices (e.g., \% grassland and \% forested area respectively).

Ellis and Jones (2014) found that in impounded streams in Canada sites near dams had large substrate size and transitioned to smaller substrate as distance from dams increased. Hanks (2016) showed, through the use of GAMs, that while sites closest to dams were associated with larger substrate (i.e., higher coarseness) they also had lower values of substrate diversity. There was also a rapid change in both substrate size and diversity within the first 1,100-m below dams, 
where substrate size dropped rapidly and substrate diversity increased just as quickly. We believe that the smaller spatial scale of sampling near dams in the Hanks (2016) study afforded the present study a more complete understanding of changes in the biotic community along with the changes in the associated physicochemical variables. Thereby, and in contrast to the Ellis and Jones (2014) study, our sites near dams were dominated by fines and embedded substrate (sites predominantly beginning approximately 600-m downstream of dams) and transitioned to large, coarse substrate as distance from dam increased. In addition to the differences in spacing between our sampling sites and those of Ellis and Jones (2014), these differences may be at least in part due to the low levels of urbanization, development, and agricultural practices in their study streams relative to the streams we sampled in Pennsylvania and Ohio. In our study, it appears that dam influences extend only so far before land use practices are the most dominant factors influencing both physicochemical variables and biotic communities.

Invertebrate richness increased continuously with distance from dam within our 5,100-m stream reach and in congruence with what others have found (Gore, 1977; Ward and Stanford, 1983, Rader and Ward, 1988; Voelz and Ward, 1991; Stevens et al. 1997; Cortes et al. 2002; Ellis and Jones, 2014) appears to likely continue to increase beyond our sampled reach. Voelz and Ward (1991) and Ellis and Jones (2014) found three community types: near dam filter feeders, a more taxonomically diverse and even second community, and a third type where predators appear in the benthos. Environmental disturbances where strong gradients exist may result in studies reporting a Clemmentsian pattern of distinct aquatic communities due in large part to the scale at which sampling occurs (Weilhoefer and Pan, 2006). However, similar to what Merovich and Petty (2010) found, we suggest that if sampling is performed in a more continuous fashion, as we did, stream benthic macroinvertebrate communities will exhibit a more 
subdued and Gleasonian pattern where biotic community changes are not found in distinct stages but rather in continually evolving communities closely associated with equally smooth transitions of physicochemical variables.

\section{Conclusion}

We found only two other studies (Ellis and Jones, 2014; Hanks, 2016) that aimed to explicitly examine the SDC via field based research. As Ellis and Jones (2014) pointed out, this is surprising. The absence of such studies is also concerning since the US Army Corp of Engineers National Inventory of Dams reports 79,777 dams exist within the United States, Puerto Rico, and the US Virgin Islands, thereby creating a major disturbance in all major US watersheds. Knowledge of the impacts of dams on abiotic and biotic components of the aquatic (and terrestrial) ecosystems is paramount for successful management these systems (Jones, 2012; Ellis and Jones, 2013; Ellis and Jones, 2014, Hanks, 2016).

Many studies report thermal regime to strongly influence biotic communities; however, other than with EPT richness, temperature was not significant in our study. This may be in part due to low power (we sampled three hypolimnetic streams and three hyperlimnetic stream.) and further work should be performed to specifically evaluate whether or not differences exist between these two thermal regimes and if differences exist, what those differences are and the magnitude of those differences. It is clear that the influence of dams on substrate is a key driver of aquatic community structure and therefore function but what is unclear is the interaction of land use practices with explicit dam effects and how the biotic communities respond to such synergies. While this may be difficult to evaluate, we suggest future studies should attempt to tease apart these two factors influencing aquatic systems. In agreement with Ellis and Jones 
(2014) and Hanks (2016) that there appears to be two gradients that exist below dams: near dam effects (within the first $\sim 1,000-\mathrm{m}$ ) and those beyond $\sim 1,000-\mathrm{m}$. It may be that near dam effects are explicitly due to the dam and beginning at approximately 1,000-m below dams, land use practices become an important factor, but this needs to be explored further and formally tested.

Functional richness is an important component of healthy aquatic ecosystems and understanding how disturbances, including dams, influence functional richness is important for managers and basic ecologists alike. The inclusion of metrics such as GLIMPSS in future studies will aid in developing a complete understanding of the impact dams have on the quality of the macroinvertebrate community. In addition to continuing research to further understand the influence of dams within the context of the SDC, more work should be done in understanding how natural disturbances similar to dams (e.g., waterfalls-see Robinson and Rand, 2005) influence downstream aquatic systems. Such an approach will allow for reasonable expectations of physicochemical variables and biotic communities below impoundments.

Our results indicate tolerance and dispersal ability of macroinvertebrates are likely important drivers in which taxa are able to both colonize and persist areas near dams. High flow events can result in disturbed streambeds, leading to changes in aquatic macroinvertebrate communities (Bunn and Hughes, 1997). Such scouring flows are often contributing factors to substrate composition below dams (Jones, 2010). There may be a synergistic effect of these two macroinvertebrate classifications and this should be further studied.

This study is in general agreement with the SDC. Findings of the two other studies (Ellis and Jones, 2014; Hanks, 2016) which explicitly aimed to test the SDC state that in addition to the often cited long-distance recovery gradient, there is also a short, near dam recovery gradient, which should be incorporated into future studies related to the SDC. Continued efforts to 
explicitly test the SDC in a systematic manner across both space and time as well as making comparisons to a nearby reference condition will aid in the successful management of disturbed ecosystems. When possible research should include the influence of land use on aquatic habitat and biotic communities and further gains in understanding the synergy between dam influences and those of land use practices will aid in a more complete understanding of the SDC and how to best manage impounded systems. 


\section{References}

Allan, J. D. 2004. Landscapes and riverscapes: the influence of land use on stream ecosystems. Annual Review of Ecology, Evolution, and Systematics 35:257-284.

Bailey, R. C., R. H. Norris, and T. B. Reynoldson. 2001. Taxonomic resolution of benthic macroinvertebrate communities in bioassessments. Journal of the North American Benthological Society 20(2):280-286.

Barbour, M. T. and J. Gerritsen. 1996. Subsampling of benthic samples: a defense of the fixedcount method. Journal of the North American Benthological Society 15(3):386-391.

Barbour, M. T., J. Gerritsen, B. D. Snyder, and J. B. Stribling. 1999. Rapid bioassessement protocols for use in streams and wadeable rivers: periphyton, benthic macroinvertebrates and fish. $2^{\text {nd }}$ edition. EPA 841-B-022. Office of Water, US Environmental Protection Agency, Washington, DC.

Bernhardt, E. S., B. D. Lutz, R. S. King, J. P. Fay, C. E. Carter, A. M. Helton, D. Campagna, and J. Amos. How many mountains can we mine? Assessing the regional degradation of Central Appalachian rivers by surface coal mining. Environmental Science and Technology 46:8115-8122.

Bunn, S. E. and J. M. Hughes. 1997. Dispersal and recruitment in streams: evidence from genetic studies. Journal of the North American Benthological Society 16(2):338-346.

Camargo, J. A. and N. J. Volze. 1998. Biotic and abiotic changes along the recovery gradient of two impounded rivers with different use. Environmental Monitoring and Assessment 50:143-158.

Casas, J. J., C. Zamora-Munoz, F. Archila, and J. Alba-Tercedor. 2000. The effect of a headwater dam on the use of leaf bags by invertebrate communities. Regulated Rivers: Research and Management 16:577-591.

Chuffney, T. F., R. A. Brightbill, J. T. May, I. R. Waite. 2010. Response of benthic macroinvertebrates to environmental changes associated with urbanization in nine metropolitan areas. Ecological Applications 20(5):1384-1401.

Cortes, R., M. Ferreira, S. Oliveira, and D. Oliveira. 2002. Macroinvertebrate community structure in a regulated river segment with different flow conditions. River Research and Applications 18(4):367-382.

Covich, A. P., M. A. Palmer, and T. A. Crowl. 1999. The role of benthic invertebrate species in freshwater ecosystems: zoobenthic species influence energy flows and nutrient cycling. BioScience 449(2): 119-127. 
Ellis, L. E. and N. E. Jones. 2013. Longitudinal trends in regulated rivers: a review and synthesis within the context of the serial discontinuity concept. Environmental Reviews 21(3):136148.

Ellis, L. E. and N. Jones. 2014. A test of the serial discontinuity concept: longitudinal trends of benthic invertebrates in regulated and natural rivers of northern Canada. River Research and Applications 32(3):462-472.

Freedman, J. A., B. D. Lorson, R. B. Taylor, R. F. Carline, and J. R. Stauffer Jr. 2013. River of the dammed: longitudinal changes in fish assemblages in response to dams. Hydrobiologia 727(1):19-33.

Gore, J. A. 1977. Reservoir manipulations and benthic macroinvertebrates in a Prairie River. Hydrobiologia 55(2):113-123.

Graf, W. L. 1999. Dam nation: A geographic census of American dams and their large-scale hydrologic impacts. Water Resources Research 35(4):1305-1311.

Hanks, R. D. 2016. The Influence of Dams on Downstream Larval and Juvenile Fish and Benthic Macroinvertebrate Community Structure and Associated Physicochemical Variables. Doctoral Dissertation. West Virginia University, Morgantown.

Harvey, B. C. 1987. Susceptibility of young-of-the-year fishes to downstream displacement by flooding. Transactions of the American Fisheries Society 116:851-855.

Jakob, C., C. T. Robinson, U. Uehlinger. 2003. Longitudinal effects of experimental floods on stream benthos downstream from a large dam. Aquatic Science 65:223-231.

Johnson, L. B., C. Richards, G. E. Host, and J. W. Arthur. 1997. Landscape influences on water chemistry in Midwestern stream ecosystems. Freshwater Biology 37:193-208.

Jones, N. E. 2010. Incorporating lakes within the river discontinuum: longitudinal changes in ecological characteristics in stream-lake networks. Canadian Journal of Fisheries and Aquatic Sciences 67(8):1350-1362.

Jones, N. E. 2011. Spatial patterns of benthic invertebrates in regulated and natural rivers. River Research and Applications 29(3):343-351.

Jones, N. E. 2013. Patterns of benthic invertebrate richness and diversity in the regulated Magpie River and neighbouring natural rivers. River Research and Applications 29(3):10901099.

Katano, I., J. Negishi, T. Minagawa, H. Doi, Y. Kawaguchi, and Y. Kayaba. 2009. Longitudinal macroinvertebrate organization over contrasting discontinuities: effects of a dam and a tributary. Journal of the North American Benthological Society 28(2):331-351. 
Kraft, K. J. and N. D. Mundahl. 1984. Effect of intermittent flow regulation on temperature and macroinvertebrate distribution and abundance in a Michigan River. Freshwater Invertebrate Biology 3:21-35.

Lemkuhl, D. M. 1972. Changes in thermal regime as a cause of reduction in benthic fauna downstream of a reservoir. Journal of Fisheries Research Board of Canada 29(9):13291332.

Maynard, C. M. and S. N. Lane. 2012. Reservoir compensation releases: impact on macroinvertebrate community of the Derwent River, Northumberland, UK-a longitudinal study. River Research and Applications 28:692-702.

McCune, B. and J. B. Grace. 2002. Analysis of Ecological Communities. MjM Software, Gleneden Beach, OR.

Mendoza-Lera, C., A. Larranaga, J. Perez, E. Descals, A. Martinez, O. Moya, I. Arostegui, and J. Pozo. 2012. Headwater reservoirs weaken terrestrial-aquatic linkage by slowing leaflitter processing in downstream regulated reaches. River Research and Applications 28:13-22.

Merovich, G. T. and J. T. Petty. 2010. Continuous response of benthic macroinvertebrate assemblages to a discrete disturbance gradient: consequences for diagnosing stressors. Journal of the North American Benthological Society 29(4):1241-1257.

Merritt, R. W. and K. W. Cummins (Editors). 1996. An introduction to the aquatic insects of North America. $3^{\text {rd }}$ edition. Kendall/Hunt Publishing Co., Dubuque, Iowa.

Moog, O. 1993. Quantification of daily peak hydropower effects on aquatic fauna and management to minimize environmental impacts. Regulated Rivers: Research and Management 8:5-14.

Munn, M. D. and M. A. Brusven. 1991. Benthic macroinvertebrate communities in nonregulated and regulated waters of the Clearwater River, Idaho, USA. Regulated Rivers: Research and Management 6:1-11.

Munn, M. D. and M. A. Brusven. 2004. The influence of Dworshak Dam on epilithic community metabolism in the Clearwater River, U.S.A. Hydrobiologia 513:121-127.

Oksanen, J., F. G. Blanchet, R. Kindt, P. Legendre, P. R. Minchin, R. B. O’Hara, G. L. Simpson, P. Solymos, M. H. H. Stevens, and H. Wagner. 2016. vegan: Community Ecology Package. R packager version 2.3-3. http://CRAN.R-project.org/package=vegan.

Palmer, M., A. Covich, B. Finlay, J. Hyde, R. Johnson, and C. Ricci. 1997. Biodiversity and ecosystem processes in freshwater sediments. Ambio 571-577. 
Peckarsky, B. L., P. R. Fraissinet, M. A. Penton, and D. J. Conklin. 1990. Freshwater macroinvertebrates of North-eastern North America. Cornell University Press, Ithaca, New York.

Poff, N. L., and D. D. Hart. 2002. How Dams Vary and Why It Matters for the Emerging Science of Dam Removal. BioScience 52(8):659-668.

Parasiewicz, P., S. Schmutz, and O. Moog. 1998. The effect of managed hydropower peaking on physical habitat, benthos and fish fauna in the River Bregenzerach in Austria. Fisheries Management and Ecology 5:403-417.

Pond, G. J. and S. E. McMurray. 2002. A macroinvertebrate bioassessment index for headwater streams in the Eastern Coalfield Region, Kentucky. Kentucky Department for Environmental Protection. DOW. Water Quality Branch, Frankfort, KY.

Pond, G. J., M. E. Passmore, N. D. Pointon, J. K. Felbinger, C. A. Walker, K. J. G. Krock, J. B. Fulton, and W. L. Nash. 2014. Long-term impacts on macroinvertebrates downstream of reclaimed mountaintop mining valley fills in Central Appalachia. Environmental Management 54:919-933.

Pond, G. J., M. E. Passmore, F. A. Borsuk, L. Reynolds, and C. J. Rose. 2008. Downstream effects of mountaintop coal mining: comparing biological conditions using family- and genus-level macroinvertebrate bioassessment tools. Journal of the North American Benthological Society 27(3):717-737.

Rader, R. B., N. J. Voelz, and J. V. Ward. 2007. Post-Flood Recovery of a Macroinvertebrate Community in a Regulated River: Resilience of an Anthropogenically Altered Ecosystem. Restoration Ecology 16:24-33.

Rader, R. B. and J. V. Ward. 1988. Influence of regulations on environmental conditions and the macroinvertebrate community in the upper Colorado River. Regulated Rivers: Research and Management 2: 597-618.

Rice, S. P., M. T. Greenwood, and C. B. Joyce. 2001. Tributaries, sediment sources, and the longitudinal organisation of macroinvertebrate fauna along river systems. Canadian Journal of Fisheries and Aquatic Sciences 58(4):824-840.

Robinson, J. L. and P. S. Rand. 2005. Discontinuity in fish assemblages across an elevation gradient in a southern Appalachian watershed, USA. Ecology of Freshwater Fish 14:1423.

Roy, A. H., A. D. Rosemond, M. J. Paul, D. S. Leigh, and J. B. Wallace. 2003. Stream macroinvertebrate response to catchment urbanisation (Georgia, U.S.A.). Freshwater Biology 48(2):329-346. 
Saltveit, S., J. T. Bremnes, and J. E. Brittain. 1994. Effect of changed temperature regime on benthos of a Norwegian regulated river. Regulated Rivers: Research and Management 9:93-102.

Schnieder D.C. 2001. The rise of the concept of scale in ecology. Bioscience. 51(7):545-553.

Stanford, J., and J. V. Ward. 2001. Revisiting the serial discontinuity concept. Regulated Rivers: Research \& Management 17(4-5):303-310.

Stevens, L. E., J. P. Shannon, and D. W. Blinn. 1997. Colorado River benthic ecology in Grand Canyon, Arizona, USA: dam, tributary and geomorphological influences. Regulated Rivers: Research and Management 13:129-149.

Storey, A. W., D. H. Edward, P. Gazey. 1991. Recovery of aquatic macroinvertebrate assemblages downstream of the Canning Dam, Western Australia. Regulated Rivers: Research and Management 6:213-224.

Sutherland W. J. ed. 2006. Ecological Census Techniques. $2^{\text {nd }}$ ed. Cambridge University Press. New York.

Thompson, L. C., S. A. Cocherell, S. N. Chun, J. J. Cech, and A. P. Klimley. 2011. Longitudinal movement of fish in response to a single-day flow pulse. Environmental Biology of Fish 90:253-261.

Townsend, C. R., M. R. Scarsbrook, and S. Doledec. 1997. Quantifying disturbance in streams: alternative measures of disturbance in relation to macroinvertebrate species traits and species richness. Journal of the North American Benthological Society 16(3):531-544.

Valentine, S., J. G. Wasson, and M. Philippe. 1995. Effects of hydropower peaking on epilithon and invertebrate community tropic structure. Regulated Rivers: Research and Management 10:105-119.

Vannote, R.L., G.W. Minshall, K.W. Cummins, J.R. Sedell, and C.E. Cushing. 1980. The river continuum concept. Canadian Journal of Fisheries and Aquaculture Science 37:130-137.

Voelz, N. J. and J. V. Ward. 1990. Macroinvertebrate response along a complex regulated stream environmental gradient. Regulated Rivers: Research and Management 5:365374.

Voelz, N. J. and J. V. Ward. 1991. Biotic Responses along the Recovery Gradient of a Regulated Stream. Canadian Journal of Fisheries and Aquatic Sciences 48(12)2477-2490.

Ward, J. V. and J. A. Stanford. 1979. Ecological Factors Controlling Stream Zoobenthos with Emphasis on Thermal Modification of Regulated Streams. In The Ecology of Regulated Streams, Ward, J. V. and J. A. Stanford (eds). Plenum Press: New York; 35-55. 
Ward J.V. and J.A. Stanford. 1983. The serial discontinuity concept of lotic eco- systems. In Dynamics of Lotic Ecosystems, Fontaine TD, Bartell SM (eds). Ann Arbor Scientific Publishers: Ann Arbor, MI; 29-42.

Ward, J. V., K. Tockner, U. Uehlinger, and F. Malard. 2001. Understanding natural patterns and processes in river corridors as the basis for effective river restoration. Regulated Rivers: Research \& Management 17(4 5):311-323.

Weilhoefer, C. L. and Y. Pan. 2006. Diatom assemblages and their associations with environmental variables in Oregon Coast Range streams, USA. Hydrobiologia 561:207219.

Wiens J.A. 1989. Spatial scaling in ecology. Functional Ecology. 3:385-397.

Wilson, E. O. 1992. The Diversity of Life. New York. W. W. Norton.

Wood, S. 2006. Generalized additive models: an introduction with R. Chapman and Hall, Boca Raton, Florida.

Yeager, B. L. 1993. Dams. Pages 57 - 113. In C. F. Bryan and D. A. Rutherford, editors. Impacts on warmwater streams: Guidelines for evaluation, Second Edition. Southern Division, American Fisheries Society, Little Rock, Arkansas.

Zhang, Y., B. Malmqvist, and G. Englund. 1998. Ecological processes affecting community structure of blackfly larvae in regulated and unregulated rivers: a regional study. Journal of Applied Ecology 35:367-686.

Zuur, A. F., E. N. Leno, N. J. Walker, A. A. Saveliev, and G. M. Smith. 2009. Mixed effects models and extensions in ecology with R. $1^{\text {st }}$ edition. Springer, New York. 
Table 1. Generalized additive model summary statistics for the best model to richness, functional richness, GLIMPSS, EPT richness, $\% 5$ dominant taxa, \% CF richness, \% CG richness, \% $\mathrm{HB}$ richness, \% $\mathrm{PR}$ richness, \% $\mathrm{SH}$ richness, \% $\mathrm{HT}$ richness, \% MT richness, \% LT richness, \% HD richness, and \% LD richness using distance alone and with additional habitat variables. \% Dev Exp $=\%$ deviance explained; Coarse $=$ substrate coarseness; $\mathrm{DO}=$ dissolved oxygen; Distance $=$ Distance from dam; $\%$ For $=\%$ forested area within a subwatershed; $\% \mathrm{Dev}=\%$ developed area within a subwatershed; Road Dens=Density of roads within a subwatershed; and Temp=Temperature; GLIMPSS=Genus Level Index of Most Probably Stream Status; EPT=Ephemeroptera, Plecoptera, and Trichoptera richness; $\% 5$ Dom Genera $=\% 5$ dominant genera; $\% \mathrm{CF}=\%$ collector/filterer; $\% \mathrm{CG}=\%$ collector/gatherer; $\% \mathrm{HB}=\%$ herbivore; $\% \mathrm{PR}=\%$ predator; $\% \mathrm{SH}=\%$ shredder; $\% \mathrm{HT}=\%$ highly tolerant taxa; $\% \mathrm{MT}=\%$ mildly tolerant taxa; $\% \mathrm{LT}=\%$ low tolerant taxa; $\% \mathrm{HD}=\%$ high dispersing taxa; $\% \mathrm{LD}=\%$ low dispersing taxa.

\begin{tabular}{|c|c|c|c|c|c|c|c|c|c|c|c|c|c|c|}
\hline \multirow[b]{3}{*}{ Response } & \multicolumn{3}{|c|}{ Distance alone } & \multicolumn{11}{|c|}{ Full Model } \\
\hline & & $\% \operatorname{Dev}$ & & & \% Dev & & & & & & & & & \\
\hline & $r$ & Exp & $p$ & $r$ & Exp & Coarse & Depth & Distance & DO & Flow & $\%$ Forest & $\%$ Dev & Road Dens & Temp \\
\hline Richness & 0.40 & 17.1 & $<0.001$ & 0.78 & 65.0 & $<0.01$ & -- & $<0.001$ & -- & -- & $<0.001$ & -- & $<0.001$ & -- \\
\hline Functional Richness & 0.30 & 10.3 & 0.02 & 0.61 & 42.4 & $<0.01$ & -- & $<0.01$ & -- & -- & -- & $<0.001$ & -- & -- \\
\hline GLIMPSS & 0.33 & 13.0 & $<0.01$ & 0.87 & 80.5 & $<0.01$ & -- & $<0.001$ & -- & -- & $<0.001$ & $<0.001$ & -- & -- \\
\hline EPT & 0.49 & 25.4 & $<0.001$ & 0.82 & 70.4 & $<0.01$ & -- & $<0.001$ & -- & -- & $<0.001$ & $<0.001$ & -- & $<0.001$ \\
\hline \% 5 Dom Genera & 0.10 & 0.1 & 0.82 & 0.75 & 61.0 & -- & -- & -- & 0.03 & -- & $<0.01$ & $<0.001$ & 0.01 & -- \\
\hline \% CF Richness & 0.22 & 5.8 & 0.37 & 0.40 & 21.8 & -- & $<0.01$ & -- & -- & -- & 0.04 & -- & -- & -- \\
\hline$\%$ CG Richness & 0.42 & 18.5 & $<0.001$ & 0.73 & 61.2 & $<0.01$ & $<0.01$ & $<0.001$ & 0.03 & 0.03 & $<0.001$ & 0.03 & 0.02 & -- \\
\hline$\%$ HB Richness & 0.22 & 6.5 & 0.08 & 0.69 & 51.7 & -- & -- & $<0.01$ & -- & -- & $<0.001$ & -- & -- & -- \\
\hline$\%$ PR Richness & 0.10 & 0.1 & 0.8 & 0.73 & 64.1 & $<0.001$ & -- & $<0.001$ & 0.02 & $<0.001$ & $<0.001$ & -- & -- & -- \\
\hline$\%$ SH Richness & 0.37 & 19.4 & $<0.001$ & 0.56 & 36.7 & -- & -- & $<0.001$ & -- & -- & $<0.001$ & -- & -- & -- \\
\hline \% HT Richness & 0.40 & 17.6 & $<0.001$ & 0.82 & 71.9 & $<0.001$ & -- & $<0.001$ & -- & -- & $<0.001$ & -- & -- & -- \\
\hline$\%$ MT Richness & 0.10 & 1.7 & 0.21 & 0.75 & 65.4 & 0.02 & -- & $<0.01$ & -- & $<0.001$ & $<0.001$ & $<0.001$ & -- & -- \\
\hline \% LT Richness & 0.66 & 44.3 & $<0.001$ & 0.73 & 57.9 & -- & -- & $<0.001$ & -- & 0.04 & & $<0.001$ & $<0.01$ & -- \\
\hline$\%$ HD Richness & 0.17 & 8.0 & 0.1 & 0.40 & 20.6 & -- & -- & 0.03 & $<0.001$ & -- & -- & $<0.01$ & $<0.01$ & -- \\
\hline$\%$ LD Richness & 0.17 & 5.2 & 0.31 & 0.36 & 13.9 & -- & -- & -- & -- & -- & $<0.001$ & -- & -- & -- \\
\hline
\end{tabular}


Table 2. Relationships of distance, habitat, functional, tolerance, and dispersal groups, and select macroinvertebrate metrics to nonmetric multidimensional scaling (NMDS) ordination of macroinvertebrate genera in 3 dimensions by vector fitting (linear model) and surface fitting (nonlinear generalized additive model). Corresponding $\mathrm{r}$ and $\mathrm{p}$-values are given. $\mathrm{p}$-values are estimated from 1000 randomizations of the data.

\begin{tabular}{|c|c|c|c|c|}
\hline \multirow[b]{2}{*}{ Variable } & \multicolumn{2}{|c|}{ All Sites } & \multicolumn{2}{|c|}{ Dammed Sites } \\
\hline & Vector $r$ ( $p$-value $)$ & Surface $r$ ( $p$-value) & Vector $r$ ( $p$-value $)$ & Surface $r$ ( $p$-value) \\
\hline Distance & $0.35(<0.001)$ & $0.33(<0.001)$ & $0.43(<0.001)$ & $0.43(<0.001)$ \\
\hline \multicolumn{5}{|l|}{ Habitat } \\
\hline Width & $0.53(<0.001)$ & $0.65(<0.001)$ & $0.51(<0.001)$ & $0.64(<0.001)$ \\
\hline Embeddedness & $0.32(<0.01)$ & $0.47(<0.001)$ & $0.46(<0.001)$ & $0.58(<0.001)$ \\
\hline Boulder & $0.1(0.71)$ & $0.36(<0.01)$ & $0.1(0.84)$ & $0.25(0.07)$ \\
\hline Cobble & $0.53(<0.001)$ & $0.62(<0.001)$ & $0.52(<0.001)$ & $0.59(<0.001)$ \\
\hline Coarse Gravel & $0.23(0.03)$ & $0.22(0.04)$ & $0.23(0.09)$ & $0.21(0.08)$ \\
\hline Fine Gravel & $0.1(0.62)$ & $0.00(0.94)$ & $0.15(0.34)$ & $0.25(0.04)$ \\
\hline Sand & $0.3(<0.01)$ & $0.33(<0.01)$ & $0.23(0.08)$ & $0.20(0.08)$ \\
\hline Fines & $0.5(<0.001)$ & $0.56(<0.001)$ & $0.43(<0.001)$ & $0.53(<0.001)$ \\
\hline Bedrock & $0.15(0.32)$ & $0.07(0.28)$ & $0.15(0.42)$ & $0.00(0.60)$ \\
\hline Coarseness & $0.47(<0.001)$ & $0.32(<0.001)$ & $0.44(<0.001)$ & $0.55(<0.001)$ \\
\hline Depth & $0.54(<0.001)$ & $0.57(<0.001)$ & $0.4(<0.01)$ & $0.51(<0.001)$ \\
\hline Flow & $0.1(0.64)$ & $0.00(0.56)$ & $0.45(<0.001)$ & $0.49(<0.001)$ \\
\hline Dissolved Oxygen & $0.27(0.02)$ & $0.28(0.02)$ & $0.2(0.14)$ & $0.40(<0.01)$ \\
\hline Conductivity & $0.27(0.03)$ & $0.36(<0.01)$ & $0.27(0.03)$ & $0.40(<0.01)$ \\
\hline $\mathrm{pH}$ & $0.37(<0.01)$ & $0.54(<0.001)$ & $0.45(<0.001)$ & $0.47(<0.001)$ \\
\hline Temperature & $0.38(<0.001)$ & $0.46(<0.001)$ & $0.38(<0.001)$ & $0.55(<0.001)$ \\
\hline Road density & $0.15(0.29)$ & $0.30(0.03)$ & $0.2(0.16)$ & $0.47(<0.001)$ \\
\hline$\%$ developed area & $0.34(<0.01)$ & $0.49(<0.001)$ & $0.23(0.13)$ & $0.37(<0.01)$ \\
\hline$\%$ forested area & $0.54(<0.001)$ & $0.59(<0.001)$ & $0.45(<0.001)$ & $0.45(<0.001)$ \\
\hline$\%$ grassland & $0.53(<0.001)$ & $0.57(<0.001)$ & $0.45(<0.001)$ & $0.45(<0.001)$ \\
\hline \multicolumn{5}{|l|}{ Functional Group Richness } \\
\hline Collector Filterer & $0.53(<0.001)$ & $0.26(0.06)$ & $0.53(<0.001)$ & $0.34(0.01)$ \\
\hline Collector Gatherer & $0.57(<0.001)$ & $0.60(<0.001)$ & $0.48(<0.001)$ & $0.59(<0.001)$ \\
\hline Predator & $0.77(<0.001)$ & $0.39(<0.001)$ & $0.77(<0.001)$ & $0.39(<0.01)$ \\
\hline Herbivore & $0.57(<0.001)$ & $0.55(<0.001)$ & $0.35(<0.001)$ & $0.40(<0.01)$ \\
\hline Shredder & $0.68(<0.001)$ & $0.46(<0.001)$ & $0.64(<0.001)$ & $0.41(<0.001)$ \\
\hline \multicolumn{5}{|l|}{ Tolerance Richness } \\
\hline High tolerance & $0.39(<0.001)$ & $0.82(<0.001)$ & $0.4(<0.001)$ & $0.8(<0.001)$ \\
\hline Medium tolerance & $0.85(<0.001)$ & $0.5(<0.001)$ & $0.86(<0.001)$ & $0.54(<0.001)$ \\
\hline Low tolerance & $0.83(<0.001)$ & $0.69(<0.001)$ & $0.77(<0.001)$ & $0.48(<0.001)$ \\
\hline \multicolumn{5}{|l|}{ Dispersal Richness } \\
\hline High dispersal & $0.74(<0.001)$ & $0.17(0.10)$ & $0.71(<0.001)$ & $0.14(0.15)$ \\
\hline Low dispersal & $0.85(<0.001)$ & $0.17(0.10)$ & $0.82(<0.001)$ & $0.14(0.15)$ \\
\hline \multicolumn{5}{|l|}{ Metrics } \\
\hline EPT & $0.91(<0.001)$ & $0.92(<0.001)$ & $0.89(<0.001)$ & $0.89(<0.001)$ \\
\hline$\% 5$ dominant genera & $0.68(<0.001)$ & $0.71(<0.001)$ & $0.67(<0.001)$ & $0.70(<0.001)$ \\
\hline GLIMPSS & $0.88(<0.001)$ & $0.91(<0.001)$ & $0.85(<0.001)$ & $0.89(<0.001)$ \\
\hline
\end{tabular}




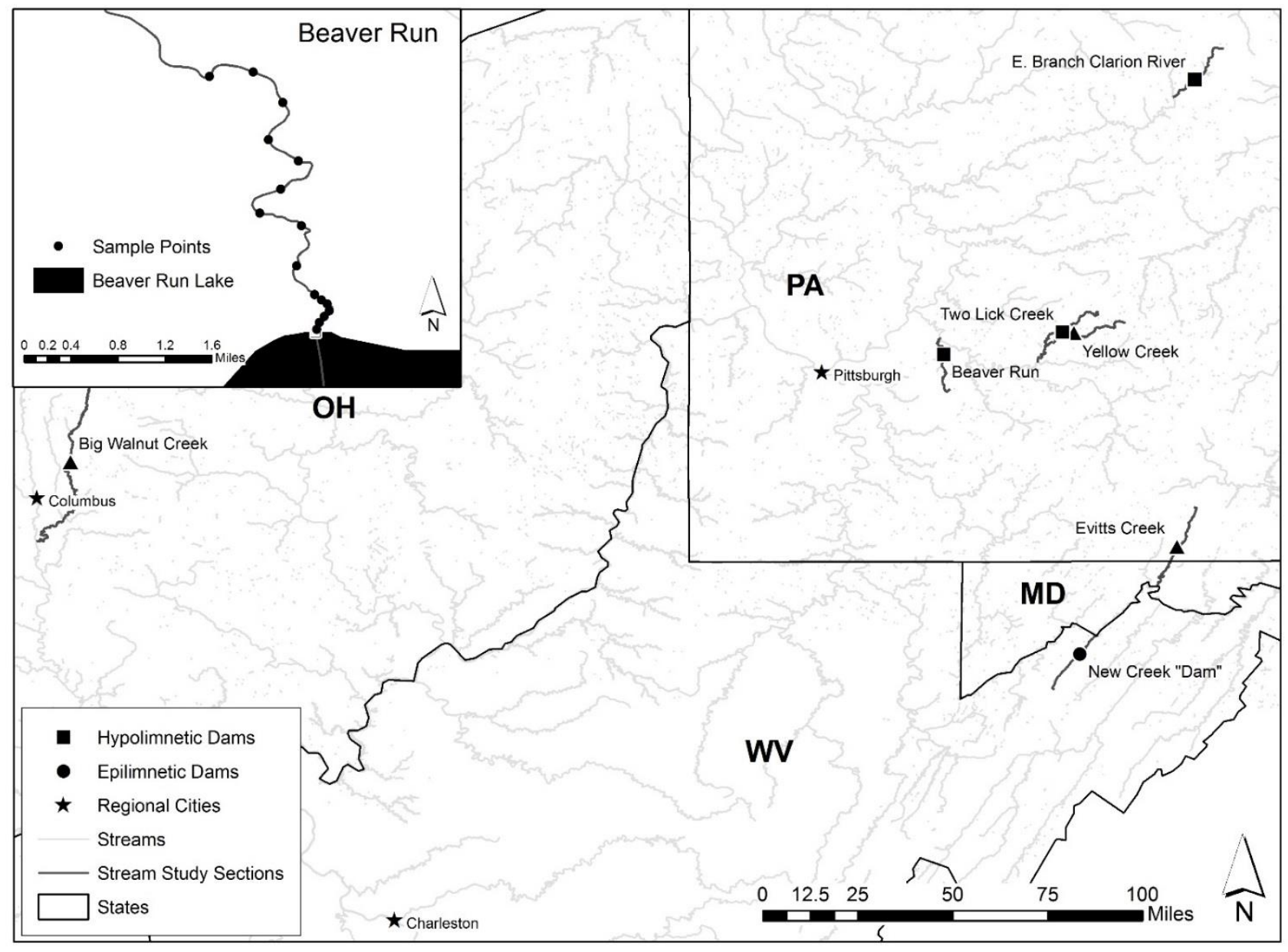

Figure 1. Location of study dams and streams. Dams with hypolimnetic releases are designated by solid squares, while solid circles represent dams with epilimnetic releases. The inset map displays the spacing of sample sites along the stream continuum below dams using Beaver Run as an example. 


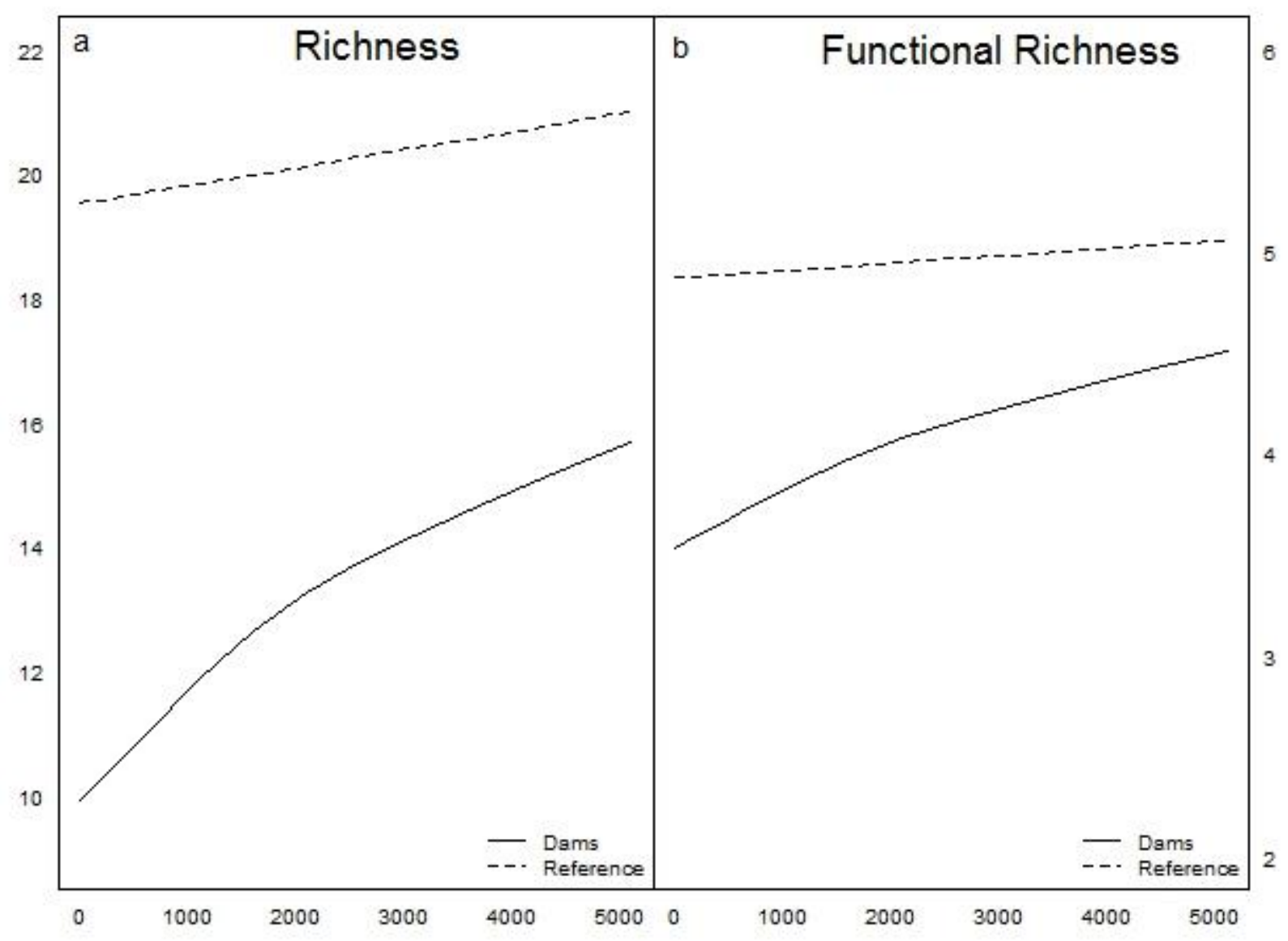

\section{Distance $(m)$}

Figure 2. Estimated richness and functional richness for dammed and reference streams along the longitudinal gradient below dams (dammed streams) and hypothetical dam (reference stream) for aquatic macroinvertebrate genera. 


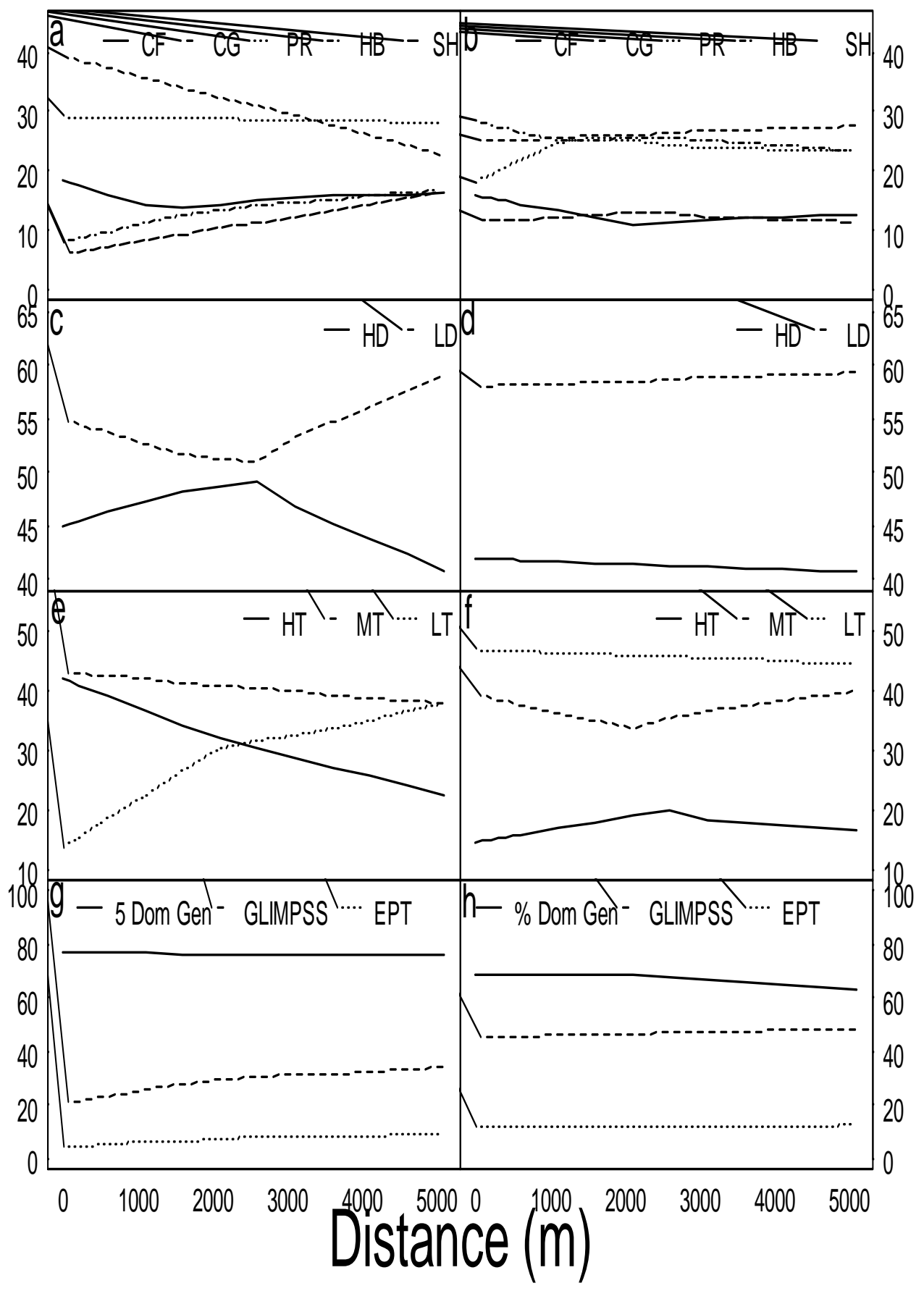

Figure 3. Estimated \% composition for dammed (panels a, c, e, g) and reference (b, d, f, h) streams along their longitudinal continuum for functional feeding groups (a, b), dispersal (c, d), tolerance (e, f), and select macroinvertebrate metrics $(\mathrm{g}, \mathrm{h})$. 


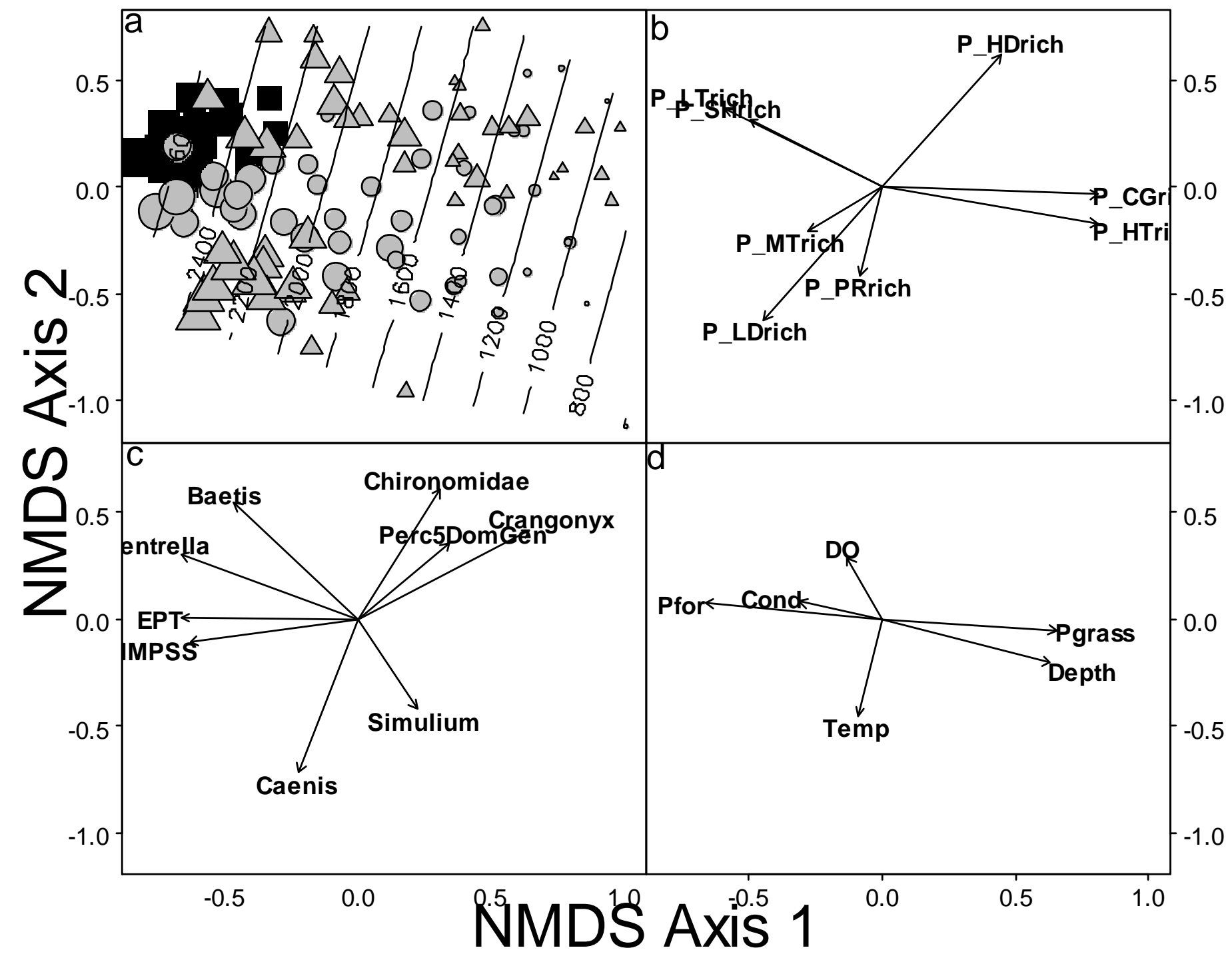


Figure 4. Nonmetric multidimensional scaling (NMDS) ordination of macroinvertebrate samples (Bray-Curtis coefficient) in 2 dimensions labeled by release type (epilimnetic, hypolimnetic, and reference condition as denoted by squares, triangles, and circles respectively) (a) with surface fitted distance as contour lines; functional groups (feeding, tolerance, and dispersal groups) (b); with select genera (weighted mean position) and macroinvertebrate metrics (c); and select habitat variables (in stream, water quality, and land use) (d). Stress = 17.7 in the three dimensional solution. Two convergent solutions were found after 4 runs. P_LTrich=\% low tolerant richness, $\mathrm{P} \_$HTrich $=\%$ high tolerance richness, $\mathrm{P} \_$MTrich $=\%$ medium tolerance richness, $\mathrm{P} \_$HDrich $=\%$ high dispersal richness, P_LDrich=\% low dispersal richness, P_SHrich=\% shredder richness, P_CGrich=\% collector gatherer richness, P_PRrich=\% predator richness, Perc5DomGen=\% 5 dominant genera, EPT=Ephemeroptera, Plecoptera, and trichoptera richness, GLIMPSS=Genus Level Index of Most Probably Stream Status, DO=dissolved oxygen, For=\% forested land, Pgrass=\% grassland, Cond=Conductivity, and Temp=temperature. Vectors show linear trends where the length of a vector for a specified variable is indicative of the relative correlation strength (scaled to unit length) where its direction indicates the direction of most rapid increase in ordination space. 


\section{R. DANIEL \\ 210 Percival Hall \\ Morgantown, WV 26506 \\ 864.200.8167 \\ rhanks@mix.wvu.edu}

\section{EDUCATION}

Ph.D. Fisheries Biology, Anticipated Spring 2016

West Virginia University

Dissertation Title: Influence of dams on downstream early life stage fish and aquatic macroinvertebrate community structure and associated physicochemical variables

Advisor: Dr. Kyle J. Hartman

M.S. Biology, May 2004

Western Carolina University, Cullowhee, North Carolina

Thesis Title: An investigation of benthic fish movement

Advisor: Dr. Thomas H. Martin

B.S. Biology, December 1999

Presbyterian College, Clinton, South Carolina

\section{ACADEMIC POSITIONS}

Instructor and graduate research assistant

July 2010-Present

West Virginia University

Freshman Biology Coordinator

August 2005-July 2010

Presbyterian College, Clinton, South Carolina.

Biology teacher

2003-2005

Wando High School, Mt. Pleasant, South Carolina.

\section{Graduate teaching assistant}

2001-2003

Western Carolina University, Cullowhee, North Carolina

\section{TECHNICAL PUBLICATIONS}

Hanks, D., R. Andrew, and A. Anderson. 2015. West Virginia University graduate students lead citizen science program. Fisheries Magazine 40 (7):302.

Welsh, S., B. Lenz, D. Hanks, and K.J. Hartman. Winter habitat used by fishes in the Bellville Pool, Ohio River. Rivers Research and Applications. (In Progress)

Hanks, R. D. and K. J. Hartman. Comparison of three larval sampling methods in shallow, complex wadeable streams. North American Journal of Fisheries Management. (In Progress) 
Hanks, R. D. and K. J. Hartman. Identifying impacts from dams on downstream microhabitat variables and land use that may affect richness, abundance, and diversity of aquatic macroinvertebrates. River Research and Applications. (In Progress)

Hanks, R. D. and K. J. Hartman. Identifying impacts from dams that may affect abundance, richness, diversity, and community structure for larval and juvenile fish. Canadian Journal of Fisheries and Aquatic Sciences. (In Progress)

Hanks, R. D. and K. J. Hartman. Understanding aquatic macroinvertebrate community response to land use and dam influences on downstream microhabitat variables. Freshwater Science. (In Progress)

\section{TEACHING EXPERIENCE}

\section{Present West Virginia University}

- Co-Instructor: Wildlife Ecosystem Ecology (Wildlife and Fisheries Management 313 Lecture). A course covering basic principles of ecosystem and population ecology, emphasizing structure and function, succession, adaptations of organisms to the environment, and survey of major ecosystems with emphasis on their roles as wildlife habitat (Co-Instructor).

\section{3-2014 West Virginia University}

- Instructor: Remote Sensing of the Environment (Forestry 326 Lecture and Lab). An introductory course designed to provide students with the ability to measure and interpret various aspects of our natural resources from photography, radar, and infrared imagery through the use of GIS.

- Instructor: Foundations of Applied GIS (Resource Management 440 Lecture). An introductory course designed to provide the necessary background and techniques to use GIS technology to analyze and solve spatial problems. An emphasis is placed on acquisition, management, and manipulation of spatial data (2014).

- Instructor: Foundations of Applied GIS (Resource Management 440 Lab). An introductory course designed to provide the necessary background and techniques to use GIS technology to analyze and solve spatial problems. An emphasis is placed on acquisition, management, and manipulation of spatial data (2013 and 2014).

\section{5-2010 Presbyterian College}

- Instructor: Biology 101/102 Lecture. A course in general biology entailing a broad introduction of the fundamental principles of living organisms. The major areas of study being biomolecules, cell biology, genetics, evolution, development, physiology, and ecology (1-3 Lectures taught each semester).

- Instructor: Biology 101/102 Lab. A course designed to complement and supplement the lecture material as well as give students a better understanding of the nature of science through a variety of laboratory exercises and experiments (2-4 Lectures taught each semester).

- Instructor: Biology 314: Ecology. A study of the interrelationships of plants and animals in their physical and biological environments. Structure and dynamics of the major ecosystems, with emphasis on individual behavior, populations and communities. Lab and field work includes studies of natural and polluted systems.

- Instructor: Biology 401: Senior Seminar in Biology. This course requires students to gain an indepth knowledge of a selected current topic in biology by conducting an exhaustive literature search, give an oral presentation of the results of this search, and prepare a written paper in acceptable scientific form. 
- Instructor: Interdisciplinary Studies 105: Why We Run. This is a class designed to give the students an appreciation for the human body's endurance abilities by studying various animals and their unique abilities and to understand these in an evolutionary context.

- Instructor: Interdisciplinary Studies 105: Walking with a House on Your Back. This is a course designed to introduce students to and give them a solid foundation in wilderness backpacking.

\section{3-2005 Wando High School}

- College Preparatory and Honors Biology. A course designed to introduce high school students to biology through a combination of lectures, discussion, and laboratory exercises.

- Human Anatomy and Physiology. A course designed to introduce high school students to human anatomy and physiology through a combination of lectures, discussion, and laboratory exercises.

\section{1-2003 Western Carolina University}

- Instructor: Principles of Biology II (Biology 141). Introductory biology course for majors covering the animal kingdom from cnidarians to mammals.

- Instructor: Principles of Biology II (Biology 141 Laboratory). Introductory biological laboratory course for majors covering the animal kingdom from cnidarians to mammals.

- Teaching Assistant: Human Genetics Laboratory (Biology 102). Introductory biological laboratory course for non-majors designed to teach students how science (more specifically biology) works, with an emphasis on human genetics.

- Teaching Assistant: Human Biology Laboratory (Biology 104). Introductory biological laboratory course for non-majors designed to teach students how science (more specifically biology) works, with an emphasis on human biology.

- Teaching Assistant: General Ecology Laboratory (Biology 304). Co-instructor. Upper level undergraduate biological laboratory course intended to introduce students to field studies in ecology through an intellectual and hands on approach.

- Teaching Assistant: Human Physiology Laboratory (Biology 292). Biological laboratory course intended to enlighten students on how physiological processes occur and why they are important to the human body.

- Teaching Assistant: Methods of Microbiology (Biology 414). Upper level undergraduate biological laboratory class emphasizing traditional cultural based techniques for studying ad identifying microorganisms as well as modern molecular techniques for determining species identification of laboratory and environmental strains.

- Co-Instructor: Natural History of Yellowstone National Park (Biology 493/592). Teacher assistant to Dr. Séan O'Connell for an undergraduate and graduate level course aiming to discover the biological, geographical, and geological features and diversity that make Yellowstone National Park unique.

\section{GRANTS}

\section{4}

West Virginia Division of Natural Resources Cooperative Research and Education/Management Grant. This is a one year grant with the expectation of subsequent grant submissions extending through 2018 to survey a variety of taxa within Coopers Rock State Forest, WV. These citizen science surveys are intended as a means of gaining a full understanding of the taxa within the park and as an educational 
tool for various local stakeholders. The grant was modelled after the Great Smokey Mountains National Park Discover Life in America (DLiA) program. (\$20,278)

Each year 2010 - 2015

PhD travel award from the Davis College of Agriculture, Natural Resources, and Design for traveling to national American Fisheries Society annual meetings. (\$800/year)

\section{9}

Faculty development grant at Presbyterian College. Grant for summer travel to the Rocky Mountain Greater Ecosystem Area to investigate Rocky Mountain and high altitude ecosystems. Study areas included Rocky Mountain National Park, the Wind River Range, Teton National Park, Yellowstone National Park, and the Beartooth Mountains. (\$2,200)

\section{7}

Faculty development grant at Presbyterian College. Grant for summer travel to the Columbia River Gorge to study fish passage devices along the Columbia River. Ten dams along the Columbia River were visited to investigate design features of each dam's fish passage device. $(\$ 1,705)$

\section{RESEARCH EXPERIENCE}

\section{Graduate Research Assistant}

2010- Present

Dr. Kyle J. Hartman's Lab

West Virginia University, Morgantown, West Virginia.

Areas of research:

- Assessment of mitigation efforts on fish reproductive success and crayfish populations in the Stony River, Grant County, West Virginia.

- Brook trout (Salvelinus fontinalis) population and habitat assessment in headwater streams of the Monongahela National Forest, West Virginia.

- Assessment of impacts on fish and aquatic macroinvertebrates in the Monongahela River from thermal effluent of the Morgantown Energy Facility, WV.

\section{Undergraduate honors research at Presbyterian College (Advisor)}

2010

- Zack Snipes: Impacts of sedimentation from road construction on crayfish (Cambarus spp.) populations.

- Bradley Buckallew: Molecular analysis of crayfish (Cambarus spp.) diets and the impact of sedimentation from road construction.

\section{Undergraduate research at Presbyterian College (Advisor)}

2009

- Boone Walker: Distribution and habitat preferences of salamanders in a headwater stream in the Piedmont of South Carolina.

\section{Undergraduate research at Presbyterian College} 1999

- An evaluation of the morphological variation of neuromast organs in northern dusky salamander (Desmognathus fucus) and channel catfish (Ictalurus punctatus) using scanning electron microscopy.

- A survey of frog calls of the greater Laurens County area, South Carolina. 
1998

- A survey of mussel species of the greater Laurens County area, South Carolina

\section{NONTECHNICAL PUBLICATIONS}

Hanks, D., R. Andrew, and K. Hartman. 2015. WVU Student Subunit leads citizen scientists towards "discovering" local fauna. Education Section of the American Fisheries Society.

Hanks, D., R. Andrew, and A. Anderson. 2014. Discovering life in West Virginia. Branchlines: WVU Division of Forestry and Natural Resources newsletter.

\section{PAPER PRESENTATIONS}

Hanks, D. and K. Hartman. 2015. Do Differences in Reservoir Discharge Temperatures Influence Downstream Aquatic Macroinvertebrate Communities? They Dam Near Do! American Fisheries Society annual meeting. Portland, OR.

Hanks, D. and K. Hartman. 2014. Dam bugs and beyond: influences of dams on downstream aquatic macroinvertebrate community structure and associated physiochemical variables. American Fisheries Society annual meeting. Quebec City, Canada.

Hanks, D. and K. Hartman. 2013. Influences of dams on downstream larval fish and aquatic macroinvertebrate community structure and associated physiochemical variables. American Fisheries Society annual meeting. Little Rock, AR.

Hanks, D. and K. Hartman. 2013. Influences of dams on downstream larval fish community structure and associated water quality and habitat variables. OH/WV American Fisheries Society joint meeting. Huntington, WV.

Hanks, D. and K. Hartman. 2012. Influences of dams on downstream larval fish community structure and associated water quality variables. American Fisheries Society annual meeting. Saint Paul, MN.

Hanks, D. and K. Hartman. 2012. Dam influences on downstream larval fish community structure and associated water quality variables. North American Association of Fish and Wildlife Agencies annual meeting. Charleston, WV.

Hanks, D. and K. Hartman. 2011. Progress towards restoring crayfish and fish populations in Stony River, Grant County, WV. WV/VA Chapters joint American Fisheries Society annual spring technical meeting. Cacapon State Park, Berkeley Springs, WV.

\section{POSTER PRESENTATIONS}

Hanks, D. and R. Andrew. 2015. Discover Life in West Virginia (DLiWV). American Fisheries Society annual meeting. Portland, OR.

Hanks, D. and R. Andrew. 2015. Discover Life in West Virginia (DLiWV). Submitted to Coopers Rock State Forest. Coopers Rock State Forest, WV.

Hanks, D. 2012. Comparison of three larval fish sampling methods in shallow, complex, wadeable rivers. American Fisheries Society annual meeting. Saint Paul, MN.

Hanks, D. 2011. An evaluation of a spot-and-sweep method for collection of larval fish in lotic freshwater environments. WV/VA Chapters joint American Fisheries Society Annual Spring Technical Meeting. Cacapon State Park, Berkeley Springs, WV.

Hanks, D. 2011. An evaluation of a spot-and-sweep method for collection of larval fish in lotic freshwater environments. West Virginia University Graduate Student Research Symposium. West Virginia University, Morgantown, WV. 


\section{TECHNICAL REPORTS}

Hartman, K. and D. Hanks. 2015. 2014 Final Progress Report: Stony River Biota and Restoration Monitoring.

Hartman, K. and D. Hanks. 2014. 2014 Final Progress Report: Stony River Biota and Restoration Monitoring.

Hartman, K. and D. Hanks. 2013. 2010-2013 Final Progress Report: Evaluating the Efficacy of the four year Stony River Biota and Restoration Monitoring Project.

Hartman, K. and D. Hanks. 2012. 2012 Final Progress Report: Stony River Biota and Restoration Monitoring.

Hartman, K. and D. Hanks. 2011. 2011 Final Progress Report: Stony River Biota and Restoration Monitoring.

Hartman, K. and D. Hanks. 2010. 2010 Final Progress Report: Stony River Biota and Restoration Monitoring.

\section{GUEST AND INVITED LECTURES}

- Keynote Speaker: “A River Ran Through it: tragedy of the ultimate commons”. Presentation for the Coopers Rock Foundation on aquatic resources (Fall 2014).

- Guest Lecture: GIS for Natural Resources (RESM 441). GIS use and applications in forestry. This class emphasizes GIS use in environmental and natural resource management (Fall 2014).

- Invited Lecture: A tale of two thermal regimes: Two Lick and Yellow Creek, Indiana, PA. Informational lecture about aquatic macroinvertebrates and larval fish in two streams of interest to the Ken Sink chapter of Trout Unlimited (Fall 2014).

- Invited Lecture: Giving an effective scientific presentation. Workshop presentation for the West Virginia University chapter of the American Fisheries Society (Fall 2014).

- Invited Lecture: Lectured to the Monongahela Master Naturalists on Introduction to Ichthyology (Fall 2012, 2013, and 2014).

- Guest Lecture: Wildlife Ecosystem Ecology (WMAN 313). Temperature influences and thermal balance. This class addresses basic principles of ecosystem, community, and population ecology (Spring 2014).

- Guest Lecture: Wildlife Ecosystem Ecology (WMAN 313). Lectured on life history patterns. This class addresses basic principles of ecosystem, community, and population ecology (Spring 2014).

- Guest Lecture: Wildlife Ecosystem Ecology (WMAN 313). Lectured on interspecific competition. This class addresses basic principles of ecosystem, community, and population ecology (Spring 2014).

- Guest Lecture: Wildlife Ecosystem Ecology (WMAN 313). Lectured on intraspecific competition. This class addresses basic principles of ecosystem, community, and population ecology (Spring 2014).

- Invited Lecture: Lectured to the Master Naturalist of Canaan Valley on Introduction to Ichthyology (Summer 2013).

- Guest Lecture: Advanced Wildlife and Fisheries Management (WMAN 450). Lecture on human dimensions of wildlife and fisheries management. This class is the capstone course for Wildlife and Fisheries Management majors (Spring 2013).

- Guest Lecture: Advanced Wildlife and Fisheries Management (WMAN 450). Lecture on management of undesirable species. This class is the capstone course for Wildlife and Fisheries Management majors (Spring 2013). 
- Invited Lecture: Lecture at Presbyterian College on Influences of dams on downstream larval fish and associated water quality and habitat variables... with a word about diversity (Fall 2012).

- Guest Lecture: Remote Sensing of the Environment (Forestry 326). Lecture on georeferencing. This class is designed to introduce forestry students to GIS (Spring 2011).

- Guest Lecture: Wildlife and Fisheries Techniques (WMAN 300). Lecture on larval fish sampling and identification techniques. This class is designed to introduce students to common techniques in wildlife and fisheries (Fall 2011, 2012, and 2013).

- Teaching Assistant: Statistical Analysis in Program R. This class was a two day seminar for WV DNR (Spring 2012).

- Teaching Assistant: Statistical Analysis in Program R. This class was a one day seminar for the North Eastern Association of Fish and Wildlife Agencies annual meeting (Spring 2012).

\section{HONORS AND AWARDS}

2012, 2013, and 2014

- Best photo in the West Virginia University Division of Forestry and Natural Resources Graduate Student Photo Contest.

2013

- National Mentor of the Year for the EnvironMentors Program.

- Best student presentation at the OH/WV American Fisheries Society joint meeting. Huntington, WV.

2012

- Mentored high school student Kaveen Herath to a second place finish in the national

EnvironMentors Science Fair. Washington D.C.

2003

- 2002-2003 Teaching Assistant of the Year. Western Carolina University Department of Biology.

1999

- South Atlantic Conference All Conference Selection, Soccer. Presbyterian College.

- Captain of Varsity Soccer Team. Presbyterian College.

1998

- Honorable mention in Presbyterian College Honors Book for field research. A survey offrogs calls of the Greater Laurens County, SC area.

- Captain of Varsity Soccer Team. Presbyterian College.

1997

- South Atlantic Conference All Conference Selection, Soccer. Presbyterian College. 1995

- Atlantic Coast Conference Honor Roll, Soccer. Clemson University.

\section{SERVICE}

- Board of Directors for the Coopers Rock Foundation (Morgantown, WV) (2015-Present)

- President of the West Virginia University Chapter of the American Fisheries Society (2012-2013)

- Judge for the WVU Davis College Wildlife and Fisheries Undergraduate Research Symposium (2011Present)

- Mentor for high school students in the EnvironMentors Program (2011-2012 and 2012-2013) 
- Graduate Student Member of the Davis College Dean Selection Committee (WVU)

- Freshman Biology Coordinator faculty member search committee (Presbyterian College)

- Genetics faculty member search committee (Presbyterian College)

- Board of Directors for the Joe Adair Outdoor Education Center (Laurens, SC)

- Wilderness Activities Program-Faculty Advisor (Presbyterian College)

- Bike Club-Faculty Advisor (Presbyterian College)

- Green Hose Committee-Presbyterian College's Sustainability Committee

- Committee on Athletic Affairs (Presbyterian College)

- Student Life Committee (Presbyterian College)

- Academic Advisor (Presbyterian College)

- Student Council Faculty Advisor (Wando High School)

- Coherent Curriculum Committee (Wando High School)

\section{PROFESSIONAL ASSOCIATIONS}

- American Fisheries Society

- Early Life History Section

- Education Section

- Fish Habitat Section

- West Virginia Chapter of the American Fisheries Society

- West Virginia University Student Chapter of the American Fisheries Society

\section{MEETING SESSIONS MODERATED}

"New Perspectives in Fish Habitat: Remote Sensing, Modeling, and Scaling" session of the American Fisheries Society annual meeting. Saint Paul, MN (2012).

Technical sessions of the WV/VA Chapters of the American Fisheries Society Annual Spring Technical Meeting, Cacapon State Park, Berkeley Springs, WV (2011).

\section{TECHNICAL ABILITIES}

- Geographic Information Systems (ArcGIS 10.2)

- R language and environment for statistical computing

- Sampling Techniques: adult fish (backpack electrofishing, boat electrofishing, Fyke netting, gill netting, minnow traps, and seining); larval fish (quatrefoil light traps, drift -nets, and sweep nets); crayfish (trapping, electrofishing, spotlight surveys); aquatic macroinvertebrates (kicknetting); Aquatic habitat (BVET)

- U.S. Department of the Interior certified Motor Boat Operator 


\section{REFERENCES}

\section{Dr. Kyle J. Hartman}

Professor of Wildlife and Fisheries Resources

West Virginia University

Division of Forestry and Natural Resources

310A Percival Hall

Morgantown, WV 26506

304.293.4797

kyle.hartman@mail.wvu.edu

\section{Dr. John C. Inman}

Charles A. Dana Professor of Biology

Presbyterian College

205 Lassiter Hall

Clinton, SC 29325

864.833.8401

jinman@presby.edu

\section{Dr. Michael P. Strager}

Associate Professor

West Virginia University

Division of Resource Management

2004 Agricultural Sciences Building

Morgantown, WV 26506

304.293.6463

mstrager@wvu.edu

\section{Dr. Jim Wetzel}

Department Chair

Pulaski L. Bealy Smith Professor of Biology

Presbyterian College

202 Lassiter Hall

Clinton, SC 29325

864.833.8412

jwetzel@presby.edu 